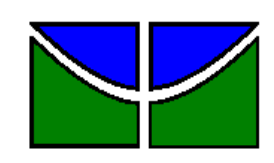

UNIVERSIDADE DE BRASÍLIA

FACULDADE DE CIÊNCIAS DA SAÚDE

PROGRAMA DE PÓS-GRADUAÇÃO EM ENFERMAGEM

RAÍZA RANA DE SOUZA LIMA

READMISSÕES PEDIÁTRICAS EM UM HOSPITAL PÚBLICO DO DISTRITO FEDERAL

Orientadora: Dra. Diana Lúcia Moura Pinho

BRASÍLIA

2016 


\author{
UNIVERSIDADE DE BRASÍLIA \\ FACULDADE DE CIÊNCIAS DA SAÚDE \\ PROGRAMA DE PÓS-GRADUAÇÃO EM ENFERMAGEM
}

RAÍZA RANA DE SOUZA LIMA

READMISSÕES PEDIÁTRICAS EM UM HOSPITAL PÚBLICO DO DISTRITO

FEDERAL

\begin{abstract}
Dissertação apresentada como requisito parcial para a obtenção do Título de Mestre em Enfermagem pelo Programa de Pós-Graduação em Enfermagem da Universidade de Brasília. Área de Concentração: Cuidado, Gestão e Tecnologia em Saúde e Enfermagem

Linha de Pesquisa: Processo de Cuidar em Saúde e Enfermagem
\end{abstract}

Orientadora: Dra. Diana Lúcia Moura Pinho

BRASÍLIA

2016 
Lima, Raíza Rana de Souza

L732 Readmissões Pediátricas em um Hospital Público do Distrito Federal / Raíza Rana de Souza Lima; orientadora Diana Lúcia Moura Pinho. -- Brasília, 2016. 99 p.

Dissertação (Mestrado - Mestrado em Enfermagem) -- Universidade de Brasília, 2016.

1. Readmissão do Paciente. 2. Cuidados de Enfermagem. 3. Pediatria. I. Moura Pinho, Diana Lúcia, orient. II. Título. 
RAÍZA RANA DE SOUZA LIMA

\title{
READMISSÕES PEDIÁTRICAS EM UM HOSPITAL PÚBLICO DO DISTRITO \\ FEDERAL
}

\begin{abstract}
Dissertação apresentada como requisito parcial para a obtenção do Título de Mestre em Enfermagem pelo Programa de Pós-Graduação em Enfermagem da Universidade de Brasília.
\end{abstract}

Aprovado em 12 de agosto de 2016.

BANCA EXAMINADORA

Profa Dra. Diana Lúcia Moura Pinho - Presidente Universidade de Brasília

Profa Dra Alessandra Ribeiro Ventura Oliveira - Membro Externo Universidade Católica de Brasília

Profa Dra Marina Morato Stival- Membro Externo

FCE/Universidade de Brasília

Profa. Dra. Walterlânia Silva Santos - Suplente

PPGENF/Universidade de Brasília 
Dedico este trabalho à minha família e aos meus professores que tanto me incentivaram e acreditaram em mim. 


\section{AGRADECIMENTOS}

Ao Senhor da minha vida, que abre portas que não esperamos e nos dá forças para adentrá-las.

À minha mãe, ao meu pai e à minha irmã Paula, exemplos de dedicação e superação! Deus queira que eu siga meu caminho profissional com a mesma garra de vocês. Amo infinitamente!

Ao meu amado noivo Daniel, presente divino que me ensina a ser alguém melhor todos os dias. Você é esplêndido em todos os sentidos!

Ao meu sogro Sérgio, por todas as noites mal dormidas e por tamanha dedicação em me auxiliar na tabulação e análise dos dados desse trabalho.

À minha sogra Valéria, pela compreensão, incentivo e suporte nos dias e noites de execução da pesquisa.

À minha orientadora, professora Diana, por todos os conselhos, correções e paciência ao longo desses dois anos repletos de contratempos.

Às professoras do Programa de Pós-graduação em Enfermagem, por serem exemplos inspiradores da arte do cuidar e do ensinar.

À Coordenação de Aperfeiçoamento de Pessoal de Nível Superior (CAPES), pela concessão da bolsa de mestrado. 
Acho que sentimentos se perdem em palavras. Todos deveriam ser transformados em ações, ações que tragam resultados.

(Florence Nightingale) 


\section{RESUMO}

LIMA, R.R.S. Readmissões Pediátricas em um Hospital Público do Distrito Federal. 2016. 99 folhas. Dissertação (Mestrado) - Departamento de Enfermagem, Faculdade de Ciências da Saúde, Universidade de Brasília, Brasília, 2016.

A readmissão hospitalar (RH) é considerada um indicador da qualidade da assistência hospitalar e, indiretamente, da atenção primária. Alguns fatores podem favorecer as $\mathrm{RH}$, como baixa qualidade dos cuidados assistenciais, alta precoce, falta de adesão do usuário e de seus familiares ao tratamento, idade, ausência de orientações específicas e de acompanhamento pósalta, assim como condições socioeconômicas e culturais. Portanto, para um cuidado resolutivo, é necessário conhecer o perfil das internações e das $\mathrm{RH}$, otimizando o planejamento e a implementação de estratégias. Para o levantamento das referidas questões, este trabalho teve como objetivo analisar o perfil de readmissões de crianças atendidas na pediatria do Hospital Regional de Ceilândia (HRC) nos meses de março, abril e maio de 2015. Trata-se de um estudo exploratório e descritivo, com abordagem mista explanatória sequencial. Os dados secundários foram coletados no sistema Trakcare; já os primários, por meio de entrevistas, com os enfermeiros da pediatria e com os responsáveis por crianças readmitidas, em situação de internação. A análise dos dados quantitativos foi realizada por frequência simples e absoluta, e a relação entre as variáveis, pelo teste do qui-quadrado. O conteúdo das entrevistas foi analisado pela técnica de Bardin. No período de março a maio de 2015, foram admitidas 660 crianças; destas, 249 foram readmitidas. A taxa de readmissão do período foi de 37,7\%. As crianças do sexo masculino e na faixa etária de lactentes foram a maior parte das readmitidas. Quanto à classificação de risco, houve predomínio das cores verde e laranja. As causas mais evidentes para as readmissões foram as doenças dos sistemas respiratório $(49,9 \%)$, digestivo/infecciosas $(10,6 \%)$, sintomas febris $(8,5 \%)$ e nervoso $(6,8 \%)$. Dez enfermeiros da pediatria participaram da pesquisa. Do conteúdo das entrevistas depreendeu-se que a unidade não possui uma rotina institucionalizada para a orientação da alta à criança e à sua família. Constatou-se que a estratégia utilizada nas orientações de alta é a comunicação verbal e estão relacionadas, principalmente, aos cuidados com a terapêutica medicamentosa e a data do retorno para avaliação. Os treze familiares das crianças readmitidas associaram as frequentes readmissões à evolução da patologia e à presença de condições crônicas. Os participantes reafirmaram que as orientações da equipe de enfermagem no momento da alta eram pontuais aos cuidados com a terapêutica medicamentosa ou aos dispositivos invasivos como sondas e traqueostomias, não havendo o enfoque quanto às orientações sobre os cuidados gerais relacionados às condições crônicas de saúde e a importância do acompanhamento da criança pós-alta. Pode-se dizer que os fatores associados à readmissão de crianças estão relacionados à faixa etária dos lactentes, com problemas respiratórios associados a condições crônicas, além da falta de efetividade no acompanhamento pós-alta. Assim, é pertinente refletir sobre o papel da equipe de enfermagem no planejamento de intervenções capazes de proporcionar a adaptação da criança e de seus familiares ao longo da hospitalização, no momento da alta e no pós-alta. A combinação de estratégias de orientações verbais e escritas pode auxiliar na compreensão da trajetória de adoecimento e adaptação, evitando as RH.

Descritores: Readmissão do Paciente; Cuidados de Enfermagem; Pediatria. 


\begin{abstract}
LIMA, R.R.S. The Profile of the Pediatric Readmissions in a Public Hospital of Distrito Federal. 2016. 99 pages. Dissertation (Master's degree) - Department of Nursing, Faculty of Health Sciences, University of Brasília, Brasília, 2016.

The hospital readmission (HR) is regarded as an indicator of the quality of hospital care and, indirectly, of primary care. Some factors may foster HR, such as low quality of supportive care, early discharge, lack of treatment adherence on the part of users and their families, age, absence of specific guidance and post-discharge follow-up, as well as socioeconomic and cultural conditions. Therefore, in order to perform a resolute care, one needs to know the profile of admissions and of HR, thereby enhancing the planning and the implementation of strategies. In order to raise the aforementioned questions, this study had the purpose of analyzing the profile of readmissions of children treated in the pediatric sector of the Regional Hospital in Ceilândia (HRC) in March, April and May 2015. This is an exploratory and descriptive study, with a mixed sequential explanatory approach. Secondary data were collected in the TrakCare system; and the primary data were obtained through interviews with the nurses who work in the pediatric sector and with those responsible for the readmitted children, in situation of admission. The analysis of the quantitative data was held by means of simple and absolute frequency, and the relationship between the variables took place through the chi-square test. The content of the interviews was analyzed through the Bardin's technique. In the period from March to May 2015, 660 children were admitted; of these, 249 were readmitted. The readmission rate of the period was $37.7 \%$. Male children and in the age of infants were the largest part of the readmitted. Concerning the risk classification, there was a predominance of the green and orange colors. The most prominent causes for the readmissions were the respiratory system diseases (49.9\%), digestive/infectious diseases (10.6\%), febrile symptoms (8.5\%) and nervous diseases $(6.8 \%)$. This research had the participation of ten nurses from the pediatric sector. From the content of the interviews, it can be surmised that the unit does not have an institutionalized routine for the guidance of the discharge for children and their families. It was found that the strategy used in the guidance of discharge is the verbal communication, where the messages are mainly related to the care in relation to the drug therapy and the return date for assessment. The thirteen relatives of the readmitted children have associated the frequent readmissions to the evolution of the pathology and the presence of chronic conditions. Participants reaffirmed that the guidance of the nursing team at the moment of discharge were specific to the care in relation to the drug therapy or to invasive devices, such as probes and tracheostomies, without a focus on the guidance on the general care related to the chronic health conditions and the importance of following-up the child after the hospital discharge. One can say that the factors associated with the readmission of children are related to the age group of infants, with respiratory problems associated with chronic conditions, besides the lack of effectiveness in the post-discharge follow-up. Accordingly, it is relevant to reflect about the role of the nursing team in the planning of interventions capable of providing the adaptation of children and their families over the period of admission, at the moment of discharge and in the post-discharge. The combination of guidance of verbal and written strategies can help us to understand the trajectory of illness and adaptation, thereby avoiding HR.
\end{abstract}

Descriptors: Patient Readmission; Nursing Care; Pediatrics. 


\section{RESUMEN}

\section{LIMA, R.R.S. EI Perfil de las Readmisiones Pediátricas en un Hospital Público del Distrito}

Federal. 2016. 99 hojas. Disertación (Maestría) - Departamento de Enfermería, Facultad de Ciencias de la Salud, Universidad de Brasília, Brasília, 2016.

La readmisión hospitalaria $(\mathrm{RH})$ puede ser considerada como un indicador de la calidad de la atención hospitalaria e, indirectamente, de la atención primaria. Algunos factores pueden favorecer las RH, como baja calidad de los cuidados asistenciales, alta precoz, falta de adhesión al tratamiento por parte de los usuarios y sus familiares, edad, ausencia de orientaciones específicas y de seguimiento después del alta, así como las condiciones socioeconómicas y culturales. Por lo tanto, para una atención resolutiva, se hace necesario conocer el perfil de las internaciones y de las RH, optimizando el planeamiento y la implementación de estrategias. Para el levantamiento de dichas cuestiones, este trabajo tuvo como objetivo analizar el perfil de las readmisiones de niños atendidos en la pediatría del Hospital Regional de Ceilândia (HRC) en marzo, abril y mayo de 2015. Se trata de un estudio exploratorio y descriptivo, con planteamiento mixto explicativo secuencial. Los datos secundarios fueron recogidos en el sistema TrakCare; y los primarios mediante entrevistas con los enfermeros de la pediatría y con los responsables de los niños readmitidos, en situación de internación. El análisis de los datos cuantitativos fue efectuado por medio de frecuencia simple y absoluta, y la relación entre las variables mediante la prueba de chi-cuadrado. El contenido de las entrevistas fue analizado a través de la técnica de Bardin. En el transcurso del período comprendido entre marzo y mayo de 2015, 660 niños fueron admitidos; de estos, 249 fueron readmitidos. La tasa de readmisión fue del 37,7\%. Los niños del sexo masculino y en la franja de edad de lactantes correspondieron a la mayor parte de las readmisiones. En cuanto a la clasificación de riesgo, hubo un predominio de los colores verde y naranja. Las causas más evidentes para las readmisiones fueron las enfermedades del sistema respiratorio (49,9\%), enfermedades digestivas/infecciosas $(10,6 \%)$, síntomas febriles $(8,5 \%)$ y enfermedades nerviosas $(6,8 \%)$. Diez enfermeros de la pediatría participaron en esta investigación. A partir del contenido de las entrevistas, se dedujo que la unidad no tiene una rutina institucionalizada para la orientación del alta al niño y su familia. Se constató que la estrategia utilizada en las orientaciones del alta es la comunicación verbal, principalmente relacionadas con los cuidados con la terapéutica de medicamentos y la fecha de regreso para evaluación. Los trece parientes de los niños readmitidos han asociado las frecuentes readmisiones a la evolución de la patología y a la presencia de condiciones crónicas. Los participantes reafirmaron que las orientaciones del equipo de enfermería en el momento del alta eran dirigidas a los cuidados con la terapéutica de medicamentos o a los dispositivos invasivos, tales como sondas y traqueotomías, sin un enfoque en cuanto a las orientaciones sobre los cuidados generales relacionados con las condiciones crónicas de salud y la importancia del seguimiento del niño después del alta. Se puede decir que los factores asociados a la readmisión de los niños están relacionados con la franja de edad de los lactantes, con problemas respiratorios asociados a las condiciones crónicas, además de la falta de efectividad en el seguimiento después del alta. Así, es pertinente reflexionar sobre el rol del equipo de enfermería en el planeamiento de intervenciones capaces de proporcionar la adaptación del niño y de sus familiares a lo largo de la hospitalización, en el momento del alta y después del alta. La combinación de estrategias de orientaciones verbales y escritas puede ayudar en la comprensión de la trayectoria de enfermedad y adaptación, eludiendo la RH.

Descriptores: Readmisión del Paciente; Atención de Enfermería; Pediatría. 


\section{LISTA DE FIGURAS}

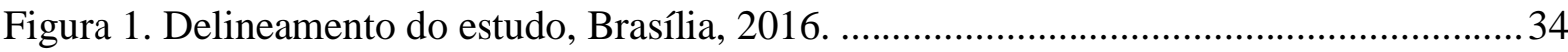

Figura 2. Fluxograma das etapas do estudo, Brasília, 2016.................................................. 40

Figura 3. Crianças readmitidas e classificação de risco alterada, Brasília, 2016. ....................58

Figura 4. Número de crianças readmitidas por eventos de readmissão com alteração da

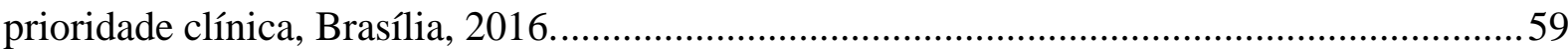




\section{LISTA DE TABELAS}

Tabela 1. Distribuição das crianças atendidas segundo sexo e faixa etária, Brasília, 2016. ....41

Tabela 2. Distribuição das crianças atendidas segundo a procedência, Brasília, 2016. 42

Tabela 3. Distribuição das crianças atendidas por grupo diagnóstico e faixa etária, Brasília, 2016. 43

Tabela 4. Distribuição das crianças atendidas por classificação de risco e faixa etária, Brasília, 2016.

Tabela 5. Distribuição das crianças atendidas por grupo diagnóstico e classificação de risco, Brasília, 2016.

Tabela 6. Distribuição das crianças atendidas por doenças do sistema respiratório e faixa etária, Brasília, 2016. 46

Tabela 7. Taxa de crianças readmitidas e sem retorno, Brasília, 2016.

Tabela 8. Distribuição das crianças readmitidas segundo sexo e faixa etária, Brasília, 2016.. 47

Tabela 9. Distribuição da frequência de atendimentos por eventos de readmissão das crianças, Brasília, 2016. 48

Tabela 10. Distribuição das crianças readmitidas por grupo diagnóstico e faixa etária, Brasília, 2016.

Tabela 11. Distribuição dos eventos de readmissão por grupo diagnóstico e faixa etária, Brasília, 2016.

Tabela 12. Distribuição das readmissões e eventos de readmissão por doenças do sistema respiratório e faixa etária, Brasília, 2016.

Tabela 13. Distribuição das readmissões e eventos de readmissão por doenças respiratórias e classificação de risco, Brasília, 2016.

Tabela 14. Distribuição da frequência de alteração do grupo diagnóstico na(s) readmissão(ões),

Brasília, 2016.

Tabela 15. Distribuição das readmissões e eventos de readmissão por classificações de risco,

Brasília, 2016.....

Tabela 16. Distribuição das readmissões e eventos de readmissão por classificação de risco e faixa etária, Brasília, 2016.

Tabela 17. Distribuição das crianças readmitidas por grupo diagnóstico e classificação de risco, Brasília, 2016. 
Tabela 18. Distribuição dos eventos de readmissão por grupo diagnóstico e classificação de

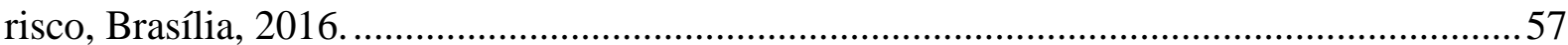




\section{LISTA DE SIGLAS}

ACCR - Acolhimento com Classificação de Risco

ACSC - Ambulatory Care-Sensitive Conditions

AIDPI - Atenção Integral às Doenças Prevalentes na Infância

APS - Atenção Primária à Saúde

CAPS - Centro de Atenção Psicossocial

CEP/FS - Comitê de Ética em Pesquisa da Faculdade de Ciências da Saúde

CEP/FEPECS - Comitê de Ética em Pesquisa da Fundação de Ensino e Pesquisa em Ciências da Saúde

CID - Classificação Internacional de Doenças

CNS - Conselho Nacional de Saúde

CS - Centro de Saúde

CSAP - Condições Sensíveis à Atenção Primária

EUA -Estados Unidos da América

HRC - Hospital Regional de Ceilândia

ICSAP - Internação por Condição Sensível à Atenção Primária

IVAS - Infecção das Vias Aéreas Superiores

MAR - Modelo de Adaptação de Roy

ODM - Objetivos de Desenvolvimento do Milênio

ONU - Organização das Nações Unidas

OMS - Organização Mundial de Saúde

OPAS - Organização Panamericana de Saúde

PAISC -Programa de Atenção Integral à Saúde da Criança

PNAISC - Política Nacional de Atenção Integral à Saúde da Criança

PS - Pronto-Socorro

PSF - Programa Saúde da Família

RA - Região Administrativa

RH - Readmissão Hospitalar

SES/DF - Secretaria de Saúde do Distrito Federal

SUS - Sistema Único de Saúde

TCLE - Termo de Consentimento Livre e Esclarecido

TR - Taxa de Readmissão

UICD - Unidade de Internação de Curta Duração 
UNICEF - Fundo das Nações Unidas para a Criança

UPA - Unidade de Pronto Atendimento 


\section{SUMÁRIO}

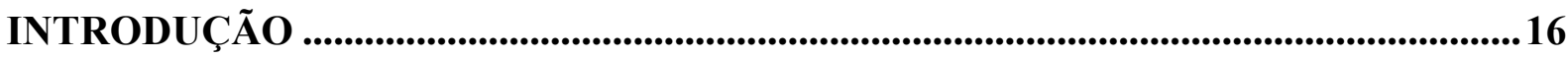

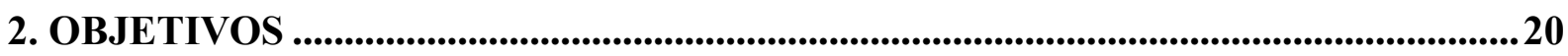

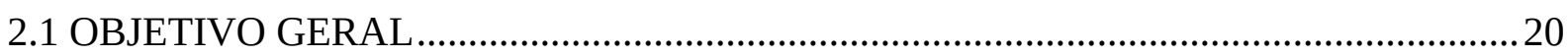

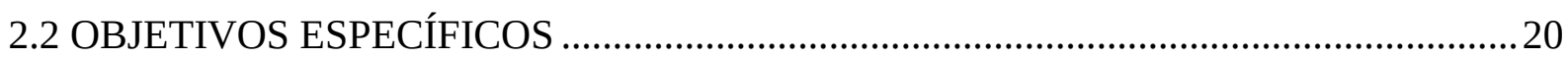

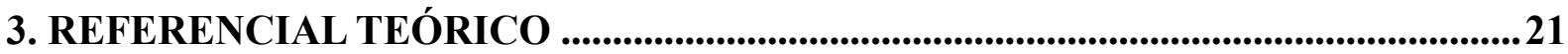

3.1 CONTEXTUALIZAÇÃO DA SAÚDE DA CRIANÇA................................................... 21

3.2 AS DOENÇAS PREVALENTES NA INFÂNCIA E AS CAUSAS DE INTERNAÇÕES .............23

3.3 A ASSISTÊNCIA HOSPITALAR E AS READMISSÕES COMO INDICADORES DE

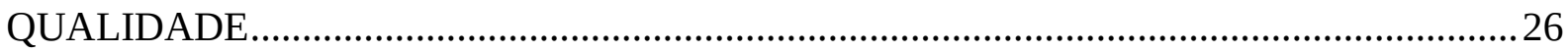

3.4 A ASSISTÊNCIA DE ENFERMAGEM À CRIANÇA READMITIDA .............................29

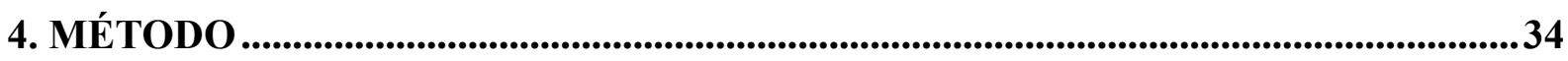

4.1 TIPO DE ESTUDO

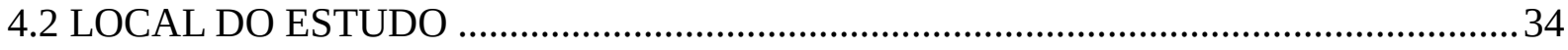

4.3 PARTICIPANTES ………………………………………………………………...... 35

4.4 COLETA E ANÁLISE DE DADOS - PROCEDIMENTOS E INSTRUMENTOS ............35

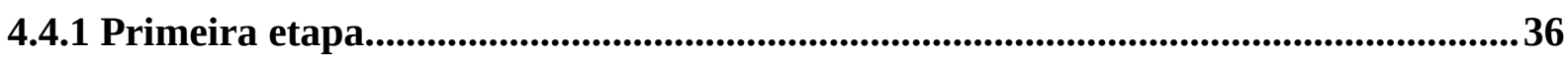

4.4.1.1 Coleta de Dados Quantitativos - Levantamento de Dados Secundários Retrospectivos ... 36

4.4.1.2 Organização, Categorização e Codificação dos Dados ................................................36

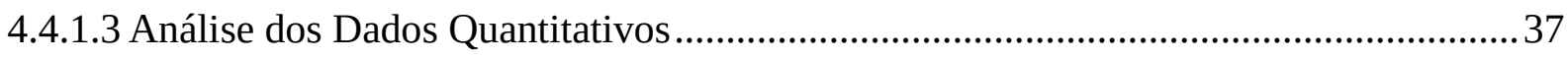

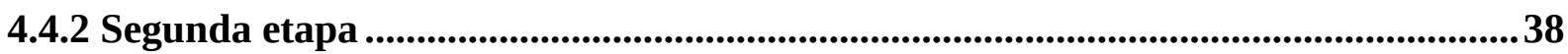

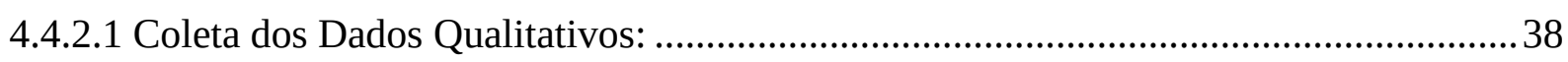

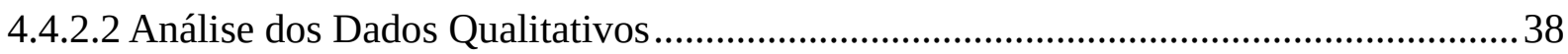

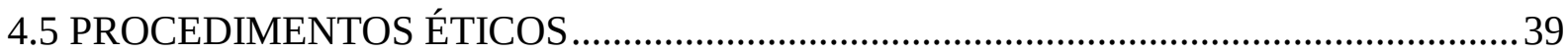

5. RESULTADOS E DISCUSSÃO DOS DADOS QUANTITATIVOS...................................41

5.1 O PERFIL DA DEMANDA DE ATENDIMENTOS NO PRONTO-SOCORRO

PEDIÁTRICO DO HRC ......................................................................................... 41

5.2 AS READMISSÕES NÃO PROGRAMADAS DA PEDIATRIA DO HRC .......................47

6. RESULTADOS E DISCUSSÃO DOS DADOS QUALITATIVOS ...................................69

6.1 PERCEPÇÃO DOS ENFERMEIROS E FAMILIARES NA ALTA HOSPITALAR .........69

6.1.1 Perfil sociodemográfico dos enfermeiros........................................................................69

6.1.2 Percep̧̧ão dos enfermeiros...............................................................................................69

6.1.3 Perfil sociodemográfico dos familiares entrevistados ...................................................75

6.1.4 Percep̧̧ão dos familiares.................................................................................................76

7. INTEGRAÇÃO DOS ESTUDOS QUANTITATIVO E QUALITATIVO.......................79 


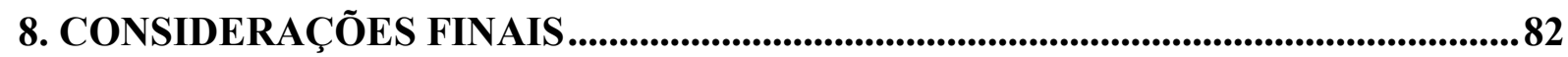

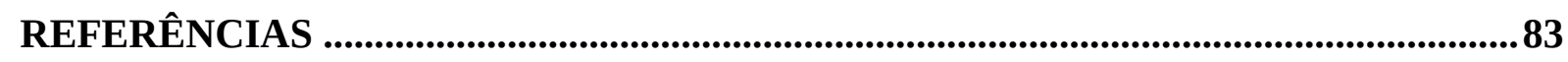

APÊNDICE A - Termo de consentimento livre e esclarecido utilizado com os responsáveis

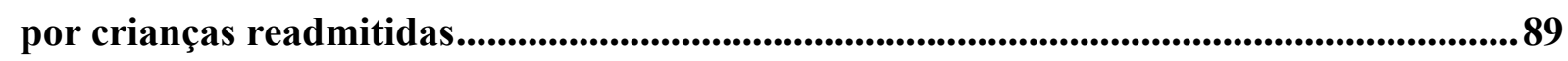

APÊNDICE B - Termo de consentimento livre e esclarecido utilizado com os enfermeiros .90

APÊNDICE C - Banco de dados para a coleta dos dados secundários................................91

APÊNDICE D - Roteiro de entrevista com os enfermeiros ....................................................92

APÊNDICE E - Roteiro de entrevista utilizado com os responsáveis por crianças

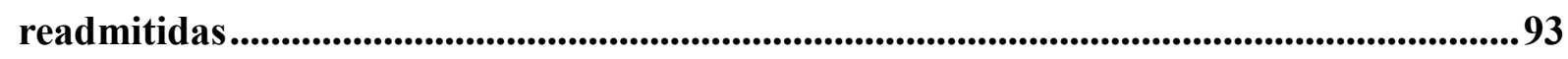

ANEXO A - Parecer de Aprovação no Comitê de Ética em Pesquisa .................................94

ANEXO B - Comprovante de Submissão do Artigo .........................................................97 


\section{INTRODUÇÃO}

A qualidade da assistência à saúde diz respeito ao alcance das metas propostas referentes à otimização do planejamento e implementação de um plano de cuidados efetivo designado ao paciente, de tal forma que seja alcançada a sua satisfação. Todavia, a definição de qualidade no campo da saúde pode ser compreendida de forma subjetiva, devido à diversidade de serviços de saúde, de processos de trabalho, de políticas e estruturas organizacionais (BRASIL, 2013).

Diante da subjetividade que permeia o conceito de qualidade da assistência à saúde, a sua avaliação tem ganhado espaço devido ao desenvolvimento e disponibilidade de tecnologias da informação aplicadas nos cuidados em saúde. Tais tecnologias devem ser implementadas tendo como objetivo a garantia da resolutividade do cuidado, através da prevenção e da promoção da saúde, alcançando a satisfação do usuário e diminuindo custos públicos evitáveis (MOREIRA, 2010).

Para que a resolutividade na assistência à saúde seja efetiva, diversas políticas e estratégias devem ser implementadas. O Sistema Único de Saúde (SUS) tem como um de seus princípios a hierarquização. A hierarquização da assistência diz respeito à complexidade dos níveis assistenciais, sendo a atenção primária à saúde (APS) a porta de entrada do sistema, em que a maior parte dos agravos podem e devem ser resolvidos (NEDEL et al., 2008).

A APS possui responsabilidade pela assistência à saúde desde o pré-natal, acompanhando tanto a saúde da mãe como a do bebê antes do nascimento, bem como no crescimento e desenvolvimento saudável da criança após o parto. Esse acompanhamento contínuo e integral pode auxiliar a evitar as doenças prevalentes da infância como as pneumonias, diarreias, distúrbios intestinais, meningites, tuberculoses e distúrbios nutricionais, principalmente na faixa etária de 0 até 5 anos de idade (PARANHOS et al., 2011).

Entretanto, quando ocorrem lacunas e/ou falhas na APS, a população busca outros níveis, como as emergências e urgências dos hospitais, ocasionando a superlotação dos prontossocorros, a sobrecarga dos profissionais da linha de frente desses setores e, consequentemente, as Internações por Condições Sensíveis à Atenção Primária (ICSAP), ou seja, internações que ocorreram por agravos que poderiam ter sido resolvidos no nível da APS, além das frequentes readmissões hospitalares (RH) (CAMPOS; THEME-FILHA, 2012).

A avaliação da qualidade dos cuidados em saúde é feita por intermédio da utilização de indicadores, sendo um desses indicadores as RH. Esse é um indicador amplo, pois possibilita verificar não apenas a qualidade no contexto da assistência hospitalar, mas, indiretamente, a resolutividade do cuidado pós-alta (MOREIRA, 2010). 
Sabe-se que as taxas de readmissão podem variar de $0,47 \%$ a $25,4 \%$ de acordo com as características demográficas e segundo o intervalo entre a admissão índice e a readmissão. Acredita-se que a análise de usuários readmitidos nos primeiros 7 dias após a alta é um possível indicador da qualidade da assistência hospitalar, enquanto que os intervalos de readmissão mais longos podem estar associados a doenças crônicas, às condições socioeconômicas e ao acesso limitado aos cuidados ambulatoriais (CASTRO et al., 2005).

Diversos fatores podem estar relacionados às readmissões, como a alta precoce, a baixa adesão do usuário e de seus familiares ao tratamento, a idade, os cuidados inadequados de saúde executados tanto pela equipe quanto pela família, a falta de acompanhamento e orientações para o seguimento pós-alta, assim como as condições socioeconômicas e culturais (MOREIRA, 2010).

Apesar de não haver um consenso sobre as causas específicas das readmissões, grupos prevalentes de diagnósticos podem estar relacionados à ocorrência das RH, como doenças crônicas, respiratórias, neurológicas e infectocontagiosas. Além destes, a literatura destaca a falta de individualização do cuidado, que pode influenciar a alta precoce sem orientações eficientes, que pode ter como consequência as RH não planejadas. Nesse processo, a escuta qualificada das queixas do paciente possibilita a individualização de um plano de cuidados (MOREIRA, 2010; NIETSCHE et al. 2012).

Durante o processo de hospitalização, entre os profissionais da equipe de saúde, a enfermagem possui papel fundamental na orientação dos usuários e seus familiares visando à promoção e à manutenção da saúde, tanto no ambiente hospitalar quanto em domicílio. $\mathrm{O}$ enfermeiro, desde a sua formação, é visto como um profissional educador capaz de instrumentalizar tecnologias disponíveis na rede ou criá-las, para que auxiliem na educação e no treinamento efetivo para o preparo da alta hospitalar (ALMEIDA et al., 2013).

O planejamento individualizado da alta hospitalar é um aspecto importante para a qualidade do cuidado da equipe de enfermagem, pois remete ao acompanhamento do paciente e da família na identificação das principais demandas e dúvidas para que diminua o estresse familiar em domicílio, as complicações relacionadas à doença e, consequentemente, as readmissões (ALMEIDA et al., 2013).

Para o planejamento e tomada de decisões relacionadas às patologias e ao cuidado integral, é importante identificar os possíveis fatores de risco para internações e consequentes RH. Os principais fatores associados às patologias e às queixas respiratórias e gastrointestinais, por vezes evitáveis e sensíveis à atenção primária, principalmente em menores de 5 anos de idade, incluem a exposição a poluentes ambientais, a aglomeração domiciliar, o estado 
nutricional, a sazonalidade climática, os esquemas de imunização incompletos, a condição socioeconômica e a exposição a agentes biológicos (SOUZA et al., 2012b).

Após um estudo realizado em Portugal, em uma unidade de internação de curta duração pediátrica (UICD), o qual teve como objetivo conhecer o perfil das readmissões, constatou-se que os diagnósticos de internação mais frequentes eram as síndromes febris, vômitos, traumatismos cranioencefálicos, convulsões febris, dores abdominais, asma, gastroenterites agudas, diarreias, convulsões apiréticas, bronquiolites e intoxicações. Após 72 horas de alta, os diagnósticos de readmissão mais frequentes foram as síndromes febris, as gastroenterites agudas e as convulsões febris. De 70 crianças que tiveram alta, em 72 horas, 7 delas retornaram ao serviço de emergência com novos diagnósticos de maior importância clínica (LEITE; FARIA, 2009).

Berry et al. (2013) ao analisarem os percentuais de readmissões e os seus principais diagnósticos em 72 hospitais infantis nos Estado Unidos, demostraram que de 568.845 internações índice estudadas, a taxa de readmissão no período de 30 dias foi de $6,5 \%$. Neste período, 39\% das crianças foram readmitidas nos primeiros 7 dias e $61 \%$ em 14 dias. Do total de internações índices, $35 \%$ das crianças readmitidas tinham comorbidades associadas, como doenças cardíacas congênitas, paralisia cerebral e asma. Os autores constataram que quanto maior o número de condições crônicas que a criança apresentava, maior era a probabilidade de readmissão. Por fim, 48,3\% da totalidade das readmissões possuíam diagnóstico relacionado com o mesmo sistema de órgãos da internação índice.

Estudo realizado no Brasil sobre a RH, por Castro et al. (2005), com a finalidade de identificar as características de risco para a readmissão, analisou 48 mil admissões entre julho de 1996 e junho de 2000 em um hospital geral público de grande porte, dentre as quais 19\% foram pediátricas. Um quinto das admissões no período tratava-se de eventos de readmissões e $15 \%$ dos pacientes tinham pelo menos uma readmissão durante os 4 anos.

O retorno do usuário à unidade hospitalar pode ser programado quando há necessidade de fazer exames para avaliação após a alta e para a realização de procedimentos eletivos. Entretanto, o usuário pode retornar ao serviço de saúde de forma não programada, em função do agravamento da condição que o trouxe na primeira admissão (admissão índice), da falta de acompanhamento ambulatorial na atenção primária, entre outras causas (BERRY et al., 2013).

A RH não programada, segundo Berry et al. (2013), é a primeira admissão no prazo de 30 dias após a alta de uma admissão índice. Para Tubbs-Cooley et al. (2013), a RH é definida como qualquer hospitalização recorrente que aconteça dentro de 14 dias ou entre 15 e 30 dias a partir da alta de uma primeira hospitalização. 
Os eventos das RH têm sido estudados internacionalmente, porém, no Brasil ainda são pouco explorados, principalmente no que diz respeito às readmissões pediátricas (BERRY et al., 2011; FEUDTNER et al., 2009). Sabe-se que as ocorrências de RH são um problema tanto para as instituições de saúde, devido aos custos com internações, quanto para a segurança e o conforto dos usuários e seus familiares. (BORGES et al., 2008).

Segundo Oliveira et al. (2010), a compreensão do perfil das internações pediátricas e dos fatores de risco associados é essencial para que se conheça os principais motivos de hospitalizações e se essas são por causas evitáveis ou não evitáveis. Além de identificar as causas, esse entendimento permite o desenvolvimento de estratégias que levem em conta o perfil da população assistida, para acompanhar o desempenho do serviço de saúde na prevenção de complicações no após a alta, na habilidade dos profissionais de enfermagem em transmitir as orientações do cuidado pós-alta, além de possibilitar a adaptação dos usuários e família do ambiente dos serviços de saúde para o retorno às atividades cotidianas.

Neste cenário, aprofundar o estudo sobre o fenômeno das readmissões hospitalares é importante, a fim de identificar a gravidade das crianças atendidas, compreender as causas, os fatores associados ao evento, bem como as condições da alta, as orientações instituídas e as formas de acesso aos serviços para acompanhamento e manutenção dos cuidados no pós-alta.

A Regional de Saúde de Ceilândia/DF, dentre as quinze regionais que compõem o sistema de saúde do DF, possui o maior volume de atendimentos tanto nas emergências quanto nas consultas eletivas. Segundo dados da Secretaria de Saúde do Distrito Federal- SES/DF no período de janeiro a dezembro 2014, foram realizados 409.211 atendimentos de emergência.

Considerando a abrangência dessa problemática, questiona-se: Qual o perfil das crianças atendidas na emergência do Hospital Regional de Ceilândia- HRC? Quais são as causas de readmissões pediátricas no HRC? Qual a percepção dos familiares e enfermeiros acerca da causa da readmissão e das formas de orientação para a alta instituídas ou utilizadas? 


\section{OBJETIVOS}

\subsection{OBJETIVO GERAL}

Analisar o perfil de readmissões de crianças atendidas na pediatria do Hospital Regional de Ceilândia (HRC) nos meses de março, abril e maio de 2015.

\subsection{OBJETIVOS ESPECÍFICOS}

- $\quad$ Caracterizar o perfil da demanda das crianças atendidas;

- Identificar o perfil sociodemográfico e de saúde das crianças readmitidas;

- Verificar a taxa de readmissão não programada, no período;

- $\quad$ Caracterizar os fatores relacionados à readmissão;

- $\quad$ Apreender a percepção dos enfermeiros e dos familiares acerca do acompanhamento na alta;

- Descrever as estratégias de orientação na alta hospitalar. 


\section{REFERENCIAL TEÓRICO}

\subsection{CONTEXTUALIZAÇÃO DA SAÚDE DA CRIANÇA}

O Brasil e outros países que compõem a Organização das Nações Unidas (ONU) planejaram estratégias para o alcance, até 2015, dos Objetivos de Desenvolvimento do Milênio (ODM). Foram traçados oito objetivos, dentre eles está a redução da mortalidade infantil que, por vezes, é consequente de causas evitáveis relacionadas a fatores biológicos, sociais, culturais e falhas dos sistemas de saúde. O objetivo a ser alcançado representa a redução de dois terços dos níveis de 1990 de mortalidade infantil (BARROS et al., 2010; BRASIL, 2009).

As causas evitáveis são classificadas como: redutíveis por imunização, por adequada atenção à gestação, ao parto, ao feto e ao recém-nascido, por ações de prevenção, diagnóstico e tratamento precoces e por parcerias entre outros setores. Tais causas devem ser analisadas à luz das tecnologias e conhecimentos disponíveis para as práticas de saúde, pois além de serem fundamentais para a compreensão do perfil de adoecimento em menores de 5 anos de idade, são essenciais para a elaboração de um plano de cuidados que evite o agravamento das condições de saúde, as consequentes internações e readmissões e, principalmente, o óbito (MALTA et al., 2010).

Apesar da taxa mundial de mortalidade na infância ter reduzido em $47 \%$ entre os anos de 1990 e 2012, isto é, de 90 para 48 mortes a cada mil nascidos vivos, sabe-se que, em 2012, 6,6 milhões de crianças menores de 5 anos de idade foram a óbito por doenças evitáveis. Felizmente, no Brasil, o objetivo já foi alcançado. Houve a redução de 53,7 em 1990 para 17,7 óbitos por mil nascidos vivos em 2011. Entretanto, o nível de mortalidade ainda é alto e diante da complexidade que permeia a saúde da criança, medidas de prevenção, promoção e reabilitação precisam ser implementadas por intermédio da parceria entre os serviços de saúde (BRASIL, 2014).

A partir da década de 80, o Ministério da Saúde passou a priorizar o planejamento e a implementação de ações básicas de saúde para o controle dos agravos e doenças prevalentes na infância, com vistas à redução da morbimortalidade infantil. Como primeiro passo, propôs o Programa de Assistência Integral à Saúde da Criança (PAISC), em 1984, com o objetivo de otimizar a resolutividade dos serviços de saúde por meio de ações de promoção da saúde e prevenção de agravos (CURSINO; FUJIMORI, 2012).

O PAISC foi proposto com o desenvolvimento de cinco ações básicas: acompanhamento do crescimento e desenvolvimento, aleitamento materno e orientação para o desmame, controle de doenças diarreicas, controle de infecções respiratórias agudas e controle de doenças 
preveníveis por imunização. Essas ações deveriam se constituir no centro da atenção prestada em toda a rede básica de serviços de saúde (CURSINO; FUJIMORI, 2012).

Em 1996, a estratégia de atenção integrada às doenças prevalentes na infância (AIDPI), firmada e elaborada pela Organização Panamericana de Saúde (OPAS), pela Organização Mundial de Saúde (OMS) e pelo Fundo das Nações Unidas para a Criança (Unicef), teve como objetivo a diminuição da mortalidade infantil, em menores de 5 anos, pelas doenças prevalentes na infância. Para que esse objetivo continuasse sendo alcançado, houve a necessidade do fortalecimento das ações de promoção à saúde e prevenção desses agravos através do vínculo entre os serviços de saúde, a comunidade e a família (BRASIL, 2003).

O programa AIDPI abrange de forma integral e sistemática as doenças prevalentes na infância bem como o atendimento clínico efetivo fundamentado em ações curativas, de promoção de saúde e prevenção dos agravos. Apesar de o Brasil já ter alcançado o objetivo de redução da mortalidade infantil, a contínua implementação do AIDPI tem como finalidade a capacitação dos profissionais de saúde para que seja estabelecido o acolhimento da criança e de sua família, gerando um atendimento integral e individualizado por intermédio de um plano de cuidados efetivo (PARANHOS et al., 2011).

A eficácia da contínua implementação do AIDPI auxiliando na continuidade de redução das taxas de mortalidade infantil depende da existência de um canal de comunicação efetivo entre os profissionais de saúde e os familiares das crianças a fim de haver o compartilhamento de saberes e a compreensão da real situação e do contexto social em que estão inseridos (SIQUEIRA; DIAS, 2011).

Com a finalidade de intervir nessa realidade e orientar a ação de todos os profissionais que lidam com a criança, o Ministério da Saúde lançou, em 2004, a Agenda de Compromissos para a Saúde Integral da Criança e Redução da Mortalidade Infantil. Esse documento aponta que o foco de atenção de todo profissional deve ser a criança em toda e qualquer oportunidade que se apresente, seja na unidade de saúde, no domicílio ou nos espaços coletivos, como creche, pré-escola e escola (BRASIL, 2004).

Desse modo, a criança tem sido beneficiada pelo cuidado integral e multiprofissional, abordando holisticamente a criança, a fim de prover resposta satisfatória na produção do cuidado, não se restringindo apenas às demandas apresentadas. Compreende, ainda, a integração entre todos os serviços de saúde, da atenção básica à atenção especializada, apoio diagnóstico e terapêutico até a atenção hospitalar de maior complexidade, com o acompanhamento de toda a trajetória da criança pela atenção básica (BRASIL, 2004). 
Apesar de as políticas terem contribuído para a melhoria do quadro de morbimortalidade infantil, a situação de saúde da criança brasileira ainda representa um grande desafio, pois as chances de sobrevivência são muito diferentes entre as regiões brasileiras e a maioria das doenças e mortes infantis é evitável, o que sugere problemas na qualidade da atenção básica e da assistência prestada à criança (BRASIL, 2012).

Diante disso, em agosto de 2015, o Ministério da Saúde lançou a Política Nacional de Atenção Integral à Saúde da Criança (PNAISC), com o objetivo de promover e proteger a saúde da criança e o aleitamento materno, mediante a atenção e cuidados integrais e integrados da gestação aos 9 (nove) anos de vida, com especial atenção à primeira infância ( 0 a 5 anos de idade) e às populações de maior vulnerabilidade, visando à redução da morbimortalidade e um ambiente facilitador à vida com condições dignas de existência e pleno desenvolvimento (BRASIL, 2015).

A PNAISC tem como finalidade orientar e qualificar as ações e serviços de saúde da criança no território nacional, considerando os determinantes sociais e condicionantes para garantir o direito à vida e à saúde, visando à efetivação de medidas que permitam o nascimento e o pleno desenvolvimento na infância, de forma saudável e harmoniosa, bem como a redução das vulnerabilidades e riscos para o adoecimento e outros agravos, a prevenção das doenças crônicas na vida adulta e da morte prematura de crianças (BRASIL, 2015).

Um dos eixos estratégicos da PNAISC diz respeito à atenção integral a crianças com agravos prevalentes na infância e com doenças crônicas, com ênfase em estratégias para o diagnóstico precoce, qualificação do manejo de doenças prevalentes na infância e ações de prevenção de doenças crônicas e de cuidado dos casos diagnosticados, em todos os níveis de assistência (BRASIL, 2015).

Portanto, a atenção à saúde da criança deve ser orientada por estratégias resolutivas e integrais que interfiram diretamente no crescimento e desenvolvimento saudável da população infantil, desde o seu nascimento, prevenindo as doenças prevalentes na infância em qualquer oportunidade, seja na escola, na atenção básica e até mesmo no hospital.

\subsection{AS DOENÇAS PREVALENTES NA INFÂNCIA E AS CAUSAS DE INTERNAÇÕES}

A APS tem como responsabilidade a cobertura da demanda de um conjunto de diagnósticos que podem e devem ser resolvidos nesse nível do SUS, onde as internações poderiam ser evitadas caso houvesse uma assistência efetiva de qualidade. Os problemas de saúde decorrentes de causas evitáveis que poderiam ser resolvidos na APS são chamados de condições sensíveis à atenção primária (CSAP) (NEDEL et al., 2010). 
A efetividade da assistência primária deve refletir na redução dos números de hospitalizações infantis, sendo um indicador indireto da qualidade dos cuidados prestados, pressupondo que tais doenças, como as prevalentes na infância, não tiveram atendimento oportuno, culminando no agravamento da condição de saúde e consequente internação (NEDEL et al., 2008).

Um dos principais instrumentos que permite avaliar a qualidade da atenção básica é o ICSAP, também utilizado pelos Estados Unidos da América (EUA), desde de 1990, chamado de Ambulatory Care-Sensitive Conditions (ACSC) (CAMINAL et al., 2004). No Brasil, em 2008, foi publicada a portaria do Ministério da Saúde MS/GM n 221, de 17 de abril de 2008, em que foi apresentada a Lista Brasileira de Internações por Condições Sensíveis à Atenção Primária organizada por grupos de causa de internação e diagnóstico (BRASIL, 2008).

A Lista Brasileira de Internações por Condições Sensíveis à Atenção Primária foi publicada com o intuito de ser utilizada como instrumento de avaliação de desempenho tanto da APS quanto da assistência hospitalar no âmbito Nacional, Estadual e Municipal. Dentre as causas de internação e diagnósticos estão as doenças preveníveis por imunização e condições sensíveis, gastroenterites infecciosas e complicações, anemia por deficiência de ferro, deficiências nutricionais, infecções de ouvido, nariz e garganta, pneumonias bacterianas, asma, doenças pulmonares, epilepsias, infecções do trato urinário e rim, doenças relacionadas ao prénatal e parto, dentre outras, muitas vezes coincidentes com as doenças prevalentes na infância (BRASIL, 2008).

Nos EUA, a ACSC é utilizada sob a perspectiva de estudos direcionados a comparações entre usuários que possuem ou não seguros de saúde, o custo das internações evitáveis e a relação delas com a faixa etária e etnia dos usuários (PROBIST et al., 2009). Já no Brasil, o ICSAP, juntamente à lista, tem como um de seus objetivos o acompanhamento de patologias agudas e crônicas a fim de reduzir as internações (ALFRADIQUE et al., 2009).

Um estudo realizado no Brasil, com o objetivo de identificar as principais causas de hospitalização infantil em crianças de 0 a 4 anos de idade, entre os anos de 1998 e 2007, mostrou que, de maneira geral, as doenças infecciosas e parasitárias, as do aparelho respiratório e do aparelho digestivo estão entre as causas principais de internação nas cinco regiões brasileiras. Dentre as principais causas de internação, segundo os autores do estudo, as doenças do aparelho respiratório foram as que mais acometeram crianças de 0 a 4 anos, correspondendo a 40,3\% das internações, seguidas de $21,6 \%$ de internações por doenças infecciosas e parasitárias, doenças do aparelho digestivo $(5,5 \%)$ e doenças do aparelho geniturinário (2,2\%) (OLIVEIRA et al., 2010). 
Quanto às regiões, os mesmos autores destacam que as hospitalizações por doenças infecciosas e parasitárias acometem mais as crianças no norte e nordeste, enquanto as do aparelho respiratório e digestivo são mais prevalentes no sul e centro-oeste; por conseguinte, as do aparelho geniturinário são mais recorrentes na região sudeste. As diferenças entre as regiões são caracterizadas pelo estilo de vida da população, pelas condições socioeconômicas e pela rede de atenção disponível em cada região (OLIVEIRA et al., 2010).

Em pesquisa realizada no Paraná, que teve como objetivo caracterizar o perfil da morbidade hospitalar de acordo com a faixa etária de 0 a 5 anos e o diagnóstico no período de 1998 a 2009, evidenciou-se que houve um declínio de 16,1 \% no coeficiente de internação de 1998 se comparado ao ano de 2009, ou seja, em 1998, 121,5 a cada 1000 crianças foram internadas, enquanto que, em 2009, esse patamar reduziu para 101,9. As doenças do aparelho respiratório $(56,4 \%)$, as infecciosas e parasitárias $(14,5 \%)$ e as perinatais $(12,6 \%)$ foram as principais causas de internação registradas (OLIVEIRA et al., 2012).

A frequência elevada de internações infantis causadas por condições sensíveis à atenção básica e passíveis de prevenção, diagnóstico e tratamento precoce pode significar uma assistência inadequada a certos grupos populacionais bem como as suas condições socioeconômicas e de saúde, o que pode indicar condições precárias de assistência à saúde (ELIAS; MAGAJEWSKI, 2008).

Apesar desse cenário, as taxas de mortalidade infantil por condições sensíveis à atenção básica vêm reduzindo devido a programas de saúde voltados para a assistência integrada às doenças prevalentes na infância, como o AIDPI. No Brasil, o Ministério da Saúde, desde a implantação da Programa de Saúde da Família (PSF), tem identificado significativa redução das internações infantis devido ao acompanhamento e assistências às crianças com problemas agudos. Houve uma redução de $33 \%$ no percentual de internações em menores de 5 anos de idade por pneumonia e desidratação em populações cobertas pelo PSF entre 1999 e 2001 (BRASIL, 2006).

A redução das internações infantis por condições sensíveis à atenção primária, caracterizadas por patologias agudas relacionadas a doenças infecciosas e parasitárias ou afecções respiratórias, tem demonstrado um estado de transição da morbidade hospitalar. Essa mudança tem ocorrido pelo investimento em estratégias como o AIDPI bem como pela transformação da dinâmica social, contribuindo para a redução da morbidade e mortalidade infantil por causas evitáveis. Corroborante a isso, outro estudo mostrou que o perfil das internações infantis, no Brasil, tem sido caracterizado pela prevalência de doenças crônicas (DUARTE et al., 2012). 


\subsection{A ASSISTÊNCIA HOSPITALAR E AS READMISSÕES COMO INDICADORES DE QUALIDADE}

Os indicadores de saúde podem ser considerados medidas que fornecem informações a respeito de situações de saúde e, ao serem padronizados, passam a ser instrumentos capazes de retratar uma realidade de maior proporção, sendo utilizados principalmente por gestores de saúde para apreender os resultados obtidos na assistência (MOREIRA, 2010).

As informações contidas nos indicadores estão estritamente relacionadas aos dados demográficos e estatísticos, sendo aprimorados e aplicados em situações como a de mortalidade e morbidade, resultando em dados que mostram as características de diferentes eventos e otimizando o planejamento de intervenções necessárias (MOREIRA, 2010).

A avaliação da qualidade dos cuidados em saúde por meio da utilização de indicadores, por vezes, tem como foco a assistência hospitalar, sendo um desses indicadores a readmissão hospitalar (RH). A Taxa de Readmissão (TR) é obtida através da razão entre o número de readmissões em um período estipulado após a alta hospitalar pelo número de pessoas admitidas no mesmo hospital, no mesmo período e que têm potencial para serem incluídas no numerador (BERRY et al., 2013; MOREIRA, 2010).

Apesar dos poucos estudos que existem na literatura nacional sobre a RH, o tema é debatido internacionalmente desde a década de 60, mas foi a partir do ano 2000 que passou a ser explorado de forma mais intensa. A temática RH é abordada além do seu conceito e do seu perfil de morbidade, alcançando os impactos econômicos e epidemiológicos sobre a estrutura e sobre o contexto das instituições hospitalares, cuja predominância é notória.

Alguns autores consideram RH as admissões posteriores com o mesmo diagnóstico da internação índice, ou seja, da primeira admissão, enquanto outros consideram as que ocorreram no mesmo estabelecimento de saúde, independente do diagnóstico (MAURER; BALLMER, 2004). Há ainda os que definem RH apenas pelo tempo entre as internações, que geralmente variam de 7 dias a 1 ano após a alta (ZAMIR et al., 2006). Portanto, as diferenças conceituais estão relacionadas ao tempo entre as internações, aos diagnósticos e ao local da readmissão.

A partir da alta da admissão índice, as readmissões no período pós-alta imediato (14 dias) estão relacionadas principalmente com a baixa qualidade dos cuidados hospitalares. Por outro lado, aquelas que ocorreram após as primeiras duas semanas podem ser decorrentes de fatores não hospitalares, como condições sociodemográficas, econômicas e acompanhamento ambulatorial ineficiente. (BERRY et al., 2013).

Após uma admissão índice, o paciente pode ser readmitido para tratar uma doença 
diferente do primeiro diagnóstico, ou ainda pode retornar pelo mesmo problema da primeira internação, podendo o retorno estar relacionado com a qualidade dos cuidados durante a internação, a inadequada assistência e acompanhamento ambulatorial após a alta e o agravamento da doença primária. Fatores individuais como a idade, renda, estado civil, ocupação, escolaridade; fatores clínicos como a gravidade da doença e fatores de acesso e acompanhamento também estão relacionados ao risco de readmissão (BERRY et al., 2013).

No que se refere às frequente readmissões, um estudo retrospectivo com o objetivo de descrever a utilização de recursos, as características clínicas, e as razões de admissão e readmissões em hospitais pediátricos retratou que crianças que enfrentam 4 ou mais readmissões, predominantemente, são aquelas com condições crônicas complexas como agravos neuromusculares, neoplásicos ou cardiovasculares ou pacientes em uso de aparato tecnológico, como traqueostomia ou gastrostomia (BERRY et al., 2011).

Concomitante às condições crônicas complexas, e, geralmente, como consequência dessas condições, as causas mais frequentes de hospitalização e readmissões são a asma, a pneumonia e a convulsão. Esse grupo de pacientes mostra-se relacionado a aproximadamente $23 \%$ das taxas de internação que poderiam ser evitadas, evidenciando um grande impacto financeiro sobre as instituições hospitalares (BERRY et al., 2011).

Outro estudo sobre a comparação da prevalência e da magnitude da variação das taxas de readmissões pediátricas entre 72 hospitais mostrou que os 10 diagnósticos com maior prevalência na readmissão foram: anemia, neutropenia, procedimentos de derivação ventricular, crise de anemia falciforme, apendicectomia, gastroenterite, convulsões, asma, bronquiolite, pneumonia, e infecção das vias respiratórias superiores. Além disso, foi evidenciada grande variabilidade nas taxas de readmissão entre os hospitais, classificando-os com alto ou baixo desempenho, sendo o nível de desempenho um indicador da qualidade da assistência (BERRY et al., 2013).

Além do impacto da prescrição medicamentosa correta e das orientações específicas para cada caso, outro fator relacionado à diminuição da taxa de readmissão por asma consiste no compromisso do familiar em recorrer ao acompanhamento ambulatorial pós-alta corretamente, estando essa medida associada à redução das readmissões (BERGET et al., 2014).

O êxito do compromisso do familiar no cuidado com a criança após a alta hospitalar é proporcional ao investimento da equipe de enfermagem nas orientações fornecidas durante a assistência hospitalar. A alta deve ser parte da sistematização da assistência de enfermagem, que busca utilizar a melhor tecnologia de ensino para a compreensão e aplicabilidade das orientações, de acordo com o estilo de vida de cada núcleo familiar (HOWRYLAK et al., 2014). 
O estilo de vida da criança e, principalmente, de seus familiares e responsáveis também está diretamente relacionado a possíveis episódios de readmissão. Uma coorte explorou a relação entre a exposição à fumaça do tabaco e as taxas de readmissão em crianças hospitalizadas por asma. Foi visto que a presença de cotinina detectável no soro ou na saliva da criança foi associada à maior chance de readmissão, remetendo à periculosidade do tabagismo passivo em crianças com doenças respiratórias (HOWRYLAK et al., 2014).

Sabe-se que as doenças respiratórias, em especial os casos de asma, bronquiolite e pneumonia, são mais frequentes em crianças menores de 2 anos (lactentes), em famílias de baixa renda e com condições de moradia precárias, o que mostra o impacto dos fatores sociodemográficos sobre os eventos de readmissão (RIESE et al., 2014)

A qualidade do cuidado assistencial prestado pela equipe de enfermagem às crianças hospitalizadas também influencia no processo saúde-doença, recuperação, alta e em possíveis readmissões. Um estudo relevante sobre readmissões pediátricas realizado em 225 hospitais investigou a relação entre a razão paciente/enfermeiro e as taxas de readmissão. Foi observado que crianças tratadas em hospitais em que o enfermeiro não é sobrecarregado são menos susceptíveis às readmissões entre 15 e 30 dias após a alta (TUBBS-COOLEY et al., 2013).

$\mathrm{O}$ aprofundamento a respeito das readmissões e seus fatores associados como a qualidade das informações no momento da alta, a qualidade da assistência prestada durante a internação, a continuidade dos cuidados, os diagnósticos associados e a disponibilidade de acesso aos serviços ambulatoriais de acompanhamento são de fundamental relevância para investigação sobre o assunto (MOREIRA, 2010).

Para Moreira (2010), as readmissões podem estar relacionadas à idade, sexo, à presença de doenças crônicas, cuidados inadequados de saúde tanto durante a hospitalização quanto em domicílio, alta precoce e inadequados processos de reabilitação, além de falta de organização e qualidade do cuidado após a alta hospitalar.

O cuidado com o paciente e sua rede de apoio não se restringe apenas aos cuidados técnicos e fragmentados, para que a qualidade da assistência seja evidente, é importante que a equipe de saúde estabeleça uma comunicação bidirecional com o objetivo de apreensão das demandas existentes (GOZZO et al., 2012).

A associação de readmissões por inadequados cuidados de saúde tanto durante o processo de hospitalização quanto no pós-alta são em parte responsabilidade dos profissionais diretamente envolvidos na assistência. O processo de educação em saúde, no qual seria possível um enfoque apropriado dos cuidados prestados tanto pelos profissionais, quanto pelo próprio 
paciente e familiares, pode fazer parte de um plano de cuidados mais elaborado durante a hospitalização e após a alta (MOREIRA, 2010; BORGES; TURRINI, 2011).

A qualidade das informações que são coletadas e percebidas pelos profissionais de saúde ao longo da hospitalização possui papel fundamental na organização da assistência intrahospitalar, no preparo para a alta e, principalmente no cuidado pós- alta. A continuidade do cuidado de acordo com as demandas apresentadas é responsabilidade não só da família, mas também dos profissionais de contrarreferência nos cuidados ambulatoriais e de atenção básica (GOZZO et al., 2012).

Quando a readmissão potencialmente evitável ocorre, significa que ela poderia ter sido evitada com a otimização do gerenciamento do quadro clínico do paciente, do planejamento e implementação de alta de maneira efetiva e no momento certo, além da previsão e provisão de recursos no domicílio para atender às necessidades do paciente (BORGES; TURRINI, 2011).

Entretanto, a responsabilidade das readmissões não está apenas nas mãos dos profissionais de saúde, pois também refletem a potencialidade do paciente no autocuidado e no enfrentamento e adaptação às suas condições biopsicossociais e culturais que interferem no comportamento frente a esse processo (BORGES; TURRINI, 2011).

\subsection{A ASSISTÊNCIA DE ENFERMAGEM À CRIANÇA READMITIDA}

A qualidade da assistência prestada à saúde da criança, seja a agravos de doenças infectocontagiosas, respiratórias ou a distúrbios crônicos, também é responsabilidade dos profissionais de enfermagem que prestam assistência direta às crianças e a suas famílias, que no momento da internação encontram-se fragilizadas e necessitam de auxílio e acolhimento para que se adaptem ao seu contexto, tanto durante a internação quanto após a alta (BORGES et al., 2008).

A assistência de enfermagem à saúde da criança deve ter como foco a percepção holística da vivência da criança tanto na hospitalização quanto após a alta, uma vez que deve ser assistida integralmente. O cuidado à criança hospitalizada demanda uma escuta qualificada, requerendo que o profissional compreenda tanto a experiência no lugar da criança quanto do familiar que a acompanha. Com isso, haverá a otimização da assistência e a resolutividade por intermédio da satisfação destes usuários (LELIS et al., 2011).

A família é um suporte para o contexto da criança em situação de adoecimento, portanto a equipe de enfermagem deve considerar os familiares como aliados no cuidado à saúde, oferecendo meios que permitam a participação deles e a manutenção saudável do núcleo 
familiar, que geralmente se encontra em situações de sofrimento e ansiedade por não saber e não entender o estado de saúde de seu ente querido (SILVA; SANTOS, 2010; SALAZAR, 2011).

A valorização da saúde desse familiar deve ser uma forma de empoderamento, pois quando compreende e é protagonista, é capaz de participar do cuidado prestado pela equipe de enfermagem. O cuidado prestado pela equipe de saúde vai da escuta qualificada à compreensão da singularidade e individualidade, tendo como consequência o processo de tratamento e recuperação mais acolhedor e humano (SILVA; SANTOS, 2010; SALAZAR, 2011; MARTINS et al., 2010).

É necessário que a assistência de enfermagem ultrapasse a barreira biomédica, centrada na patologia, e valorize a subjetividade, conceito este que as tecnologias duras (maquinaria e tecnologias de ponta) e dura-leve (saberes estruturados) não alcançam. A utilização de tecnologias leves, centradas nas relações interpessoais, são capazes de apreender as demandas e necessidades e empoderar o paciente e sua rede social a enfrentar o processo saúde-doença e de alta através da adaptação à sua situação (MERHY, 2005; SELLI et al., 2008; FOWLER; SÁ, 2009; TRENTINI et al., 2011).

Em contrapartida à imensa variedade de equipamentos, procedimentos e profissionais diretamente envolvidos na assistência, principalmente com o avanço das tecnologias duras, ainda é predominante a dificuldade da equipe de enfermagem em planejar e implementar intervenções que incentivem a continuidade da assistência após a alta hospitalar, como a educação em saúde (NIETSCHE et al., 2012).

O processo de alta hospitalar deve ser considerado como uma intervenção de educação em saúde que exerce papel importante na integralidade e continuidade do cuidado. Constantemente, os pais e responsáveis possuem dúvidas e inseguranças quanto aos cuidados básicos com a criança e quanto às condições, temporárias ou permanentes, referentes aos seus agravos. Nesse contexto, o planejamento e a implementação da alta pelos profissionais de saúde e, principalmente, pela equipe de enfermagem deve enfatizar o acesso às informações sobre a continuidade da assistência ambulatorial e em domicílio pelos pais, sendo determinante à qualidade do cuidado (NIETSCHE et al., 2012).

A qualidade do cuidado relacionada à preocupação com o preparo dos pais e responsáveis para o cuidado após a alta hospitalar incide diretamente na continuidade da eficiência dos tratamentos hospitalares recebidos. O planejamento dessa intervenção tem como objetivo desenvolver o protagonismo e a responsabilidade desses atores quanto ao modo mais adequado de prestar cuidados e responder às necessidades da criança, diminuindo o estresse, 
evitando readmissões e buscando recursos disponíveis na comunidade para o atendimento após a alta (NIETSCHE et al., 2012).

Mesmo que a família seja orientada pela equipe de enfermagem quanto aos cuidados domiciliares pertinentes, por vezes, há a possibilidade de não terem compreendido o que lhes foi falado ou mostrado, de modo que durante a internação ou atendimento e no preparo para a alta há muito a ser esclarecido pelos enfermeiros e técnicos de enfermagem. A enfermagem deve prover orientações capazes de proporcionar a adaptação da criança e de seus responsáveis, a fim de reduzir a ansiedade, combinando informes orais e escritos como estratégia para a realização da continuidade dos cuidados em domicílio (GOZZO et al. 2012).

Entretanto, a continuidade do tratamento, seja curativo, preventivo ou de promoção da saúde, para que seja efetivo para a criança e seu núcleo familiar, é necessário o acolhimento com escuta qualificada entre pacientes, familiares e equipe de enfermagem, para que haja o seguimento correto do cuidado por parte de todos os envolvidos, de acordo com as reais necessidades da criança e sua extensão familiar (SOUZA, 2012a).

Contudo, para que o seguimento do plano de cuidados seja implementado fora do ambiente hospitalar de maneira segura, as orientações durante o processo de alta hospitalar devem ser claras e acessíveis, podendo ser obtidas através de um material educativo. É importante esclarecer suas finalidades: auxiliar pacientes e familiares sobre a recuperação; estimular o autocuidado; auxiliá-los a entender sua trajetória de adoecimento e sua adaptação, os tratamentos farmacológicos e não farmacológicos e estratégias de prevenção de agravos e promoção da saúde (GOZZO et al., 2012).

Um estudo realizado em um hospital público de ensino em Curitiba-PR, que teve como objetivo elaborar orientações sistematizadas de enfermagem para a alta hospitalar de pacientes oncológicos, mostrou a necessidade da equipe de enfermagem em prover, de forma clara e acessível, os principais cuidados e intervenções de acordo com as queixas mais frequentes durante e após a alta hospitalar. A implementação de um material educativo acessível contribuiu para minimizar as dúvidas referentes ao processo saúde-doença e servir de base para estimular a adesão ao tratamento proposto, evitando as readmissões (CRUZ; MONTOVANI, 2014).

Estratégias de tecnologias leves, como a implementação, pela enfermagem e equipe multiprofissional, de material educativo a respeito dos principais cuidados, demandas e dúvidas, podem contribuir para a promoção da saúde e prevenção de doenças. A teorista de enfermagem Callista Roy ratifica esse processo, afirmando que enfermagem é uma profissão que está centrada na ênfase da promoção da saúde para todos, como ciência e prática que otimiza a capacidade de adaptação e transformação ambiental do indivíduo. (ROY; ANDREWS, 2001). 
Durante o processo da doença e da hospitalização, a criança e seus familiares são alvos de estímulos, sendo o estímulo focal o principal. O focal, que gera o maior impacto, pode ser entendido como a própria doença. O estímulo contextual consiste em todos os outros fatores que influenciam diretamente o focal, como a mudança de ambiente e rotinas. Os estímulos residuais são os que influenciam indiretamente a experiência vivida naquele momento, como experiências anteriores de hospitalização e doenças pregressas na família (TREMARIN et al., 2009).

É importante conhecer o perfil da demanda apresentada para que seja possível investir na adaptação, pois acredita-se que a criança e seus familiares são um sistema que pode se adaptar às diversas situações, que são permeadas por inúmeros estímulos. O comportamento apresentado frente aos mesmos estímulos dependerá dos mecanismos de enfrentamento ou processos de controle individuais e nem sempre se consegue chegar à adaptação, tendo-se inúmeros comportamentos ineficazes (TREMARIN et al., 2009).

A implementação de um processo educativo de alta hospitalar por parte da enfermagem para a continuidade dos cuidados em domicílio pode ser vista como um estímulo contextual positivo, capaz de influenciar o enfrentamento da criança e da família através da compreensão e aplicabilidade das orientações, gerando feedbacks positivos e adaptação (TREMARIN et al., 2009).

O Modelo de Adaptação de Roy (MAR) refere que cada pessoa ou sistema familiar possui mecanismos de enfrentamento aos estímulos recebidos para o processo de adaptação, que pode ocorrer durante a hospitalização, a alta e em domicílio, no pós-alta. Os mecanismos de enfrentamento ou processos coping são formas de interagir com esses estímulos e com o ambiente em mudança e podem ser adquiridos através das experiências de vida, desenvolvidos a partir de estratégias de aprendizado (GEORGE, 2000).

Para o MAR, um dos mecanismos de enfrentamento que podem ser trabalhados pela enfermagem para a adaptação das crianças e seus familiares está na capacidade de percepção, julgamento e consequente aprendizagem. A enfermagem representa um papel educador e possui a responsabilidade de apreender as demandas e investir de maneira efetiva em orientações que possam ser colocadas em prática por intermédio do aprendizado, levando a continuidade dos cuidados pós-alta sem dificuldade de adesão (ROY; ANDREWS, 2001).

Portanto, os cuidados de enfermagem à criança e à sua extensão familiar devem ter como foco auxiliar e promover a adaptação e ajudá-los a lidar com os problemas de adaptação gerados pelo agravamento das doenças e as consequentes readmissões. O enfermeiro deve agir no preparo para as possíveis mudanças através de orientações efetivas, embasados nas tecnologias 
leves, sobre os cuidados após a alta hospitalar, fortalecendo os mecanismos de enfrentamento através da educação em saúde e evitandos as RH (GEORGE, 2000).

O MAR propõe que as potencialidades sejam identificadas e trabalhadas em cada família, de tal forma que as respostas adaptativas, estimuladas pela equipe de enfermagem no processo de aprendizagem e adaptação, funcionem como feedback positivo na adaptação. Diante disso, o enfermeiro pode ter como estratégia o enfoque nas orientações pertinentes a cada caso, a fim de evitar recaídas ou agravamento das condições de saúde, além de incentivar a adesão do acompanhamento pós-alta e, principalmente, através do exercício concreto das orientações recebidas no momento da alta. 


\section{MÉTODO}

\subsection{TIPO DE ESTUDO}

Estudo exploratório, descritivo com abordagem mista explanatória sequencial. A abordagem mista explanatória sequencial consiste na coleta e análise de dados quantitativos, no primeiro momento da pesquisa, conduzindo posteriormente à coleta e à análise de dados qualitativos. O foco da pesquisa está nos dados quantitativos, entretanto há a conexão entre as duas abordagens, possibilitando a interpretação dos dados quantitativos por meio dos dados qualitativos (CRESWELL, 2010).

Figura 1. Delineamento do estudo, Brasília, 2016.

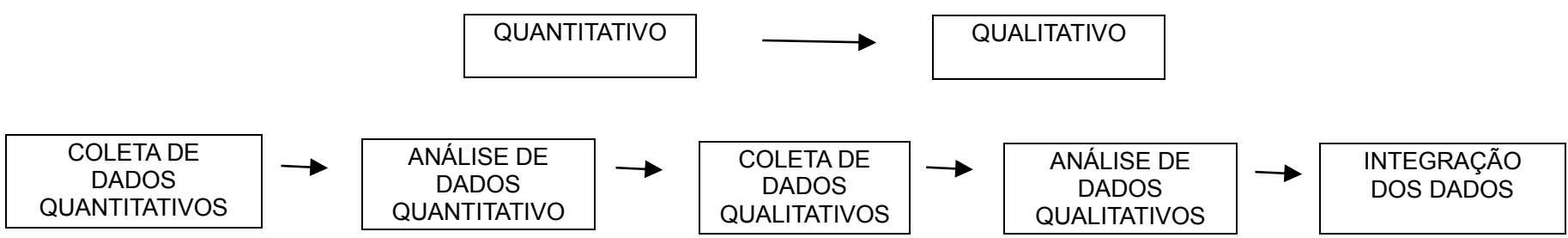

\subsection{LOCAL DO ESTUDO}

O estudo foi realizado na Regional de Saúde da Ceilândia - DF, na unidade de clínica pediátrica do HRC, localizado na Região Administrativa (RA) de Ceilândia, a maior RA do Distrito Federal, cuja população estimada no ano de 2013 era de 444.592 habitantes (CODEPLAN, 2013). Essa regional, além do HRC, que é a referência da região, possui doze Centros de Saúde (CS), três Equipes de Saúde da Família, um Centro de Atenção Psicossocial (CAPS) e uma Unidade de Pronto Atendimento (UPA) (SES/DF, 2016).

O HRC possui 296 leitos e um ambulatório com 23 especialidades. O Pronto-Socorro (PS) está estruturado em três áreas de emergência - pediátrica; ginecologia e obstetrícia e urgências gerais de adultos, que em conjunto corresponderam a cerca de 297.900 atendimentos de emergência em 2014. A área de emergência pediátrica, em 2014, totalizou aproximadamente 65.000 atendimentos (SES/DF, 2014).

A Unidade de Pediatria do HRC é organizada fisicamente em um pronto-socorro subdividido em: 01 sala para o acolhimento com avaliação e classificação de risco, 04 consultórios médicos, 01 sala para procedimentos, 01 sala para limpeza e higienização de materiais, 01 sala para terapia de reidratação oral e nebulização, 01 enfermaria onde as crianças permanecem por um período de até 24 horas com 12 leitos ativos e 01 enfermaria interna com 
29 leitos dividida em 04 alas por sistemas: respiratório, cuidados crônicos, distúrbios metabólicos e cuidados cirúrgicos.

O estudo foi realizado na Unidade de Pediatria do HRC nas enfermarias de 24 horas e na Interna. O local foi escolhido pela facilidade de acesso da pesquisadora com o campo, por ser um dos cenários de prática da graduação em enfermagem, especialmente pelo internato realizado na unidade e em função da demanda de atendimento.

\subsection{PARTICIPANTES}

A população do estudo quantitativo foi constituída de dados retrospectivos das crianças atendidas no PS e na enfermaria da pediatria do HRC nos meses de março, abril e maio de 2015, registradas no Sistema de prontuário eletrônico TrakCare da SES/DF e no livro de internações da unidade de pediatria. Foram excluídos os registros das crianças que não constavam no sistema TrakCare, por não ter o número da SES; com nome e data de nascimento incompletos e aquelas que, apesar de constarem no livro de internação da pediatria, não possuíam registro no sistema.

No período do estudo, havia o registro de atendimento de 719 crianças. Destas, foram excluídas 59 por não atenderem os critérios de inclusão, assim a amostra do estudo quantitativo foi constituída por 660 crianças que possuíam o registro completo de atendimento.

Os participantes do estudo qualitativo foram 10 enfermeiros, que atuavam na enfermaria e pronto-socorro pediátrico. Dos 17 responsáveis por crianças readmitidas no momento das entrevistas, 1 não aceitou participar da pesquisa e outros 3 estavam em exame com os pacientes, impossibilitando a coleta de dados. Portanto fizeram parte da coleta de dados 13 responsáveis por crianças internadas na condição de readmitidas na enfermaria interna e que tinham mais de 18 anos, no período de 13/01/16 a 03/02/16.

\subsection{COLETA E ANÁLISE DE DADOS - PROCEDIMENTOS E INSTRUMENTOS}

Os procedimentos utilizados na coleta de dados envolveram: o levantamento e análise de documentos - Sistema TrakCare de prontuários, livro de registro de atendimento e entrevistas. O estudo foi desenvolvido em duas etapas: na primeira, foi realizada a coleta e análise dos dados quantitativos e, na segunda, a coleta e análise dos dados qualitativos.

A coleta dos dados quantitativos foi feita por meio da análise documental: o livro de registros da pediatria, em que foram identificados o número de registro de cada criança para posterior consulta do prontuário do sistema TrakCare.

A etapa qualitativa consistiu na realização das entrevistas. Primeiramente, foram elaborados dois roteiros semiestruturados que foram pré-testados com três enfermeiros que não 
atuavam na pediatria e com três responsáveis por crianças não readmitidas, a fim de validar a clareza das questões.

Após os ajustes, as entrevistas foram realizadas pela pesquisadora no ambiente da pediatria e o seu conteúdo gravado em áudio e, posteriormente, transcrito.

\subsubsection{Primeira etapa}

\subsubsection{Coleta de Dados Quantitativos - Levantamento de Dados Secundários Retrospectivos}

Na primeira etapa foi efetuado o levantamento de dados secundários retrospectivos das crianças atendidas nos meses de março, abril e maio de 2015, na Unidade de Pediatria do HRC, visando conhecer o quantitativo de readmissões e os tipos de readmissões.

Inicialmente, para identificar o registro da SES das crianças atendidas, foi realizado o levantamento nos livros de internação da enfermaria de 24 horas e na Interna, nos quais estão registrados: nome da criança, número de SES, data de nascimento, data da admissão, diagnóstico da alta, data da alta e tipo de alta. As informações obtidas a partir do livro de registro viabilizaram a busca dos prontuários eletrônicos, no sistema Sistema TrakCare, banco de dados em que se encontram as informações dos atendimentos de cada paciente.

O acesso ao sistema Trakcare foi ocorreu através de uma plataforma online, em que o profissional de saúde, por meio de login e senha, acessa os prontuários dos usuários atendidos na rede pública de saúde do Distrito Federal.

As variáveis de interesse, coletadas do Sistema TrakCare, foram: idade, sexo, etnia, data da admissão, data de alta, diagnóstico da admissão, queixa da primeira admissão e da readmissão, intervalo de tempo (dias) entre a admissão e a readmissão e a procedência das crianças atendidas. Esses dados foram registrados em um protocolo elaborado pela pesquisadora (APÊNDICE C) que se constituiu em um banco de dados para a análise do perfil sociodemográfico das crianças atendidas e readmitidas, das causas de admissão índice e readmissão.

\subsubsection{Organização, Categorização e Codificação dos Dados}

As informações coletadas foram organizadas, categorizadas e codificadas em planilha Excel (Microsoft Office Premium), que constituíram o banco de dados a partir das variáveis: nome da criança; número registro SES; sexo; data de nascimento e idade (calculada considerando a data de 12/10/2015); raça/cor/etnia; procedência (residência); data e hora da admissão; classificação de risco da admissão e da readmissão; diagnóstico definitivo da admissão e readmissão; data, hora e tipo da alta; intervalo de dias entre a admissão e a 
readmissão.

Neste estudo, foi considerada admissão índice a primeira admissão da criança entre março e maio de 2015, sendo adotada uma margem de 1 mês anterior à data encontrada e, como readmissão, os atendimentos posteriores à admissão índice no intervalo de 30 dias na enfermaria de 24 horas e na Interna (TUBBS-COOLEY et al., 2013).

As variáveis data de nascimento e idade foram registradas e codificadas segundo as faixas etárias definidas por Tubino e Alves (2007), a saber: os latentes, as crianças recémnascidas e com idade variando até 2 anos, 11 meses e 29 dias; os pré-escolares, as crianças de 3 anos até 5 anos, 11 meses e 29 dias; os escolares, crianças de 6 anos até 9 anos, 11 meses e 29 dias; pré-púberes, crianças de 10 anos até 13 anos, 11 meses e 29 dias.

As queixas/diagnósticos das crianças admitidas e readmitidas foram categorizadas tomando como referência a Classificação Internacional de Doenças - CID 10, nos seguintes grupos: Doenças do Sistema Osteomuscular (artrites, miosites, mialgia e distrofia muscular), Doenças do Ouvido (otites), Doenças do Aparelho Circulatório (coarctação de aorta, Kawasaki e vasculite alérgica); Causas Externas (mordedura por animais, envenenamento, traumas, intoxicações exógenas, ingestão de corpo estranho e picadas de escorpião); Doenças da Pele e Tecido Subcutâneo (dermatites, furunculose e reação urticariforme); Dor (dor em joelho e ombro); Doenças Endócrinas (diabetes mellitus tipo 1, hiperinsulinemia e hipoglicemias); Doenças do Aparelho Digestivo/Infecciosas (dor abdominal, síndrome dispéptica, gastroenterite, diarreia e verminose); Doenças do Sangue e Alguns Transtornos Imunitários e Hematológicos (púrpura trombocitopênica idiopática, plaquetopenia, anemia falciforme, hemofilia, adenites); Sintomas Febris; Doenças do Sistema Nervoso (convulsões, epilepsia, síncope, síndrome conversiva, síndrome vaso-vagal, e cefaleia); Doenças do Aparelho Respiratório (asma, bronquiolite viral aguda, pneumonia, infecção das vias aéreas superiores IVAS, bronquite, gripe, tosse, traqueobronquite, obstrução nasal, cianose, falta de ar, broncoespasmo, sibilância, coqueluche); Doenças no Aparelho Geniturinário (infecção do trato urinário, glomerulonefrite, litíase renal, cistite, urolitíase, anúria, oligúria e hematúria).

\subsubsection{Análise dos Dados Quantitativos}

Os dados quantitativos foram organizados em um banco dados, utilizando planilhas Excel. O perfil sociodemográfico e de morbidade das crianças atendidas e readmitidas foram obtidos por frequência simples absoluta. A relação entre a faixa etária e as doenças/queixas do sistema respiratório nos eventos de readmissão, e a classificação de risco nas readmissões foram realizados pelo teste do Qui-quadrado, sendo considerado significativo o resultado com p-valor 
menor que 0,05 . Os resultados encontrados serão apresentados na forma de gráfico e tabelas.

A taxa de readmissão foi calculada utilizando a formula: $\mathrm{TR}=$ $\frac{\text { númerodereadmissõesemdeterminadoperíodo }}{\text { númerodeadmitidosnomesmoperíodo }}$ (MOREIRA, 2010)

\subsubsection{Segunda etapa}

\subsubsection{Coleta dos Dados Qualitativos:}

$\mathrm{Na}$ segunda etapa, os dados primários foram coletados por meio de entrevistas com os responsáveis pelas crianças readmitidas internadas e enfermeiros da unidade de pediatria do HRC, visando conhecer o perfil sociodemográfico e apreender a percepção destes acerca da causa da readmissão e das formas de orientação da alta.

Para tanto, foram utilizados dois roteiros semiestruturados para enfermeiros (APÊNDICE D) e acompanhantes/responsáveis (APÊNDICE E), constituído de duas partes. Na primeira, se encontram os dados sociodemográficos; e na segunda, questões norteadoras, com o objetivo de conhecer as principais causas de readmissão e as formas de orientação para alta na unidade de pediatria.

As entrevistas foram realizadas no ambiente da clínica pediátrica e gravadas, após o consentimento dos participantes. Posteriormente, foram transcritas em forma de texto para análise do seu conteúdo.

A coleta de dados na enfermaria interna teve a duração de 3 semanas, em 6 dias no turno diurno. No período da coleta de dados dos 27 leitos, houve variação da taxa de ocupação entre 13 e 16 leitos, destes, cerca de $22 \%$ a $37 \%$ estavam ocupados por crianças readmitidas na unidade dentro de 30 dias da admissão índice.

\subsubsection{Análise dos Dados Qualitativos}

O conteúdo das entrevistas foi transcrito na forma de texto e analisado tomando como referência as etapas preconizadas na técnica de Bardin (1977) - que consiste em: 1) pré-análise; 2) exploração do material; 3) tratamento dos resultados obtidos e interpretação.

1) Na pré-análise foi realizada a preparação do material por meio da transcrição das entrevistas, leitura flutuante e organização por unidades temáticas, de acordo com as questões norteadoras. A organização das entrevistas teve como objetivo a sistematização das ideias iniciais e a compreensão dos temas presentes na verbalização dos participantes, a fim de categorizar os temas; 
2) A exploração do material consistiu na organização das transcrições de acordo com as categorias temáticas que emergiram, e, posteriormente, na análise propriamente dita, com a escolha do recorte do texto que respondeu, de forma clara e objetiva, as questões norteadoras;

3) No tratamento e interpretação dos resultados foram explicitados os exemplos mais significativos e fiéis para cada categoria, possibilitando estabelecer inferências acerca dos temas, causas da readmissão, conteúdo e estratégias de orientação da criança na alta.

\subsection{PROCEDIMENTOS ÉTICOS}

Esta pesquisa foi desenvolvida de acordo com a Resolução do Conselho Nacional de Saúde (CNS) No 466/2012, que refere que toda pesquisa com seres humanos envolve riscos de tipos e gradações variados. Portanto, a análise ética e a exposição das possibilidades de danos e riscos foram elucidados no Termo de Consentimento Livre e Esclarecido - TCLE (APÊNDICE A e B) e na avaliação de riscos e benefícios.

O estudo foi aprovado pelo Comitê de Ética em Pesquisa com Seres Humanos da Faculdade de Ciências da Saúde da Universidade de Brasília - CEP/FS e, posteriormente, pelo Comitê de Ética em Pesquisa da Fundação de Ensino e Pesquisa em Ciências da Saúde da Secretaria de Saúde do Distrito Federal - CEP/FEPECS, sob o Parecer n 1.167.834/2015 (ANEXO A). 
Figura 2. Fluxograma das etapas do estudo, Brasília, 2016.

Fases do Estudo

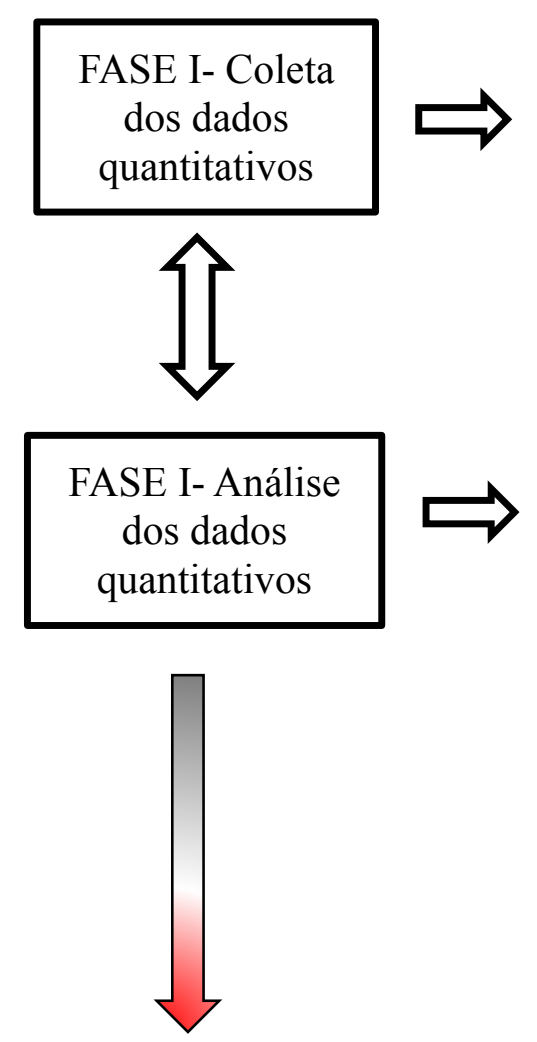

FASE II- Coleta dos dados qualitativos

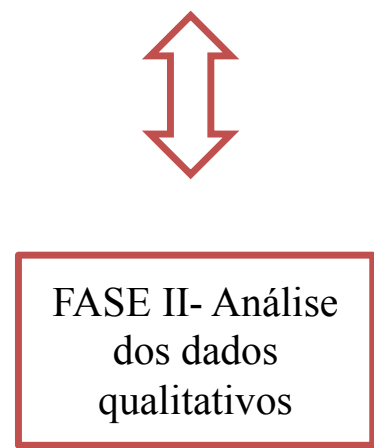

Procedimentos

Análise estatística

Frequência simples

e absoluta e

relação entre as

variáveis
Produtos
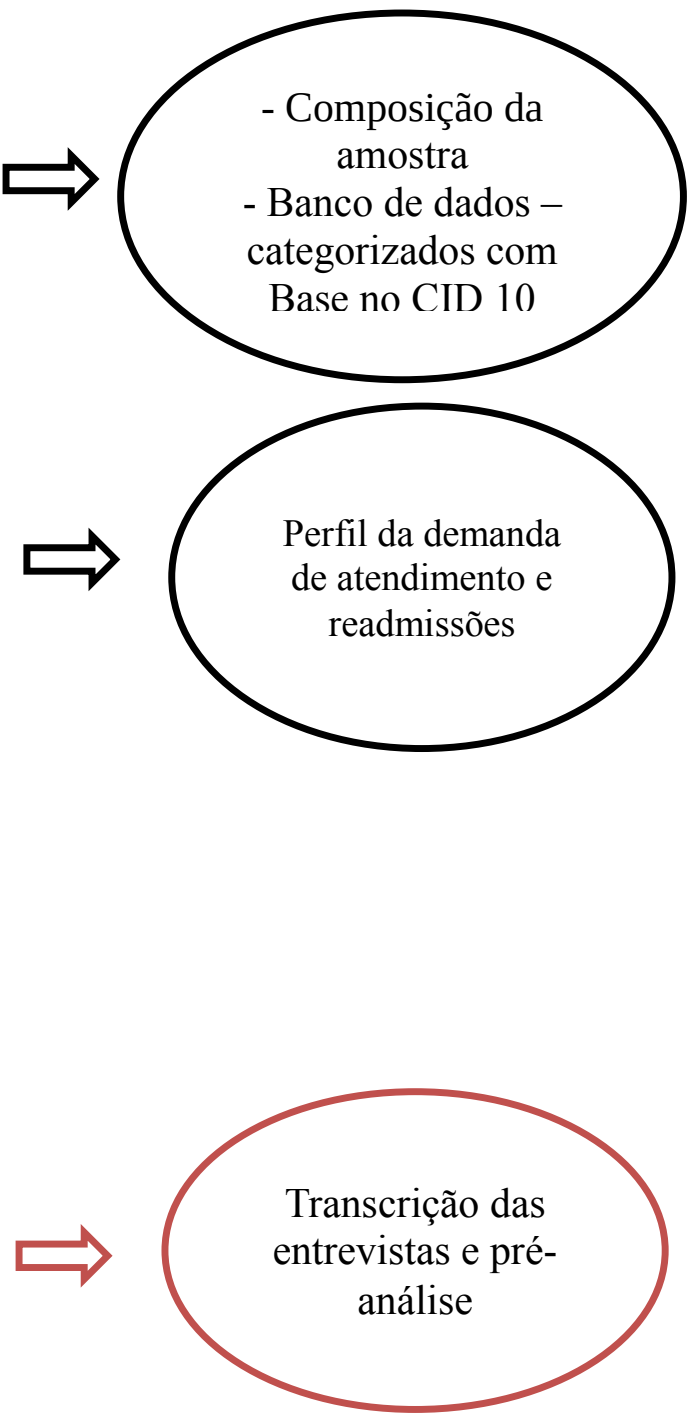

readmitidas
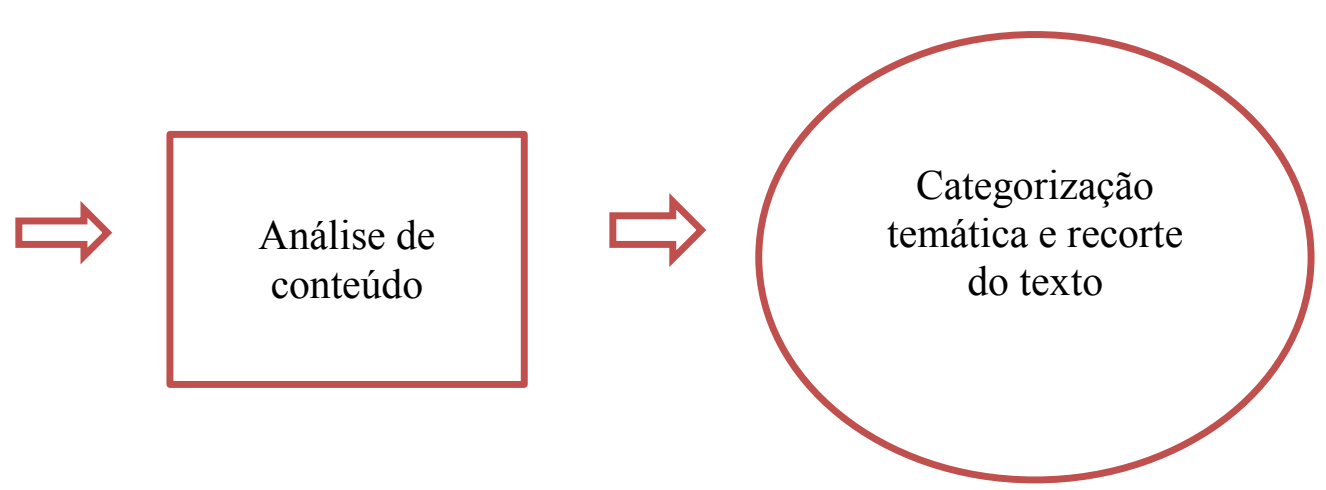


\section{RESULTADOS E DISCUSSÃO DOS DADOS QUANTITATIVOS}

\subsection{O PERFIL DA DEMANDA DE ATENDIMENTOS NO PRONTO-SOCORRO PEDIÁTRICO DO HRC}

Nos meses de março a maio de 2015 foram realizados 660 atendimentos, dos quais $44,8 \%$ (296) pertencem ao sexo feminino e 55,2\% (364), ao masculino. Quanto às faixas etárias, 47,6\% (314) são lactentes, correspondendo à faixa etária de 0 a 2 anos; os pré-escolares, de 3 a 5 anos, são 23,2\% (153) do total; os escolares, de 6 a 9 anos, compreendem 16,3\% (108) e os prépúberes, de 10 a 13 anos, 12,9\% (85) (Tabela 1).

Quanto à procedência, observou-se que as crianças eram oriundas de 16 diferentes locais. Os maiores quantitativos foram de Ceilândia, Taguatinga, Samambaia e Águas Lindas de Goiás, respectivamente. A região de Ceilândia é considerada a maior Região de Saúde do DF, por isso o maior número de crianças é procedente da própria regional (Tabela 2).

Tabela 1. Distribuição das crianças atendidas segundo sexo e faixa etária, Brasília, 2016.

\begin{tabular}{lc} 
Sexo & $\mathbf{n}(\mathbf{\%})$ \\
Masculino & $364(55,2)$ \\
Feminino & $296(44,8)$ \\
Faixa Etária & $\mathbf{n}(\mathbf{\%})$ \\
Lactente & $314(47,6)$ \\
Pré-escolar & $153(23,2)$ \\
Escolar & $108(16,3)$ \\
Pré-púbere & $85(12,9)$ \\
\hline
\end{tabular}


Tabela 2. Distribuição das crianças atendidas segundo a procedência, Brasília, 2016.

\begin{tabular}{lc}
\hline \multicolumn{1}{c}{ Procedência } & n (\%) \\
\hline Águas Lindas de Goiás-GO & $30(4,5)$ \\
Arapiraca-AL & $1(0,2)$ \\
Brasília-DF & $3(0,5)$ \\
Candangolândia-DF & $2(0,3)$ \\
Ceilândia-DF & $511(77,4)$ \\
Cocalzinho de Goiás-GO & $1(0,2)$ \\
Gama-DF & $3(0,4)$ \\
Estado de Goiás (cidades não identificadas) & $2(0,3)$ \\
Planaltina-DF & $2(0,3)$ \\
Recanto das Emas-DF & $18(2,7)$ \\
Riacho Fundo-DF & $2(0,3)$ \\
Samambaia-DF & $37(5,6)$ \\
Santa Maria-DF & $1(0,2)$ \\
Santo Antônio do Descoberto-GO & $2(0,3)$ \\
São João d'Aliança-GO & $1(0,2)$ \\
Taguatinga-DF & $44(6,6)$ \\
\hline Total Geral & $\mathbf{6 6 0}(\mathbf{1 0 0})$ \\
\hline
\end{tabular}

Nas admissões índices, os grupos de diagnósticos mais prevalentes foram os do sistema respiratório, representando 53,9\% (356) das 660 admissões; do sistema nervoso, que por sua vez, compreende 10,3\% (68); os do digestivo e doenças infecciosas, com 9,7\% (63) das ocorrências; e, por conseguinte, o grupo dos sintomas febris, que correspondem a 8,8\% (58) do total.

Os lactentes, grupo etário de maior prevalência no estudo e predominantemente classificado na cor laranja, tiveram os grupos de diagnósticos mais prevalentes referentes às doenças do aparelho respiratório, com 66,3\% (208), seguido pelos sintomas febris, que alçaram $7,3 \%$ (23). Adiante, as doenças do sistema nervoso contabilizaram 6,7\% (21) e, em seguida, as doenças do aparelho digestivo e infecciosas, que atingiram 5,1\% (16).

O grupo respiratório também foi prevalente nas faixas etárias dos pré-escolares, dos escolares e dos pré-púberes, além dos diagnósticos do sistema nervoso e digestivo/infeccioso também se destacarem nas mencionadas faixas, sendo os sintomas febris de menor destaque entre eles (Tabela 3). 
Tabela 3. Distribuição das crianças atendidas por grupo diagnóstico e faixa etária, Brasília, 2016.

\begin{tabular}{|c|c|c|c|c|c|}
\hline \multirow[b]{2}{*}{ Grupo Diagnóstico } & \multicolumn{4}{|c|}{ Faixa Etária } & \multirow[b]{2}{*}{ Total $(\%)$} \\
\hline & $\begin{array}{c}\text { Lactente } \\
\text { n }(\%)\end{array}$ & $\begin{array}{c}\text { Pré- } \\
\text { escolar } \\
\text { n (\%) }\end{array}$ & $\begin{array}{c}\text { Escolar } \\
\text { n }(\%)\end{array}$ & $\begin{array}{c}\text { Pré- } \\
\text { púbere } \\
\text { n (\%) }\end{array}$ & \\
\hline Doenças do Sistema Osteomuscular & 0 & 0 & $1(0,9)$ & $2(2,4)$ & $3(0,5)$ \\
\hline Doenças do Ouvido & $2(0,6)$ & 0 & 0 & 0 & $2(0,3)$ \\
\hline Causas Externas & $5(1,6)$ & $7(4,6)$ & $1(0,9)$ & $1(1,2)$ & $14(2,1)$ \\
\hline Doenças da Pele e Tecido Subcutâneo & $6(1,9)$ & $7(4,6)$ & $5(4,7)$ & $2(2,4)$ & $20(3,0)$ \\
\hline Doenças do Aparelho Circulatório & $1(0,3)$ & 0 & $1(0,9)$ & 0 & $2(0,3)$ \\
\hline Dor & 0 & $1(0,7)$ & $3(2,8)$ & 0 & $4(0,6)$ \\
\hline Doenças Endócrinas & $2(0,6)$ & $4(2,6)$ & $3(2,8)$ & $3(3,5)$ & $12(1,8)$ \\
\hline $\begin{array}{l}\text { Doenças do Aparelho Digestivo e } \\
\text { Infecciosas }\end{array}$ & $16(5,1)$ & $13(8,5)$ & $21(19,4)$ & $14(16,4)$ & $64(9,7)$ \\
\hline $\begin{array}{l}\text { Doenças do Sangue e Transtorno } \\
\text { Imunitários }\end{array}$ & $3(1,0)$ & $1(0,7)$ & $1(0,9)$ & $1(1,2)$ & $6(0,9)$ \\
\hline Sintomas Febris & $23(7,3)$ & $10(6,5)$ & $11(10,2)$ & $14(16,4)$ & $58(8,8)$ \\
\hline Doenças do Sistema Nervoso & $21(6,7)$ & $25(16,3)$ & $8(7,4)$ & $14(16,4)$ & $68(10,3)$ \\
\hline Não Respondeu a Chamada & $1(0,3)$ & 0 & 0 & 0 & $1(0,2)$ \\
\hline Doenças do Aparelho Respiratório & $208(66,3)$ & $74(48,3)$ & $48(44,4)$ & $26(30,6)$ & $356(53,9)$ \\
\hline $\begin{array}{l}\text { Doenças do Aparelho Respiratório e } \\
\text { Digestivo }\end{array}$ & $1(0,3)$ & 0 & 0 & 0 & $1(0,2)$ \\
\hline $\begin{array}{l}\text { Doenças do Aparelho Respiratório e } \\
\text { Geniturinário }\end{array}$ & 0 & 0 & 0 & $1(1,2)$ & $1(0,2)$ \\
\hline Sem Informação & $19(6,1)$ & $9(5,9)$ & $2(1,9)$ & $1(1,2)$ & $31(4,7)$ \\
\hline Doenças do Aparelho Geniturinário & $6(1,9)$ & $2(1,3)$ & $3(2,8)$ & $6(7,1)$ & $17(2,5)$ \\
\hline Total Geral & $314(100)$ & $153(100)$ & $108(100)$ & $85(100)$ & $660(100)$ \\
\hline
\end{tabular}

Em relação à classificação de risco atribuída às crianças no momento da admissão índice, houve maior frequência da classificação na cor laranja, caracterizada pelo protocolo Manchester como muito urgente e nível de prioridade 2, totalizando 30,5\% (201) do total de atendimentos $(660)$.

A classificação na cor amarela, que representa o atendimento urgente e nível de prioridade 3, representou 23,5\% (155) dos registros; já a classificação na cor verde, entendida como pouco urgente e nível de prioridade 4, totalizou 21,8\% (144) dos atendimentos. Por sua vez, a classificação na cor vermelha, considerada emergência e nível de prioridade 1, representou apenas 2,6\% (17) dos atendimentos. E, por derradeiro, a classificação azul, considerada não urgente e com prioridade 5 , teve menos de $1 \%$ do total de atendimentos, com $0,3 \%$ (2) (Tabela 4).

No entanto, pode-se observar que 21,4\% (141) das crianças não tiveram classificação atribuída no momento da admissão, em função da falta de tempo para classificar, pela condição 
clínica da criança devido à gravidade do seu estado ou ainda por problemas no sistema TrakCare no momento da classificação.

Tabela 4. Distribuição das crianças atendidas por classificação de risco e faixa etária, Brasília, 2016.

\section{Faixa Etária}

\begin{tabular}{lccccc}
$\begin{array}{l}\text { Classificação de } \\
\text { Risco }\end{array}$ & $\begin{array}{c}\text { Lactente } \\
\text { n (\%) }\end{array}$ & $\begin{array}{c}\text { Pré-escolar } \\
\text { n (\%) }\end{array}$ & $\begin{array}{c}\text { Escolar } \\
\text { n (\%) }\end{array}$ & $\begin{array}{c}\text { Pré-púbere } \\
\text { n (\%) }\end{array}$ & Total (\%) \\
\hline 01-vermelho & $6(0,9)$ & $4(0,6)$ & $6(0,9)$ & $1(0,2)$ & $17(2,6)$ \\
02-laranja & $87(13,2)$ & $58(8,8)$ & $34(5,2)$ & $22(3,3)$ & $201(30,4)$ \\
03-amarelo & $69(10,5)$ & $35(5,3)$ & $27(4,1)$ & $24(3,6)$ & $155(23,5)$ \\
04-verde & $72(10,9)$ & $31(4,7)$ & $21(3,2)$ & $20(3,0)$ & $144(21,8)$ \\
05-azul & $2(0,3)$ & 0 & 0 & 0 & $2(0,3)$ \\
sem classificação & $78(11,8)$ & $25(3,8)$ & $20(3,0)$ & $18(2,7)$ & $141(21,4)$ \\
\hline Total Geral & $\mathbf{3 1 4 ( 4 7 , 6 )}$ & $\mathbf{1 5 3 ( 2 3 , 2 )}$ & $\mathbf{1 0 8 ( 1 6 , 4 )}$ & $\mathbf{8 5}(\mathbf{1 2 , 8})$ & $\mathbf{6 6 0}(\mathbf{1 0 0})$ \\
\hline
\end{tabular}

Quanto à classificação de risco segundo grupos de diagnósticos, a vermelha teve maior prevalência nos grupos de diagnósticos do sistema nervoso, representando 35,3\% (6) do total de classificados nessa cor. As demais classificações destacaram-se no grupo respiratório, sendo a cor laranja responsável por 58,2\% (117) do total de 201 crianças classificadas; a amarela com 59,4\% (92) de um total de 155; verde com 45,1\% (65) de 144; azul com 50\% (1) de 2 e até os que não foram classificados 53,9\% (76) de 141 (Tabela 5). 
Tabela 5. Distribuição das crianças atendidas por grupo diagnóstico e classificação de risco, Brasília, 2016.

\begin{tabular}{|c|c|c|c|c|c|c|c|c|c|c|c|c|c|c|}
\hline \multirow{3}{*}{ Grupo Diagnóstico } & \multicolumn{12}{|c|}{ Classificação de Risco } & \multirow{3}{*}{ Total } & \multirow{3}{*}{$(\%)$} \\
\hline & \multicolumn{2}{|c|}{$\begin{array}{c}\text { 01- } \\
\text { vermelho }\end{array}$} & \multicolumn{2}{|c|}{ 02-laranja } & \multicolumn{2}{|c|}{$\begin{array}{c}\text { 03- } \\
\text { amarelo }\end{array}$} & \multicolumn{2}{|c|}{ 04-verde } & \multicolumn{2}{|c|}{ 05-azul } & \multicolumn{2}{|c|}{$\begin{array}{c}\text { sem } \\
\text { classificação }\end{array}$} & & \\
\hline & $\mathbf{n}$ & $(\%)$ & $\mathbf{n}$ & $(\%)$ & $\mathbf{N}$ & $(\%)$ & $\mathbf{n}$ & $(\%)$ & $\mathbf{n}$ & $(\%)$ & $\mathbf{n}$ & $(\%)$ & & \\
\hline $\begin{array}{l}\text { Doenças do Sistema } \\
\text { Osteomuscular }\end{array}$ & & 0 & & 0 & 1 & $(0,6)$ & 2 & $(1,4)$ & & 0 & & 0 & 3 & $(0,5)$ \\
\hline Doenças do Ouvido & & 0 & & 0 & & 0 & 1 & $(0,7)$ & & 0 & 1 & $(0,7)$ & 2 & $(0,3)$ \\
\hline Causas Externas & 1 & $(5,9)$ & 4 & $(2,0)$ & 3 & $(1,9)$ & 5 & $(3,5)$ & & 0 & 1 & $(0,7)$ & 14 & $(2,1)$ \\
\hline $\begin{array}{l}\text { Doenças da Pele e Tecido } \\
\text { Subcutâneo }\end{array}$ & & 0 & 6 & $(3,0)$ & 7 & $(4,5)$ & 7 & $(4,8)$ & & 0 & & 0 & 20 & $(3,0)$ \\
\hline $\begin{array}{l}\text { Doenças do Aparelho } \\
\text { Circulatório }\end{array}$ & & 0 & 1 & $(0,5)$ & 1 & $(0,6)$ & & 0 & & 0 & & 0 & 2 & $(0,3)$ \\
\hline Dor & & 0 & & 0 & 1 & $(0,6)$ & 2 & $(1,4)$ & & 0 & 1 & $(0,7)$ & 4 & $(0,6)$ \\
\hline Doenças Endócrinas & 4 & $(23,5)$ & 2 & $(1,0)$ & 2 & $(1,4)$ & 2 & $(1,4)$ & & 0 & 2 & $(1,4)$ & 12 & $(1,8)$ \\
\hline $\begin{array}{l}\text { Doenças do Aparelho } \\
\text { Digestivo e Infecciosas }\end{array}$ & 1 & $(5,9)$ & 16 & $(8,0)$ & 21 & $(13,5)$ & 17 & $(11,8)$ & & 0 & 9 & $(6,4)$ & 64 & $(9,7)$ \\
\hline $\begin{array}{l}\text { Doenças do Sangue e } \\
\text { Transtorno Imunitários }\end{array}$ & & 0 & 1 & $(0,5)$ & 1 & $(0,6)$ & 2 & $(1,4)$ & & 0 & 2 & $(1,4)$ & 6 & $(0,9)$ \\
\hline Sintomas Febris & & 0 & 22 & $(10,9)$ & 13 & $(8,4)$ & 13 & $(9,0)$ & & 0 & 10 & $(7,1)$ & 58 & $(8,8)$ \\
\hline $\begin{array}{l}\text { Doenças do Sistema } \\
\text { Nervoso }\end{array}$ & 6 & $(35,3)$ & 26 & $(12,9)$ & 10 & $(6,5)$ & 6 & $(4,2)$ & & 0 & 20 & $(14,2)$ & 68 & $(10,3)$ \\
\hline Não Respondeu a Chamada & & 0 & & 0 & & 0 & 1 & $(0,7)$ & & 0 & & 0 & 1 & $(0,1)$ \\
\hline $\begin{array}{l}\text { Doenças do Aparelho } \\
\text { Respiratório }\end{array}$ & 5 & $(29,4)$ & 117 & $(58,2)$ & 92 & $(59,4)$ & 65 & $(45,1)$ & 1 & $(50)$ & 76 & $(53,9)$ & 356 & $(53,9)$ \\
\hline $\begin{array}{l}\text { Doenças do Aparelho } \\
\text { Respiratório e Digestivo } \\
\text { Doenças do Aparelho }\end{array}$ & & 0 & & 0 & & 0 & & 0 & & 0 & 1 & $(0,7)$ & 1 & $(0,2)$ \\
\hline $\begin{array}{l}\text { Respiratório e } \\
\text { Geniturinário }\end{array}$ & & 0 & & 0 & & 0 & 1 & $(0,7)$ & & 0 & & 0 & 1 & $(0,2)$ \\
\hline Sem Informação & & 0 & 1 & $(0,5)$ & 2 & $(1,4)$ & 15 & $(10,4)$ & 1 & $(50)$ & 12 & $(8,5)$ & 31 & $(4,7)$ \\
\hline $\begin{array}{l}\text { Doenças do Aparelho } \\
\text { Geniturinário }\end{array}$ & & 0 & 5 & $(2,5)$ & 1 & $(0,6)$ & 5 & $(3,5)$ & & 0 & 6 & $(4,3)$ & 17 & $(2,6)$ \\
\hline Total Geral & 17 & (100) & 201 & $(100)$ & 155 & $(100)$ & 144 & (100) & 2 & (100) & 141 & (100) & 660 & (100) \\
\hline
\end{tabular}

Das 356 queixas do grupo do sistema respiratório, observou-se que a queixa de asma totalizou 32\% (114); a bronquiolite viral aguda, 21,3\% (76); a pneumonia, 11\% (39); e a infecção das vias aéreas superiores (IVAS) foi de 7,9\% (28) (Tabela 6).

As queixas de asma, bronquiolite, pneumonia e infecção das vias aéreas superiores, que são CSAP, apresentaram maior frequência no grupo dos lactentes, sendo observada a diminuição da frequência de acordo com o aumento da faixa etária, respectivamente nos préescolares, escolares e pré-púberes. 
Tabela 6. Distribuição das crianças atendidas por doenças do sistema respiratório e faixa etária, Brasília, 2016.

\begin{tabular}{lcc}
\hline Asma & n & $(\mathbf{\% )}$ \\
\hline Lactente & 36 & $(31,5)$ \\
Pré-escolar & 33 & $(29,0)$ \\
Escolar & 33 & $(29,0)$ \\
Pré-púbere & 12 & $(10,5)$ \\
Total Asma & $\mathbf{1 1 4}$ & $\mathbf{( 1 0 0 )}$ \\
& & \\
\hline Bronquiolite & & \\
\hline Lactente & 75 & $(98,7)$ \\
Pré-escolar & 1 & $(1,3)$ \\
Total Bronquiolite & $\mathbf{7 6}$ & $\mathbf{( 1 0 0 )}$ \\
& & \\
\hline Pneumonia & & \\
\hline Lactente & 21 & $(53,8)$ \\
Pré-escolar & 12 & $(30,8)$ \\
Escolar & 4 & $(10,3)$ \\
Pré-púbere & 2 & $(5,1)$ \\
Total Pneumonia & $\mathbf{3 9}$ & $\mathbf{( 1 0 0 )}$ \\
& & \\
\hline IVAS & & \\
\hline Lactente & 16 & $(57,1)$ \\
Pré-escolar & 10 & $(35,7)$ \\
Escolar & 1 & $(3,6)$ \\
Pré-púbere & 1 & $(3,6)$ \\
Total IVAS & $\mathbf{2 8}$ & $\mathbf{( 1 0 0 )}$ \\
\hline
\end{tabular}




\subsection{AS READMISSÕES NÃO PROGRAMADAS DA PEDIATRIA DO HRC}

Das 660 crianças atendidas entre os meses de março a maio de 2015, na enfermaria de 24 horas do HRC, 249 (37,7\%) eram crianças que haviam sido atendidas no período de 30 dias, a contar da admissão índice, caracterizadas desta forma como readmissão (Tabela 7).

Tabela 7. Taxa de crianças readmitidas e sem retorno, Brasília, 2016.

\begin{tabular}{lcc}
\hline Crianças & n & $(\boldsymbol{\%})$ \\
\hline Readmitidas & 249 & $(37,7)$ \\
Sem Retorno & 411 & $(62,3)$ \\
\hline Total Geral & $\mathbf{6 6 0}$ & $\mathbf{( 1 0 0 )}$ \\
\hline
\end{tabular}

Das crianças readmitidas, 47,4\% (118) eram do sexo feminino e 52,6\% (131), do masculino. A faixa etária predominante foi a dos lactentes, com 50,6\% (126) dos casos, seguida dos pré-escolares 22,1\% (55), escolares 16,9\% (42) e pré-púberes 10,4\% (26) (Tabela 8).

Tabela 8. Distribuição das crianças readmitidas segundo sexo e faixa etária, Brasília, 2016.

\begin{tabular}{lc} 
Sexo & $\mathbf{n}(\mathbf{\%})$ \\
Feminino & $118(47,4)$ \\
Masculino & $131(52,6)$ \\
Grupo Etário & $\mathbf{n}(\mathbf{\% )}$ \\
Lactente & $126(50,6)$ \\
Pré-escolar & $55(22,1)$ \\
Escolar & $42(16,9)$ \\
Pré-púbere & $26(10,4)$ \\
\hline
\end{tabular}

Quanto aos eventos de readmissão, constatou-se que das 249 crianças, cada uma, individualmente, teve entre 1, 2, 3, 4, 5 e 8 eventos de readmissão, totalizando 425 eventos.

A maior parte das crianças teve entre 1 e 2 eventos de readmissão. Das crianças readmitidas, 135 tiveram um evento de readmissão e 74 delas foram readmitidas por duas vezes. Foi observado que o número de crianças com mais de um evento de readmissão é decrescente, ou seja, a relação entre readmissões/criança é inversamente proporcional, como demonstrado na Tabela 9. 
Tabela 9. Distribuição da frequência de atendimentos por eventos de readmissão das crianças, Brasília, 2016.

\begin{tabular}{ccccc}
\hline $\begin{array}{c}\mathbf{N}^{\mathbf{0}} \text { de eventos de } \\
\text { readmissão }\end{array}$ & \multicolumn{2}{c}{ Readmissão } & \multicolumn{2}{c}{$\begin{array}{c}\text { Total de Eventos de } \\
\text { Readmissão } \\
\mathbf{( \% )}\end{array}$} \\
\hline 1 & 135 & $(54,2)$ & 135 & $(31,7)$ \\
2 & 74 & $(29,7)$ & 148 & $(34,8)$ \\
3 & 27 & $(10,9)$ & 81 & $(19,1)$ \\
4 & 7 & $(2,8)$ & 28 & $(6,6)$ \\
5 & 5 & $(2)$ & 25 & $(5,9)$ \\
8 & 1 & $(0,4)$ & 8 & $(1,9)$ \\
\hline Total Geral & $\mathbf{2 4 9}$ & $\mathbf{( 1 0 0 )}$ & $\mathbf{4 2 5}$ & $\mathbf{( 1 0 0 )}$ \\
\hline
\end{tabular}

Quanto aos grupos de diagnósticos das crianças readmitidas e nos eventos subsequentes de readmissão, foi identificado o mesmo perfil das admissões índices, ou seja, prevaleceu o grupo respiratório. Das 249 crianças readmitidas, 46,2\% (115) foram atendidas na admissão índice com problemas respiratórios, enquanto 47\% (117) foram readmitidas, pelo menos uma vez, no referido grupo (Tabela 10).

Os lactentes e pré-escolares somam 85,8\% (182) dos 212 atendimentos de readmissão no grupo respiratório, $72,4 \%$ (21) dos 29 atendimentos do sistema nervoso e $68,9 \%$ (31) dos 45 atendimentos referentes às readmissões do grupo digestivo/infeccioso (Tabela 11). Foi realizado o teste do Qui-quadrado entre a faixa etária dos lactentes e a ocorrência de doenças do sistema respiratório, sendo observada relação significativa $(\mathrm{p}<0,05)$ dessas variáveis.

Em relação aos sintomas febris, foi observado que os lactentes são os mais acometidos por esse grupo, representando 47,2\% (17) dos 36 atendimentos, mas também é evidente que os pré-escolares e pré-púberes também se apresentaram suscetíveis, contabilizando 44,4\% (16) do total (Tabela 11). 
Tabela 10. Distribuição das crianças readmitidas por grupo diagnóstico e faixa etária, Brasília, 2016.

\begin{tabular}{|c|c|c|c|c|c|c|c|c|c|c|}
\hline \multirow{3}{*}{ Grupos Diagnóstico } & \multicolumn{8}{|c|}{ Faixa Etária } & \multirow{3}{*}{ Total n } & \multirow{3}{*}{ Total (\%) } \\
\hline & \multicolumn{2}{|c|}{ Lactente } & \multicolumn{2}{|c|}{ Pré-escolar } & \multicolumn{2}{|c|}{ Escolar } & \multicolumn{2}{|c|}{ Pré-púbere } & & \\
\hline & $\mathbf{n}$ & $(\%)$ & $\mathbf{n}$ & $(\%)$ & $\mathbf{n}$ & $(\%)$ & $\mathbf{n}$ & $(\%)$ & & \\
\hline Readmissão & 126 & $(50,6)$ & 55 & $(22,1)$ & 42 & $(16,9)$ & 26 & $(10,4)$ & 249 & (100) \\
\hline $\begin{array}{l}\text { Doenças do Sistema } \\
\text { Osteomuscular }\end{array}$ & \multicolumn{2}{|c|}{0} & \multicolumn{2}{|c|}{0} & \multicolumn{2}{|c|}{0} & 1 & $(3,9)$ & 1 & $(0,4)$ \\
\hline Doenças do Ouvido & 1 & $(0,8)$ & \multicolumn{2}{|c|}{0} & \multicolumn{2}{|c|}{0} & \multicolumn{2}{|c|}{0} & 1 & $(0,4)$ \\
\hline Causas Externas & 2 & $(1,6)$ & 4 & $(7,3)$ & 1 & $(2,3)$ & 1 & $(3,9)$ & 8 & $(3,2)$ \\
\hline $\begin{array}{l}\text { Doenças da Pele e Tecido } \\
\text { Subcutâneo }\end{array}$ & 2 & $(1,6)$ & 1 & $(1,8)$ & 2 & $(4,8)$ & \multicolumn{2}{|c|}{0} & 5 & $(2,0)$ \\
\hline $\begin{array}{l}\text { Doenças do Aparelho } \\
\text { Circulatório }\end{array}$ & 1 & $(0,8)$ & \multicolumn{2}{|c|}{0} & \multicolumn{2}{|c|}{0} & \multicolumn{2}{|c|}{0} & 1 & $(0,4)$ \\
\hline Dor & \multicolumn{2}{|c|}{0} & 1 & $(1,8)$ & 3 & $(7,1)$ & \multicolumn{2}{|c|}{0} & 4 & $(1,6)$ \\
\hline Doenças Endócrinas & 2 & $(1,6)$ & 1 & $(1,8)$ & \multicolumn{2}{|c|}{0} & 2 & $(7,7)$ & 5 & $(2)$ \\
\hline $\begin{array}{l}\text { Doenças do Aparelho } \\
\text { Digestivo e Infecciosas }\end{array}$ & 8 & $(6,3)$ & 4 & $(7,3)$ & 9 & $(21,4)$ & 1 & $(3,9)$ & 22 & $(8,8)$ \\
\hline $\begin{array}{l}\text { Doenças do Sangue e } \\
\text { Transtorno Imunitários }\end{array}$ & 2 & $(1,6)$ & \multicolumn{2}{|c|}{0} & \multicolumn{2}{|c|}{0} & \multicolumn{2}{|c|}{0} & 2 & $(0,8)$ \\
\hline Sintomas Febris & 10 & $(7,9)$ & 5 & $(9,1)$ & 6 & $(14,3)$ & 7 & $(26,9)$ & 28 & $(11,3)$ \\
\hline Doenças do Sistema Nervoso & 6 & $(4,8)$ & 5 & $(9,1)$ & 2 & $(4,8)$ & 3 & $(11,5)$ & 16 & $(6,4)$ \\
\hline Não Respondeu a Chamada & 1 & $(0,8)$ & \multicolumn{2}{|c|}{0} & \multicolumn{2}{|c|}{0} & \multicolumn{2}{|c|}{0} & 1 & $(0,4)$ \\
\hline $\begin{array}{l}\text { Doenças do Aparelho } \\
\text { Respiratório }\end{array}$ & 70 & $(55,6)$ & \multicolumn{2}{|r|}{$(43,6)$} & \multicolumn{2}{|r|}{$(35,7)$} & 6 & $(23)$ & 115 & $(46,2)$ \\
\hline $\begin{array}{l}\text { Doenças do Aparelho } \\
\text { Respiratório e Digestivo }\end{array}$ & 1 & $(0,8)$ & \multicolumn{2}{|c|}{0} & \multicolumn{2}{|c|}{0} & & & 1 & $(0,4)$ \\
\hline $\begin{array}{l}\text { Doenças do Aparelho } \\
\text { Respiratório e Geniturinário }\end{array}$ & & 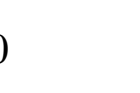 & & 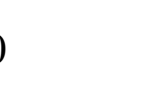 & & & 1 & $(3,9)$ & 1 & $(0,4)$ \\
\hline Sem Informação & 17 & $(13,4)$ & 9 & $(16,4)$ & 2 & $(4,8)$ & 1 & $(3,9)$ & 29 & $(11,7)$ \\
\hline $\begin{array}{l}\text { Doenças do Aparelho } \\
\text { Geniturinário }\end{array}$ & 3 & $(2,4)$ & 1 & $(1,8)$ & 2 & $(4,8)$ & 3 & $(11,5)$ & 9 & $(3,6)$ \\
\hline
\end{tabular}


Tabela 11. Distribuição dos eventos de readmissão por grupo diagnóstico e faixa etária, Brasília, 2016.

\begin{tabular}{|c|c|c|c|c|c|c|c|c|c|c|}
\hline \multirow{3}{*}{ Grupos Diagnóstico } & \multicolumn{8}{|c|}{ Faixa Etária } & \multirow{3}{*}{ Total n } & \multirow{3}{*}{ Total (\%) } \\
\hline & \multicolumn{2}{|c|}{ Lactente } & \multicolumn{2}{|c|}{ Pré-escolar } & \multicolumn{2}{|c|}{ Escolar } & \multicolumn{2}{|c|}{ Pré-púbere } & & \\
\hline & $\mathbf{n}$ & $(\%)$ & $\mathrm{n}$ & $(\%)$ & $\mathbf{n}$ & $(\%)$ & $\mathbf{n}$ & $(\%)$ & & \\
\hline Eventos de Readmissão & 224 & $(52,7)$ & 102 & $(24,0)$ & 64 & $(15,1)$ & 35 & $(8,2)$ & 425 & (100) \\
\hline $\begin{array}{l}\text { Doenças do Sistema } \\
\text { Osteomuscular }\end{array}$ & \multicolumn{2}{|c|}{0} & \multicolumn{2}{|c|}{0} & 2 & $(3,1)$ & \multicolumn{2}{|c|}{0} & 2 & $(0,5)$ \\
\hline Doenças do Ouvido & 4 & $(1,8)$ & 4 & $(3,9)$ & \multicolumn{2}{|c|}{0} & \multicolumn{2}{|c|}{0} & 8 & $(1,9)$ \\
\hline Causas Externas & 5 & $(2,2)$ & 7 & $(6,9)$ & \multicolumn{2}{|c|}{0} & 1 & $(2,9)$ & 13 & (3) \\
\hline $\begin{array}{l}\text { Doenças da Pele e Tecido } \\
\text { Subcutâneo }\end{array}$ & 3 & $(1,3)$ & 1 & (1) & 3 & $(4,7)$ & \multicolumn{2}{|c|}{0} & 7 & $(1,6)$ \\
\hline $\begin{array}{l}\text { Doenças do Aparelho } \\
\text { Circulatório }\end{array}$ & 2 & $(0,9)$ & \multicolumn{2}{|c|}{0} & \multicolumn{2}{|c|}{0} & \multicolumn{2}{|c|}{0} & 2 & $(0,5)$ \\
\hline Dor & \multicolumn{2}{|c|}{0} & 2 & (2) & \multicolumn{2}{|c|}{0} & \multicolumn{2}{|c|}{0} & 2 & $(0,5)$ \\
\hline Doenças Endócrinas & 3 & $(1,3)$ & 2 & (2) & \multicolumn{2}{|c|}{0} & 1 & $(2,9)$ & 6 & $(1,4)$ \\
\hline $\begin{array}{l}\text { Doenças do Aparelho } \\
\text { Digestivo e Infecciosas }\end{array}$ & 17 & $(7,6)$ & 11 & $(10,8)$ & 14 & $(21,9)$ & 3 & $(8,6)$ & 45 & $(10,6)$ \\
\hline $\begin{array}{l}\text { Doenças do Sangue e } \\
\text { Transtorno Imunitários }\end{array}$ & 4 & $(1,8)$ & 3 & $(2,9)$ & 1 & $(1,6)$ & 2 & $(5,7)$ & 10 & $(2,4)$ \\
\hline Sintomas Febris & 17 & $(7,6)$ & 8 & $(7,8)$ & 3 & $(4,7)$ & 8 & $(22,8)$ & 36 & $(8,5)$ \\
\hline Doenças do Sistema Nervoso & 12 & $(5,4)$ & 9 & $(8,8)$ & 5 & $(7,8)$ & 3 & $(8,6)$ & 29 & $(6,8)$ \\
\hline $\begin{array}{l}\text { Doenças do Aparelho } \\
\text { Respiratório }\end{array}$ & 134 & $(59,8)$ & 48 & $(47,1)$ & 21 & $(32,8)$ & 9 & $(25,7)$ & 212 & $(49,9)$ \\
\hline $\begin{array}{l}\text { Doenças do Aparelho } \\
\text { Respiratório e Digestivo }\end{array}$ & 2 & $(0,9)$ & 1 & (1) & \multicolumn{2}{|c|}{0} & \multicolumn{2}{|c|}{0} & 3 & $(0,7)$ \\
\hline $\begin{array}{l}\text { Doenças do Aparelho } \\
\text { Respiratório e Geniturinário }\end{array}$ & 2 & $(0,9)$ & \multicolumn{2}{|c|}{0} & \multicolumn{2}{|c|}{0} & \multicolumn{2}{|c|}{0} & 2 & $(0,5)$ \\
\hline Sem Informação & 15 & $(6,7)$ & 6 & $(5,8)$ & 11 & $(17,2)$ & 4 & $(11,4)$ & 36 & $(8,4)$ \\
\hline $\begin{array}{l}\text { Doenças do Aparelho } \\
\text { Geniturinário }\end{array}$ & 4 & $(1,8)$ & & ) & 4 & $(6,2)$ & 4 & $(11,4)$ & 12 & $(2,8)$ \\
\hline
\end{tabular}


Os agravos mais evidentes nas readmissões do grupo respiratório, assim como nas admissões índices, também foram queixas de asma, bronquiolites, infecção das vias aéreas superiores (IVAS) e pneumonia. Tanto é assim que, dos 212 eventos de readmissão por queixas relacionadas ao sistema respiratório (Tabela 10), 148 foram relacionadas a essas quatro causas (Tabela 12).

Observa-se que os referidos diagnósticos são predominantes nos grupos de menor faixa etária como os lactentes, pré-escolares e escolares. Estas faixas etárias representam $87,3 \%$ das 71 readmissões por asma, enquanto somente os lactentes são aproximadamente $98 \%$ das 58 queixas por bronquiolites e 56,7\% dos atendimentos por pneumonia (Tabela 12).

Tabela 12. Distribuição das readmissões e eventos de readmissão por doenças do sistema respiratório e faixa etária, Brasília, 2016.

\begin{tabular}{|c|c|c|c|c|c|c|}
\hline \multirow[b]{2}{*}{$\begin{array}{l}\text { Doenças do Sistema } \\
\text { Respiratório por Faixa Etária }\end{array}$} & \multicolumn{2}{|c|}{ Readmissão } & \multicolumn{2}{|c|}{$\begin{array}{c}\text { Eventos de } \\
\text { Readmissão }\end{array}$} & \multirow{2}{*}{$\begin{array}{c}\text { Total } \\
\text { n }\end{array}$} & \multirow{2}{*}{ Total (\%) } \\
\hline & $\mathbf{n}$ & $(\%)$ & $\mathbf{n}$ & $(\%)$ & & \\
\hline Asma & 30 & $(36,1)$ & 41 & $(27,7)$ & 71 & $(30,8)$ \\
\hline 1-Lactente & 11 & $(13,3)$ & 10 & $(6,8)$ & 21 & $(9,1)$ \\
\hline 2-Pré-escolar & 6 & $(7,2)$ & 15 & $(10,1)$ & 21 & $(9,1)$ \\
\hline 3-Escolar & 10 & $(12,0)$ & 10 & $(6,8)$ & 20 & $(8,7)$ \\
\hline 4-Pré-púbere & 3 & $(3,6)$ & 6 & $(4)$ & 9 & $(3,9)$ \\
\hline Asma/IVAS & 1 & $(1,2)$ & \multicolumn{2}{|c|}{ 0 } & 1 & $(0,4)$ \\
\hline 1-Lactente & 1 & $(1,2)$ & \multicolumn{2}{|c|}{0} & 1 & $(0,4)$ \\
\hline Bronquiolite & 20 & $(24,1)$ & 38 & $(25,6)$ & 58 & $(25,1)$ \\
\hline 1-Lactente & 19 & $(22,9)$ & 38 & $(25,6)$ & 57 & $(24,7)$ \\
\hline 2-Pré-escolar & 1 & $(1,2)$ & & & 1 & $(0,4)$ \\
\hline Bronquiolite/IVAS & \multicolumn{2}{|c|}{$\mathbf{0}$} & 1 & $(0,7)$ & 1 & $(0,4)$ \\
\hline 1-Lactente & \multicolumn{2}{|c|}{0} & 1 & $(0,7)$ & 1 & $(0,4)$ \\
\hline Bronquiolite/Pneumonia & \multicolumn{2}{|c|}{$\mathbf{0}$} & 2 & $(1,4)$ & 2 & $(0,9)$ \\
\hline 1-Lactente & \multicolumn{2}{|c|}{0} & 2 & $(1,4)$ & 2 & $(0,9)$ \\
\hline IVAS & 19 & $(22,9)$ & 38 & $(25,6)$ & 57 & $(24,7)$ \\
\hline 1-Lactente & 10 & $(12,1)$ & 26 & $(17,5)$ & 36 & $(15,6)$ \\
\hline 2-Pré-escolar & 8 & $(9,6)$ & 10 & $(6,7)$ & 18 & $(7,8)$ \\
\hline 3-Escolar & 1 & $(1,2)$ & 1 & $(0,7)$ & 2 & $(0,9)$ \\
\hline 4-Pré-púbere & \multicolumn{2}{|c|}{0} & 1 & $(0,7)$ & 1 & $(0,4)$ \\
\hline IVAS/Pneumonia & 2 & $(2,4)$ & 2 & $(1,4)$ & 4 & $(1,7)$ \\
\hline 1-Lactente & 1 & $(1,2)$ & 2 & $(1,4)$ & 3 & $(1,3)$ \\
\hline 2-Pré-escolar & 1 & $(1,2)$ & \multicolumn{2}{|c|}{0} & 1 & $(0,4)$ \\
\hline Pneumonia & 11 & $(13,3)$ & 26 & $(17,6)$ & 37 & $(16,0)$ \\
\hline 1-Lactente & 5 & $(6,1)$ & 16 & $(10,8)$ & 21 & $(9,1)$ \\
\hline 2-Pré-escolar & 3 & $(3,6)$ & 8 & $(5,4)$ & 11 & $(4,8)$ \\
\hline 3-Escolar & 2 & $(2,4)$ & 2 & $(1,4)$ & 4 & $(1,7)$ \\
\hline 4-Pré-púbere & 1 & $(1,2)$ & \multicolumn{2}{|c|}{0} & 1 & $(0,4)$ \\
\hline Total Geral & 83 & $(\mathbf{1 0 0})$ & 148 & (100) & 231 & (100) \\
\hline
\end{tabular}


Apesar da classificação na cor verde ser a predominante no perfil geral das readmissões, nos diagnósticos do grupo respiratório, as cores laranja e amarelo continuam em evidência em relação às 148 readmissões por asma, IVAS, bronquiolite e pneumonia, o que significa que o perfil de urgência dessas queixas continua nas readmissões (Tabela 13).

Tabela 13. Distribuição das readmissões e eventos de readmissão por causas respiratórias e classificação de risco, Brasília, 2016.

\begin{tabular}{|c|c|c|c|c|c|c|}
\hline \multirow{2}{*}{$\begin{array}{l}\text { Doenças do Sistema } \\
\text { Respiratório por } \\
\text { Classificação de Risco }\end{array}$} & \multicolumn{2}{|c|}{ Readmissão } & \multicolumn{2}{|c|}{ Eventos de Readmissão } & \multirow{2}{*}{$\begin{array}{c}\text { Total } \\
\mathbf{n}\end{array}$} & \multirow{2}{*}{$\begin{array}{c}\text { Total } \\
(\%)\end{array}$} \\
\hline & $\mathbf{n}$ & $(\%)$ & $\mathbf{n}$ & $(\%)$ & & \\
\hline Asma & 30 & $(36,1)$ & 41 & $(27,7)$ & 71 & $(30,8)$ \\
\hline 02-laranja & 10 & $(12,1)$ & 15 & $(10,1)$ & 25 & $(10,9)$ \\
\hline 03-amarelo & 8 & $(9,6)$ & 20 & $(13,5)$ & 28 & $(12,1)$ \\
\hline 04-verde & 7 & $(8,4)$ & 2 & $(1,4)$ & 9 & $(3,9)$ \\
\hline sem classificação & 5 & $(6,0)$ & 4 & $(2,7)$ & 9 & $(3,9)$ \\
\hline Asma/IVAS & 1 & $(1,2)$ & $\mathbf{0}$ & $(0,0)$ & 1 & $(0,4)$ \\
\hline 03-amarelo & 1 & $(1,2)$ & 0 & $(0,0)$ & 1 & $(0,4)$ \\
\hline Bronquiolite & 20 & $(24,1)$ & 38 & $(25,7)$ & 58 & $(25,1)$ \\
\hline 01 -vermelho & 0 & $(0,0)$ & 1 & $(0,7)$ & 1 & $(0,4)$ \\
\hline 02-laranja & 8 & $(9,7)$ & 11 & $(7,4)$ & 19 & $(8,2)$ \\
\hline 03-amarelo & 4 & $(4,8)$ & 9 & $(6,1)$ & 13 & $(5,7)$ \\
\hline 04 -verde & 5 & $(6,0)$ & 10 & $(6,8)$ & 15 & $(6,5)$ \\
\hline 05-azul & 1 & $(1,2)$ & 0 & $(0,0)$ & 1 & $(0,4)$ \\
\hline 06-branco & 0 & $(0,0)$ & 3 & (2) & 3 & $(1,3)$ \\
\hline sem classificação & 2 & $(2,4)$ & 4 & $(2,7)$ & 6 & $(2,6)$ \\
\hline Bronquiolite/IVAS & $\mathbf{0}$ & $(0,0)$ & 1 & $(0,7)$ & 1 & $(0,4)$ \\
\hline 04 -verde & 0 & $(0,0)$ & 1 & $(0,7)$ & 1 & $(0,4)$ \\
\hline Bronquiolite/Pneumonia & $\mathbf{0}$ & $(\mathbf{0 , 0})$ & 2 & $(1,4)$ & 2 & $(0,9)$ \\
\hline 02-laranja & 0 & $(0,0)$ & 2 & $(1,4)$ & 2 & $(0,9)$ \\
\hline IVAS & 19 & $(22,9)$ & 38 & $(25,6)$ & 57 & $(24,7)$ \\
\hline 01 -vermelho & 1 & $(1,2)$ & 0 & $(0,0)$ & 1 & $(0,4)$ \\
\hline 02-laranja & 7 & $(8,5)$ & 12 & $(8,1)$ & 19 & $(8,2)$ \\
\hline 03-amarelo & 5 & $(6,0)$ & 7 & $(4,7)$ & 12 & $(5,2)$ \\
\hline 04-verde & 4 & $(4,8)$ & 11 & $(7,4)$ & 15 & $(6,5)$ \\
\hline sem classificação & 2 & $(2,4)$ & 8 & $(5,4)$ & 10 & (4) \\
\hline IVAS/Pneumonia & 2 & $(2,4)$ & 2 & $(1,4)$ & 4 & $(1,7)$ \\
\hline 02-laranja & 1 & $(1,2)$ & 0 & $(0,0)$ & 1 & $(0,4)$ \\
\hline 03-amarelo & 0 & $(0,0)$ & 1 & $(0,7)$ & 1 & $(0,4)$ \\
\hline 04 -verde & 1 & $(1,2)$ & 1 & $(0,7)$ & 2 & $(0,9)$ \\
\hline Pneumonia & 11 & $(13,3)$ & 26 & $(\mathbf{1 7 , 5 )}$ & 37 & $(16,0)$ \\
\hline 02-laranja & 2 & $(2,4)$ & 7 & $(4,7)$ & 9 & $(3,9)$ \\
\hline 03-amarelo & 2 & $(2,4)$ & 6 & (4) & 8 & $(3,4)$ \\
\hline
\end{tabular}




\begin{tabular}{lcccccc}
\hline 04-verde & 2 & $(2,4)$ & 4 & $(2,7)$ & 6 & $(2,6)$ \\
06-branco & 0 & $(0,0)$ & 2 & $(1,4)$ & 2 & $(0,9)$ \\
sem classificação & 5 & $(6,1)$ & 7 & $(4,7)$ & 12 & $(5,2)$ \\
\hline Total Geral & $\mathbf{8 3}$ & $\mathbf{( 1 0 0 )}$ & $\mathbf{1 4 8}$ & $\mathbf{( 1 0 0 )}$ & $\mathbf{2 3 1}$ & $\mathbf{( 1 0 0 )}$ \\
\hline
\end{tabular}

Foi observado que das 249 crianças readmitidas, 39\% tiveram o mesmo diagnóstico da admissão índice, em comparação ao último evento de readmissão. Além disso, a maior parte dos registros de queixas diferentes da admissão índice foram de crianças que apresentaram maior quantidade de eventos de readmissão (Tabela 14). No entanto, das 152 crianças que foram readmitidas com grupos diferentes da admissão índice, 71,1\% destas retornaram ao HRC por doenças contidas nos grupos de diagnóstico considerados prevalentes, ou seja, sistemas respiratório, digestivo/infeccioso, nervoso e sintomas febris.

Tabela 14. Distribuição da frequência de alteração do grupo diagnóstico nas readmissões, Brasília, 2016.

\begin{tabular}{ccc}
\hline Eventos de Readmissão & $\begin{array}{c}\text { Quantidade de Crianças por } \\
\text { Eventos de Readmissões }\end{array}$ & $\begin{array}{c}\text { Grupo Diagnóstico Alterado } \\
\text { n (\%) }\end{array}$ \\
\hline 1 & 135 & $67(49,6)$ \\
2 & 74 & $53(71,6)$ \\
3 & 27 & $21(77,8)$ \\
4 & 7 & $6(85,7)$ \\
5 & 5 & $5(100)$ \\
8 & 1 & 0 \\
\hline Total Geral & $\mathbf{2 4 9}$ & $\mathbf{1 5 2}(\mathbf{6 1 , 0 )}$ \\
\hline
\end{tabular}

Das 249 crianças readmitidas, 32,9\% foram classificadas na admissão índice como atendimento pouco urgente (verde) e 27,7\% como muito urgente (laranja), ou seja, neste estudo, as crianças classificadas nas cores verde e laranja, no primeiro atendimento, foram mais readmitidas. Entretanto, nos episódios de readmissão, a classificação verde continuou a mais frequente $(28 \%)$, mas seguida da amarela $(22,1 \%)$ e, posteriormente, da laranja $(20,9 \%)$ (Tabela 15). De acordo com o teste do Qui-quadrado, existe influência significativa $(p<0,05)$ entre as classificações de risco e os eventos de readmissão, isto é, a classificação de risco no atendimento foi influenciada pela ocorrência de eventos de readmissão. 
Tabela 15. Distribuição das readmissões e eventos de readmissão por classificações de risco, Brasília, 2016.

\begin{tabular}{lcccccc}
\hline \multicolumn{1}{c}{ Classificação de Risco } & \multicolumn{2}{c}{ Readmissão } & \multicolumn{2}{c}{$\begin{array}{c}\text { Eventos de } \\
\text { Readmissão }\end{array}$} & Total & Total (\%) \\
& $\mathbf{n}$ & $\mathbf{\%}$ & $\mathbf{n}$ & $\mathbf{\%}$ & & \\
\hline 01-vermelho & & & & & & \\
02-laranja & 4 & $(1,6)$ & 14 & $(3,3)$ & 18 & $(2,7)$ \\
03-amarelo & 42 & $(27,7)$ & 89 & $(20,9)$ & 158 & $(23,4)$ \\
04-verde & 82 & $(16,9)$ & 94 & $(22,1)$ & 136 & $(20,2)$ \\
05-azul & 2 & $(0,8)$ & 2 & $(0,5)$ & 4 & $(0,6)$ \\
06-branco & 0 & & 19 & $(4,5)$ & 19 & $(2,8)$ \\
07-s/classificação & 50 & $(20,1)$ & 88 & $(20,7)$ & 138 & $(20,5)$ \\
\hline Total Geral & $\mathbf{2 4 9}$ & $\mathbf{( 1 0 0 )}$ & $\mathbf{4 2 5}$ & $\mathbf{( 1 0 0 )}$ & $\mathbf{6 7 4}$ & $\mathbf{( 1 0 0 )}$ \\
\hline
\end{tabular}

Quando comparadas as classificações de risco com as faixas etárias, foi observado que os níveis de classificação de risco (dos de maior para aqueles de menor prioridade), foram mais prevalentes no grupo dos lactentes, tanto em números absolutos quanto percentualmente, diminuindo a frequência das classificações de acordo com o aumento da faixa etária. Esse fenômeno foi observado tanto nas admissões índice quanto nas readmissões (Tabela 16).

Tabela 16. Distribuição das readmissões e eventos de readmissão por classificação de risco e faixa etária, Brasília, 2016.

\begin{tabular}{lcccccc}
\hline $\begin{array}{l}\text { Classificação de Risco } \\
\text { por Faixa Etária }\end{array}$ & $\mathbf{n}$ & $\mathbf{( \% )}$ & $\mathbf{n}$ & $\mathbf{( \% )}$ & Total n & $\begin{array}{c}\text { Total } \\
\mathbf{( \% )}\end{array}$ \\
\hline Lactente & $\mathbf{1 2 6}$ & $\mathbf{( 5 0 , 6 )}$ & $\mathbf{2 2 4}$ & $\mathbf{( 5 2 , 7 )}$ & $\mathbf{3 5 0}$ & $\mathbf{( 5 1 , 9 )}$ \\
01-vermelho & 2 & $(0,8)$ & 10 & $(2,3)$ & 12 & $(1,8)$ \\
02-laranja & 31 & $(12,5)$ & 50 & $(11,8)$ & 81 & $(12)$ \\
03-amarelo & 21 & $(8,4)$ & 50 & $(11,8)$ & 71 & $(10,5)$ \\
04-verde & 43 & $(17,3)$ & 64 & $(15,1)$ & 107 & $(15,9)$ \\
05-azul & 2 & $(0,8)$ & 1 & $(0,2)$ & 3 & $(0,4)$ \\
06-branco & 0 & & 6 & $(1,4)$ & 6 & $(0,9)$ \\
sem classificação & 27 & $(10,8)$ & 43 & $(10,1)$ & 70 & $(10,4)$ \\
Pré-escolar & $\mathbf{5 5}$ & $\mathbf{( 2 2 , 1 )}$ & $\mathbf{1 0 2}$ & $\mathbf{( 2 4 , 0 )}$ & $\mathbf{1 5 7}$ & $\mathbf{( 2 3 , 3 )}$ \\
01-vermelho & 1 & $(0,4)$ & 3 & $(0,7)$ & 4 & $(0,6)$ \\
02-laranja & 19 & $(7,7)$ & 27 & $(6,3)$ & 46 & $(6,8)$ \\
03-amarelo & 9 & $(3,6)$ & 22 & $(5,2)$ & 31 & $(4,6)$ \\
04-verde & 17 & $(6,8)$ & 28 & $(6,6)$ & 45 & $(6,7)$ \\
06-branco & 0 & & 3 & $(0,7)$ & 3 & $(0,4)$ \\
sem classificação & 9 & $(3,6)$ & 19 & $(4,5)$ & 28 & $(4,2)$ \\
\hline
\end{tabular}




\begin{tabular}{lcccccc}
\hline Escolar & $\mathbf{4 2}$ & $\mathbf{( 1 6 , 9 )}$ & $\mathbf{6 4}$ & $\mathbf{( 1 5 , 1 )}$ & $\mathbf{1 0 6}$ & $\mathbf{( 1 5 , 7 )}$ \\
01-vermelho & 1 & $(0,4)$ & 1 & $(0,2)$ & 2 & $(0,3)$ \\
02-laranja & 12 & $(4,8)$ & 7 & $(1,7)$ & 19 & $(2,8)$ \\
03-amarelo & 8 & $(3,2)$ & 15 & $(3,6)$ & 23 & $(3,4)$ \\
04-verde & 11 & $(4,5)$ & 19 & $(4,5)$ & 30 & $(4,4)$ \\
06-branco & 0 & & 4 & $(0,9)$ & 4 & $(0,6)$ \\
sem classificação & 10 & $(4,0)$ & 18 & $(4,2)$ & 28 & $(4,2)$ \\
Pré-púbere & $\mathbf{2 6}$ & $\mathbf{( 1 0 , 4 )}$ & $\mathbf{3 5}$ & $\mathbf{( 8 , 2 )}$ & $\mathbf{6 1}$ & $\mathbf{( 9 , 1 )}$ \\
02-laranja & 7 & $(2,8)$ & 5 & $(1,2)$ & 12 & $(1,8)$ \\
03-amarelo & 4 & $(1,6)$ & 7 & $(1,6)$ & 11 & $(1,7)$ \\
04-verde & 11 & $(4,4)$ & 8 & $(1,9)$ & 19 & $(2,8)$ \\
05-azul & 0 & & 1 & $(0,2)$ & 1 & $(0,1)$ \\
06-branco & 0 & & 6 & $(1,4)$ & 6 & $(0,9)$ \\
sem classificação & 4 & $(1,6)$ & 8 & $(1,9)$ & 12 & $(1,8)$ \\
\hline Total Geral & $\mathbf{2 4 9}$ & $\mathbf{( 1 0 0 )}$ & $\mathbf{4 2 5}$ & $\mathbf{( 1 0 0 )}$ & $\mathbf{6 7 4}$ & $\mathbf{( 1 0 0 )}$ \\
\hline
\end{tabular}

Foi evidenciado também que a classificação na cor vermelha, tanto na admissão índice quanto nos eventos subsequentes de readmissão, foi a mais frequente nos grupos de doenças do sistema nervoso e, posteriormente, nas dos sistemas respiratório e endócrino, enquanto que a classificação de risco nas cores laranja, amarelo, verde, azul e branco foram mais atribuídas, primeiramente, ao grupo respiratório, seguindo-se nos demais grupos, destacando os sintomas febris, digestivo/infeccioso e nervoso (Tabelas 17 e 18). 
Tabela 17. Distribuição das crianças readmitidas por grupo diagnóstico e classificação de risco, Brasília, 2016.

\begin{tabular}{|c|c|c|c|c|c|c|c|c|c|c|c|c|c|c|c|c|}
\hline \multirow[b]{2}{*}{ Grupo Diagnóstico } & \multicolumn{2}{|c|}{ 01-vermelho } & \multicolumn{2}{|c|}{ 02-laranja } & \multicolumn{2}{|c|}{ 03-amarelo } & \multicolumn{2}{|c|}{ 04-verde } & \multicolumn{2}{|c|}{ 05-azul } & \multicolumn{2}{|c|}{ 06-branco } & \multicolumn{2}{|c|}{$\begin{array}{c}\text { 07- sem } \\
\text { classificação }\end{array}$} & \multirow{2}{*}{$\begin{array}{c}\text { Total } \\
\mathbf{n}\end{array}$} & \multirow{2}{*}{$(\%)$} \\
\hline & $\mathbf{n}$ & $(\%)$ & $\mathbf{n}$ & $(\%)$ & $\mathbf{n}$ & $(\%)$ & $\mathbf{n}$ & $(\%)$ & $\mathbf{n}$ & $(\%)$ & $\mathbf{n}$ & $(\%)$ & $\mathbf{n}$ & $(\%)$ & & \\
\hline Readmissão & 4 & $(1,6)$ & 69 & $(27,7)$ & 42 & $(16,9)$ & 82 & $(32,9)$ & 2 & $(0,8)$ & & $\mathbf{0}$ & 50 & $(20,1)$ & 249 & (100) \\
\hline Doenças do Sistema Osteomuscular & \multicolumn{2}{|c|}{0} & \multicolumn{2}{|c|}{0} & \multicolumn{2}{|c|}{0} & 1 & $(1,2)$ & \multicolumn{2}{|c|}{0} & & 0 & \multicolumn{2}{|c|}{0} & 1 & $(0,4)$ \\
\hline Doenças do Ouvido & \multicolumn{2}{|c|}{0} & & 0 & \multicolumn{2}{|c|}{0} & \multicolumn{2}{|c|}{0} & \multicolumn{2}{|c|}{0} & & 0 & 1 & (2) & 1 & $(0,4)$ \\
\hline Causas Externas & \multicolumn{2}{|c|}{0} & 1 & $(1,4)$ & 2 & $(4,8)$ & 5 & $(6,1)$ & \multicolumn{2}{|c|}{0} & & 0 & \multicolumn{2}{|c|}{0} & 8 & $(3,2)$ \\
\hline Doenças da Pele e Tecido Subcutâneo & \multicolumn{2}{|c|}{0} & 1 & $(1,4)$ & 2 & $(4,8)$ & 2 & $(2,4)$ & \multicolumn{2}{|c|}{0} & & 0 & \multicolumn{2}{|c|}{0} & 5 & (2) \\
\hline Doenças do Aparelho Circulatório & \multicolumn{2}{|c|}{0} & 1 & $(1,4)$ & \multicolumn{2}{|c|}{0} & \multicolumn{2}{|c|}{0} & \multicolumn{2}{|c|}{0} & & 0 & \multicolumn{2}{|c|}{0} & 1 & $(0,4)$ \\
\hline Dor & \multicolumn{2}{|c|}{0} & & 0 & 1 & $(2,4)$ & 2 & $(2,4)$ & & 0 & & 0 & 1 & (2) & 4 & $(1,6)$ \\
\hline Doenças Endócrinas & 1 & $(25)$ & 1 & $(1,4)$ & 1 & $(2,4)$ & 1 & $(1,2)$ & & 0 & & 0 & 1 & $(2)$ & 5 & (2) \\
\hline Doenças do Aparelho Digestivo e Infecciosas & & ) & 7 & $(10,2)$ & 4 & $(9,5)$ & 10 & $(12,2)$ & & 0 & & 0 & 1 & (2) & 22 & $(8,8)$ \\
\hline Doenças do Sangue e Transtorno Imunitários & & ) & & 0 & & 0 & 1 & $(1,2)$ & & 0 & & 0 & 1 & $(2)$ & 2 & $(0,8)$ \\
\hline Sintomas Febris & & ) & 11 & $(16)$ & 3 & $(7,1)$ & 7 & $(8,6)$ & & 0 & & 0 & 7 & (14) & 28 & $(11,3)$ \\
\hline Doenças do Sistema Nervoso & 2 & $(50)$ & 5 & $(7,3)$ & 2 & $(4,8)$ & 2 & $(2,4)$ & & 0 & & 0 & 5 & $(10)$ & 16 & $(6,4)$ \\
\hline Não Respondeu a Chamada & & ) & & 0 & & 0 & 1 & $(1,2)$ & & 0 & & 0 & & ) & 1 & $(0,4)$ \\
\hline Doenças do Aparelho Respiratório & 1 & $(25)$ & 40 & $(58)$ & 25 & $(59,5)$ & 30 & $(36,6)$ & 1 & $(50)$ & & 0 & 18 & $(36)$ & 115 & $(46,2)$ \\
\hline Doenças do Aparelho Respiratório e Digestivo & & ) & & 0 & & 0 & & 0 & & 0 & & 0 & 1 & $(2)$ & 1 & $(0,4)$ \\
\hline $\begin{array}{l}\text { Doenças do Aparelho Respiratório e } \\
\text { Geniturinário }\end{array}$ & & ) & & 0 & & 0 & 1 & $(1,2)$ & & 0 & & 0 & & ) & 1 & $(0,4)$ \\
\hline Sem Informação & & ) & 1 & $(1,4)$ & 2 & $(4,8)$ & 15 & $(18,3)$ & 1 & $(50)$ & & 0 & 10 & $(20)$ & 29 & $(11,7)$ \\
\hline Doenças do Aparelho Geniturinário & & ) & 1 & $(1,4)$ & & 0 & 4 & $(4,9)$ & & 0 & & 0 & 4 & (8) & 9 & $(3,6)$ \\
\hline
\end{tabular}


Tabela 18. Distribuição dos eventos de readmissão por grupo diagnóstico e classificação de risco, Brasília, 2016.

\begin{tabular}{|c|c|c|c|c|c|c|c|c|c|c|c|c|c|c|c|c|}
\hline \multirow[b]{2}{*}{ Grupo Diagnóstico } & \multicolumn{2}{|c|}{ 01-vermelho } & \multicolumn{2}{|c|}{ 02-laranja } & \multicolumn{2}{|c|}{ 03-amarelo } & \multicolumn{2}{|c|}{ 04-verde } & \multicolumn{2}{|c|}{ 05-azul } & \multicolumn{2}{|c|}{ 06-branco } & \multicolumn{2}{|c|}{$\begin{array}{c}\text { 07-sem } \\
\text { classificação }\end{array}$} & \multirow{2}{*}{$\begin{array}{c}\text { Total } \\
\mathbf{n}\end{array}$} & \multirow{2}{*}{$(\%)$} \\
\hline & $\mathbf{n}$ & $(\%)$ & $\mathbf{n}$ & $(\%)$ & $\mathbf{n}$ & $(\%)$ & $\mathbf{n}$ & $(\%)$ & $\mathbf{n}$ & $(\%)$ & $\mathbf{n}$ & $(\%)$ & $\mathbf{n}$ & $(\%)$ & & \\
\hline Eventos de Readmissão & 14 & $(3,3)$ & 89 & $(20,9)$ & 94 & $(22,1)$ & 119 & (28) & 2 & $(0,5)$ & 19 & $(4,5)$ & 88 & $(20,7)$ & 425 & (100) \\
\hline Doenças do Sistema Osteomuscular & \multicolumn{2}{|c|}{0} & 1 & $(1,1)$ & & 0 & \multicolumn{2}{|c|}{0} & \multicolumn{2}{|c|}{0} & \multicolumn{2}{|c|}{0} & 1 & $(1,1)$ & 2 & $(0,5)$ \\
\hline Doenças do Ouvido & \multicolumn{2}{|c|}{0} & 1 & $(1,1)$ & & 0 & 3 & $(2,5)$ & \multicolumn{2}{|c|}{0} & \multicolumn{2}{|c|}{0} & 4 & $(4,5)$ & 8 & $(1,9)$ \\
\hline Causas Externas & \multicolumn{2}{|c|}{0} & 1 & $(1,1)$ & 3 & $(3,2)$ & 5 & $(4,2)$ & \multicolumn{2}{|c|}{0} & \multicolumn{2}{|c|}{0} & 4 & $(4,5)$ & 13 & (3) \\
\hline Doenças da Pele e Tecido Subcutâneo & \multicolumn{2}{|c|}{0} & \multicolumn{2}{|c|}{0} & 5 & $(5,3)$ & \multicolumn{2}{|c|}{0} & \multicolumn{2}{|c|}{0} & \multicolumn{2}{|c|}{0} & 2 & $(2,3)$ & 7 & $(1,6)$ \\
\hline Doenças do Aparelho Circulatório & \multicolumn{2}{|r|}{0} & \multicolumn{2}{|c|}{0} & \multicolumn{2}{|c|}{0} & 1 & $(0,8)$ & \multicolumn{2}{|c|}{0} & \multicolumn{2}{|c|}{0} & 1 & $(1,1)$ & 2 & $(0,5)$ \\
\hline Dor & \multicolumn{2}{|c|}{0} & 1 & $(1,1)$ & & 0 & 1 & $(0,8)$ & & 0 & & 0 & & 0 & 2 & $(0,5)$ \\
\hline Doenças Endócrinas & 2 & $(14,3)$ & & 0 & & 0 & & ) & & 0 & & 0 & 4 & $(4,5)$ & 6 & $(1,4)$ \\
\hline Doenças do Aparelho Digestivo e Infecciosas & & 0 & 6 & $(6,8)$ & 11 & $(11,7)$ & 19 & $(16)$ & & 0 & & 0 & 9 & $(10,3)$ & 45 & $(10,6)$ \\
\hline Doenças do Sangue e Transtorno Imunitários & & 0 & & 0 & 4 & $(4,2)$ & 2 & $(1,7)$ & & 0 & 1 & $(5,3)$ & 3 & $(3,5)$ & 10 & $(2,4)$ \\
\hline Sintomas Febris & 1 & $(7,2)$ & 9 & $(10,1)$ & 2 & $(2,1)$ & 11 & $(9,3)$ & 1 & $(50)$ & 2 & $(10,5)$ & 10 & $(11,4)$ & 36 & $(8,5)$ \\
\hline Doenças do Sistema Nervoso & 8 & $(57,1)$ & 8 & (9) & 5 & $(5,3)$ & 3 & $(2,5)$ & & 0 & 2 & $(10,5)$ & 3 & $(3,4)$ & 29 & $(6,8)$ \\
\hline Doenças do Aparelho Respiratório & 3 & $(21,4)$ & 60 & $(67,4)$ & 59 & $(62,8)$ & 53 & $(44,5)$ & & 0 & 5 & $(26,3)$ & 32 & $(36,4)$ & 212 & $(49,9)$ \\
\hline Doenças do Aparelho Respiratório e Digestivo & & 0 & 2 & $(2,3)$ & 1 & $(1,1)$ & & ) & & 0 & & 0 & & 0 & 3 & $(0,7)$ \\
\hline $\begin{array}{l}\text { Doenças do Aparelho Respiratório e } \\
\text { Geniturinário }\end{array}$ & & 0 & & 0 & 1 & $(1,1)$ & & ) & & 0 & & 0 & 1 & $(1,1)$ & 2 & $(0,5)$ \\
\hline Sem Informação & & 0 & & 0 & & 0 & 19 & $(16)$ & 1 & $(50)$ & 6 & $(31,6)$ & 10 & $(11,4)$ & 36 & $(8,4)$ \\
\hline Doenças do Aparelho Geniturinário & & 0 & & 0 & 3 & $(3,2)$ & 2 & $(1,7)$ & & 0 & 3 & $(15,8)$ & 4 & $(4,5)$ & 12 & $(2,8)$ \\
\hline
\end{tabular}


Das 249 crianças readmitidas, 81,5\% (203) foram classificadas com riscos diferentes dos da admissão índice. Entre as 135 crianças que tiveram 1 episódio de readmissão, 68,9\% (93) tiveram alterações na classificação de riscos; em relação às 74 que foram readmitidas por duas vezes, 95,9\% (71) também tiveram a classificação alterada em relação à admissão índice. O mesmo padrão de alteração da classificação de risco foi observado para aquelas crianças que tiveram 3, 4 e 5 eventos de readmissões, variando entre 86 - 100\% a alteração da classificação de risco. Por outro lado, a criança que teve 8 episódios de readmissão teve seu risco alterado uma única vez (Figura 3).

Figura 3. Crianças readmitidas e classificação de risco alterada, Brasília, 2016.

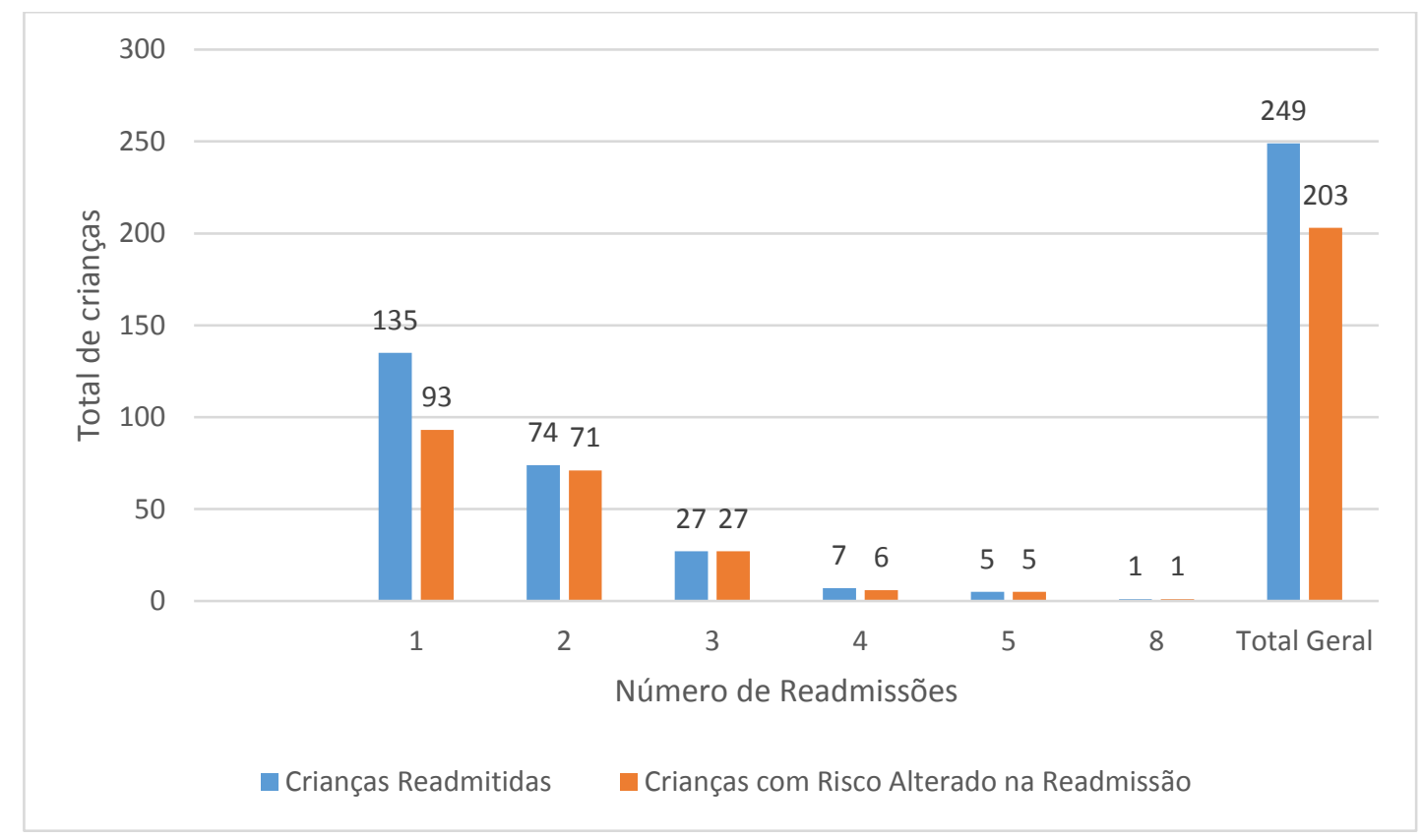

A alteração da classificação de risco foi observada comparando o risco da admissão índice com o da última readmissão. Das 93 crianças que tiveram somente 1 episódio de readmissão e com riscos diferentes dos da admissão índice, 52,7\% (49) foram classificadas, na última readmissão, com riscos de prioridade clínica inferior àqueles constatados nas admissões índices; por outro lado, os 47,3\% (44) das crianças restantes evoluíram com maior prioridade clínica (Figura 4).

Entre os 71 que tiveram 2 episódios de readmissão e foram classificados com riscos diferentes dos da admissão índice, 42,2\% (30) foram classificados, posteriormente, com risco de menor prioridade clínica, 46,5\% (33) com maior prioridade e 11,3\% (8) mantiveram a mesma classificação de risco na admissão e na última readmissão, apesar de se ter constatado uma 
variabilidade na primeira readmissão (Figura 4).

Das 27 crianças que foram readmitidas 3 vezes e cujos riscos foram alterados, 33,3\% (9) diminuíram os riscos, 33,3\% (9) aumentaram e 33,3\% (9) tiveram alguma variação nas readmissões intermediárias, mas terminaram com o mesmo risco da admissão (Figura 4).

Das 6 crianças que foram readmitidas 4 vezes, 50\% (3) foram classificadas na última readmissão com risco de maior prioridade, $16,7 \%$ (1) diminuiu a prioridade e 33,3\% (2) mantiveram o último risco igual ao da admissão, conquanto tenha havido variação no decorrer das readmissões intermediárias (Figura 4).

Das 5 crianças com 5 eventos de readmissão que foram classificadas com riscos diferentes da admissão índice, 60\% (3) foram classificadas com risco maior que o da admissão índice, $20 \%$ (1) com risco menor e os últimos 20\% (1) teve alguma alteração durante as readmissões, mas terminaram com o mesmo risco da admissão (Figura 4).

Por fim, a única criança que teve 8 eventos de readmissão no último apresentou prioridade clínica menor que a da admissão índice (Figura 4).

Figura 4. Número de crianças readmitidas por eventos de readmissão com alteração da prioridade clínica, Brasília, 2016.

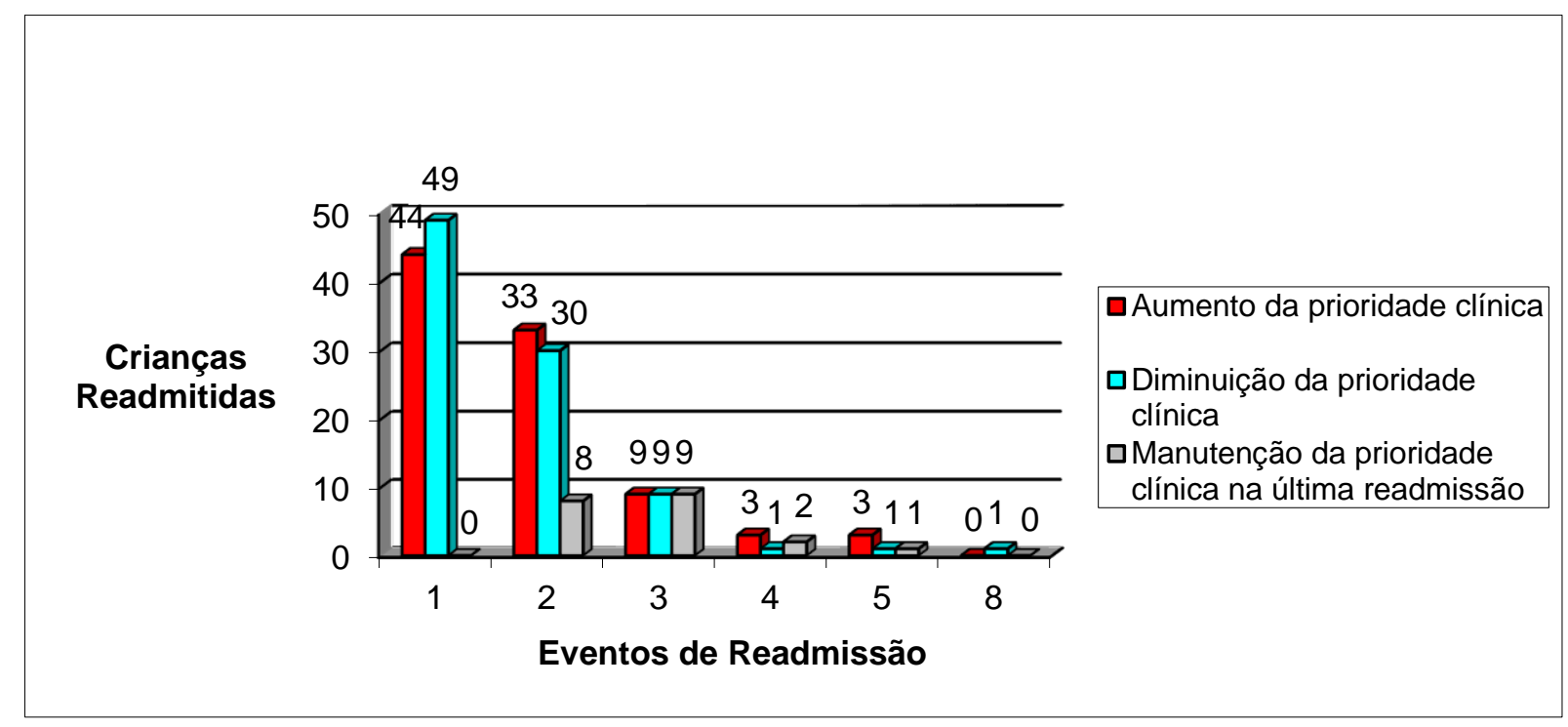


Constatou-se que há pouca diferença, em termos percentuais, entre o sexo masculino $(55,2 \%)$ e o feminino $(44,8 \%)$, assim como entre as faixas etárias de menor idade, como os lactentes e pré-escolares, esses dados convergem com os resultados de outros estudos que buscaram investigar o perfil de crianças hospitalizadas. Tais resultados mostraram que a faixa etária entre 1 e 4 anos tem maior suscetibilidade à hospitalização, principalmente o grupo dos lactentes, pois, geralmente, apresentam o sistema imunológico mais vulnerável devido à imaturidade fisiológica. Essa condição representa uma tendência à hospitalização e maior permanência nas enfermarias (FERRER, 2009; PEIXOTO et al., 2013; GRANZOTTO et al., 2014).

A maior parte dos atendimentos $(77,4 \%)$ teve como procedência a região de Ceilândia, que, se comparada ao Plano Piloto, pode ser considerada de menor renda. Um estudo de coorte sobre bronquiolite, envolvendo lactentes, buscou avaliar as características das crianças e o tratamento médico e a associação de ambas com as admissões por essa patologia. Os resultados evidenciaram que pacientes de procedências relacionadas à menor condição financeira, dentro da área de influência do hospital, eram mais propensos a serem hospitalizados se comparados aos pacientes de regiões de renda mais altas (RIESE et al., 2014).

Segundo a Pesquisa Distrital por Amostra de Domicílio (CODEPLAN, 2013), a cidade de Ceilândia é considerada a região administrativa mais populosa do DF, contando com 444.592 habitantes com renda domiciliar média de R\$ 2.504,00. Entretanto, mais de $20 \%$ dos declarantes dos domicílios ocupados informaram que ganham de 1 a 2 salários mínimos. Quanto ao uso dos serviços de saúde, mais de $80 \%$ da população não possui plano de saúde e aproximadamente 90\% deles declara utilizar os serviços do HRC (CODEPLAN, 2013).

A maior predominância da classificação laranja nesse estudo (30,5\%) pode ser explicada pelo fato de a população do estudo ser constituída, em sua maior parte $(47,6 \%)$, por lactentes. Devido à idade da criança e sua condição de vulnerabilidade e de fácil desestabilização, o protocolo Manchester indica que lactentes devem, sempre que possível, ser classificados como prioridade muito urgente, correspondendo à cor laranja.

Um estudo realizado em um pronto-socorro pediátrico de Porto Alegre - RS mostrou que a maior parte $(43,6 \%)$ das crianças admitidas foram classificadas na cor amarela, diferentemente do presente estudo, em que a cor laranja foi mais evidente. A diferença de percentual entre as cores amarelo e verde não foi significativa e, assim como a do estudo citado, houve prevalência da classificação vermelha se comparada à azul (AMTHAUER, 2015).

A superlotação dos prontos-socorros, a discrepância do número de profissionais de saúde em relação à demanda e as resultantes filas de espera têm tornado a situação dos serviços 
de urgência e emergência caótica, com a sobrecarga do trabalho e assistência de baixa qualidade. Diante disso, a dinamicidade do ACCR tem sido uma ferramenta tecnológica importante na gestão dos serviços de urgência e emergência. A identificação das classificações de riscos e prioridades clínicas do usuário permite otimizar os encaminhamentos necessários para a resolução da demanda apresentada (SHIROMA; PIRES, 2009; ANDRADE et al., 2011).

É importante destacar que a resolução das demandas por prioridade clínica vai além da classificação de risco. Ações de saúde devem ser integradas desde o momento do acolhimento, no qual o enfermeiro identifica a queixa. Intervenções como a reavaliação contínua do paciente, a orientação efetiva da família sobre os cuidados no ambiente domiciliar e o acompanhamento ambulatorial devem realizadas sempre que houver oportunidade (CAVALCANTE et al., 2012).

As crianças e seus acompanhantes demandam um tratamento diferenciado, pois no momento do início do atendimento o acompanhante também precisa ser levado em consideração, uma vez que é extensão da criança, tanto por ser responsável por ela quanto por ser capaz de influenciar no seu estado de saúde (CAVALCANTE et al., 2012).

Há concordância dos achados deste estudo quanto à prevalência das doenças respiratórias e do aparelho digestivo em relação à literatura, uma vez que tais agravos são de alta frequência, principalmente quando relacionadas à região centro-oeste brasileira. Tais resultados demonstram o impacto do estilo de vida da população e das condições socioeconômicas e de sazonalidade da região (OLIVEIRA et al., 2010; OLIVEIRA et al., 2012).

Estudos realizados com o objetivo de identificar as principais causas de hospitalização em crianças de 0 a 4 anos de idade mostraram que as doenças infecciosas e parasitárias, as do aparelho respiratório e aquelas do aparelho digestivo estão entre as causas principais de internação nas cinco regiões brasileiras. Dentre as patologias citadas, as do aparelho respiratório foram responsáveis por 40,3\% das internações (OLIVEIRA et al., 2010; OLIVEIRA et al., 2012).

Os grupos de diagnósticos mais frequentes encontrados neste estudo - como os agravos do aparelho respiratório $(53,9 \%)$, doenças do sistema nervoso (10,3\%), doenças infecciosas relacionadas ao sistema digestório $(9,7 \%)$ e sintomas febris $(8,8 \%)$ - são compatíveis com algumas das CSAP, isto é, condições que poderiam ser acompanhadas e resolvidas na atenção básica, caso tivessem assistência efetiva, como as gastroenterites infecciosas e suas complicações, infecções das vias aéreas superiores (IVAS), pneumonias, asma, doenças pulmonares, epilepsias, infecções do trato urinário e rim, muitas vezes coincidentes com as doenças prevalentes na infância (BRASIL, 2008; DUARTE, 2012). 
A frequência elevada de internações infantis causadas por CSAP e passíveis de prevenção, diagnóstico e tratamento precoce pode significar assistência inadequada a certos grupos populacionais, principalmente aqueles cujas condições socioeconômicas e de saúde são precárias (ELIAS; MAGAJEWSKI, 2008).

A relação entre os agravos mais prevalentes citados e as classificações de risco, como os neurológicos, em sua maioria, nas cores vermelha e laranja, e os respiratórios, nas cores laranja e amarelo, sugerem que os controles desses grupos poderiam ser realizados na atenção básica, já que são ICSAP. Mas, por falta de efetividade no acompanhamento ambulatorial, tais condições podem ter se agravado ou o sistema de referência e contra referência não suportou a demanda de acompanhamento.

A APS é a porta de entrada para a cobertura de um conjunto de condições que podem e devem ser resolvidas nessa instância do SUS. Com a resolução desses agravos, os serviços de urgência e emergências poderiam estar menos sobrecarregados, além de evitar as internações hospitalares (ICSAP), caso houvesse uma assistência efetiva de qualidade de acompanhamento das crianças e seus familiares (NEDEL et al., 2010).

A asma, agravo mais predominante encontrado nesse estudo e também considerado ICSAP, tanto em relação aos diagnósticos gerais quanto aos respiratórios, é considerada uma das doenças crônicas mais frequentes na infância e um problema de saúde pública no mundo, pois a sua prevalência elevada resulta em comprometimento da qualidade de vida dos pacientes e de seus familiares, além de gerar altos custos aos serviços de saúde e à sociedade (URRUTIAPEREIRA et al., 2016).

No Brasil, estima-se que a média de prevalência de asma entre crianças e adolescentes seja de $20 \%$, estando entre os vinte principais motivos de consulta na atenção básica, entretanto, ainda é uma das mais significativas causas de ICSAP, sendo a terceira causa de internação no SUS (URRUTIA-PEREIRA et al., 2016).

A deficiência do controle adequado da asma pode estar associada a vários fatores como falta de acesso dos pacientes ao sistema de saúde, tratamento ineficaz atrelado à utilização da medicação prescrita incorretamente, quer por falta de entendimento ou por falta de aderência ao tratamento, apesar da orientação recebida (URRUTIA-PEREIRA et al., 2016).

A ligação entre as doenças respiratórias mais evidentes neste estudo, como a asma, bronquiolites, IVAS e pneumonias e a sazonalidade climática tem sido foco de pesquisas, pois representa potenciais riscos à saúde, principalmente ao sistema respiratório. Os fatores de riscos incluem aqueles que são relacionados diretamente ao clima e aqueles que ocorrem indiretamente, devido a sensíveis sistemas biológicos, tais como infecções dependentes de 
vetores, patógenos que contaminam alimentos e doenças adquiridas através da água (SOUZA et al., 2012b).

Um estudo realizado na cidade de Campo Grande - MS buscou a relação entre o número de internações por doenças do aparelho respiratório em lactentes, crianças e adultos e as variações de sazonalidade e teve como resultado um aumento na morbidade e nas internações durante os meses de inverno e nos meses que prenunciam a chegada dessa estação, ou seja, o outono. A elevação das internações nesse período, entre outono e inverno, é consequente à entrada de massas de ar frio e seco, o que leva às baixas temperaturas e às chuvas e ao aumento da incidência de doenças respiratórias (SOUZA et al., 2012b).

Os seres humanos possuem uma faixa de temperatura ideal, além de serem capazes de adaptação às alterações de sazonalidade. Entretanto, tais variações climáticas são estressoras dos sistemas fisiológicos, principalmente de lactentes e crianças, que são organismos biológicos mais sensíveis, podendo ocasionar maiores agravos do sistema respiratório (SOUZA et al., 2012b).

A atenção integral à saúde da criança é uma das prioridades nas políticas públicas de saúde no Brasil por se tratar de um grupo que apresenta maior vulnerabilidade a agravos, doenças e risco de sequelas. Para atingir tal objetivo, é necessário explorar, descrever e avaliar o perfil de atendimento, a fim de compor indicadores, como a morbidade infantil, além de destacar a importância que desempenham os serviços de saúde, inclusive o serviço hospitalar (CAMPOS; THEME-FILHA, 2012).

O ambiente hospitalar é indicado para recuperar a saúde em um nível maior de complexidade, sendo as internações hospitalares um dos recursos mais utilizados para essa finalidade. O perfil de morbidade das internações pediátricas é considerado parâmetro básico para estabelecer as necessidades de saúde dessa população, tanto na atenção básica quanto no meio hospitalar, pois é nessa faixa etária que ocorre o maior número de óbitos entre as crianças, principalmente nos países em desenvolvimento, como o Brasil (CAMPOS; THEME-FILHA, 2012).

Portanto, conhecer e compreender as principais causas de hospitalização pediátricas auxilia a identificar o perfil de adoecimento, resultando na elaboração de planos de atenção à saúde voltados para as demandas das reais necessidades da criança e da sua família, com a intenção de impedir o agravamento das doenças e consequentemente evitar hospitalizações e possíveis readmissões (OLIVEIRA et al., 2010).

Quanto ao perfil de readmissão observado neste estudo, foi observada prevalência de lactentes $(50,6 \%)$, e crianças do sexo masculino (52,6\%). A taxa de readmissão de $37,7 \%$ 
observada nos meses analisados pode ser considerada elevada, quando comparamos com outros estudos internacionais e nacionais realizados em hospitais gerais e pediátricos, nos quais foram observadas taxas que variavam entre $6,5 \%$ e $23 \%$ na população infantil, com predomínio do sexo masculino e em crianças que se enquadram na faixa dos lactentes e pré-escolares. Entretanto, em nenhum dos estudos foram achados indícios que afirmem a relação entre readmissão e sexo, devido à pequena diferença estatística (BERRY et al., 2013; MOREIRA, 2010; BORGES et al., 2008).

Quanto ao número de eventos de readmissões por criança, observou-se que a maior parte apresentou apenas um episódio de readmissão, semelhante ao estudo de Gay et al. (2011), que constatou que a maior parte das crianças readmitidas tiveram apenas um episódio de readmissão, mas o pequeno subgrupo de pacientes com três ou mais readmissões foi responsável por 43,7\% de todas as readmissões no prazo de 15 dias. Esses resultados sugerem que apesar da maior parte dos agravos serem resolvidos na primeira readmissão, o maior número de readmissões por criança também é expressivo, gerando maiores custos ao sistema de saúde que podem estar relacionados à qualidade da assistência prestada.

No que se refere as readmissões recorrentes, estudo retrospectivo, realizado por Berry et al., (2011), com o objetivo de descrever a utilização de recursos, as características clínicas e as razões de admissão e readmissões em hospitais pediátricos evidenciou que as crianças que enfrentam 4 ou mais readmissões, predominantemente, são aquelas com condições crônicas complexas como agravos neuromusculares, neoplásicos ou cardiovasculares, ou pacientes em uso de aparato tecnológico, como traqueostomia ou gastrostomia.

O perfil evidenciado por Berry et al (2011) coincide com o encontrado na unidade pediátrica do $\mathrm{HRC}$, pois reflete a cronicidade dos agravos que acometem as crianças readmitidas e os possíveis fatores relacionados, como a falta de manejo e treinamento dos familiares em prestar cuidados de maior complexidade, levando ao agravamento do quadro crônico e às readmissões.

Quanto aos grupos de diagnósticos das crianças que foram admitidas e readmitidas no presente estudo, os agravos respiratórios, neurológicos, gastrointestinais e de sintomas febris foram os mais frequentes, corroborando os resultados de um estudo sobre readmissões realizado em 72 hospitais dos Estados Unidos, que demonstrou que entre os 10 diagnósticos com maior prevalência estavam as gastroenterites, convulsões, asma, bronquiolites, pneumonias, infecção das vias respiratórias superiores e febre de origem desconhecida (BERRY et al., 2013).

Foi verificado ainda que as crianças readmitidas nos grupos de diagnósticos respiratório e neurológico foram, predominantemente, classificadas na cor laranja e vermelha, apesar de a 
quantidade geral das readmissões ter sido classificada, em sua maioria, nas cores verde e amarelo, o que demonstra a manutenção do perfil de urgência na prioridade de atendimento em condições crônicas. Tais condições, no estudo de Berry et al. (2011), foram consideradas responsáveis pelas causas mais frequentes de hospitalização e readmissões observadas, como a asma, a pneumonia e a convulsão.

O estudo de Berry et al. (2013) refere que, do total de internações índices em seu estudo, $35 \%$ das crianças que foram readmitidas tinham comorbidades associadas a agravos neurológicos e respiratórios crônicos, sendo constatado que quanto mais condições crônicas a criança tinha, maior a chance de readmissão. Essas conclusões corroboram os achados desta pesquisa, uma vez que o perfil das readmissões da pediatria do HRC é caracterizado por doenças do aparelho respiratório, como a asma, e do sistema nervoso, como a epilepsia.

Ainda no estudo de Berry et al. (2011), foi visto que o grupo de pacientes diagnosticados com condições crônicas respiratórias e neurológicas se enquadravam na taxa de $23 \%$ das internações que poderiam ser evitadas. Segundo Turrini e Valera (2008), as condições potencialmente evitáveis estão relacionadas à qualidade do cuidado ao paciente e à mudança de hábito por parte da família, condições essas que poderiam ser acompanhadas e resolvidas na atenção primária, evitando o agravamento e promovendo o controle das condições crônicas.

Em relação a asma, bronquiolite, IVAS e pneumonia - agravos mais predominantes do grupo respiratório resultantes deste estudo -, foi visto que, além de geralmente estarem associadas às classificações de risco mais urgentes, os grupos etários de menor idade, como os lactentes e pré-escolares, são os mais acometidos por essas patologias. No tocante a essas características, Riese et al. (2014) expõem que, dentre as doenças respiratórias, a asma, a bronquiolite e a pneumonia são as mais frequentes em crianças menores de 2 anos que pertencem a famílias de baixa renda e em condições precárias de moradia.

Estudo realizado em Belo Horizonte - MG, cujo objetivo foi avaliar a importância da admissão índice em relação às readmissões em crianças e adolescentes asmáticos, relatou que crianças admitidas com idade menor que 24 meses tinham risco quatro vezes maior de serem readmitidas se comparadas às crianças com idades superiores. Além disso, verificou-se que a baixa escolaridade materna e comorbidades como pneumonia e bronquiolite também desencadeavam readmissões, entretanto, os fatores de maior risco para o retorno hospitalar foi a faixa etária de lactentes e a gravidade da crise asmática anterior (LASMAR et al., 2006).

Fatores controláveis, como a prescrição medicamentosa, a orientação no momento da alta e o acompanhamento ambulatorial pós-alta hospitalar, são necessários às doenças respiratórias, principalmente em lactentes que são vulneráveis imunologicamente. As referidas 
intervenções devem ser incentivadas e são indispensáveis, estando sob responsabilidade dos profissionais de saúde que percebem as condições sociais de seus pacientes (RIESE et al., 2014).

O estudo de Jurgens et al. (2014), por sua vez, explorou as readmissões entre crianças com condições crônicas complexas, buscando determinar as taxas de readmissão no prazo de 30 dias após a alta e identificar fatores sociais associados com risco aumentado de readmissão. Os resultados do estudo evidenciaram que as readmissões por condições crônicas são responsáveis por um número desproporcional de readmissões hospitalares, mostrando que 19\% dos participantes tinha pelo menos uma readmissão no prazo delimitado.

No estudo de Gay et al. (2011), a recorrência da doença da admissão índice e o curso natural do diagnóstico original ou o seu agravamento foram as razões mais comuns para readmissões ocasionadas por uma nova doença, não relacionada com a admissão índice. Esse cenário pode ser comparado ao presente estudo, pois os grupos respiratórios, neurológicos, sintomas febris e gastrointestinais continuam sendo predominantes nas crianças que tiveram as queixas e diagnósticos diferentes da admissão índice, uma vez que crianças com problemas neurológicos, frequentemente, podem broncoaspirar, levando a agravos respiratórios como pneumonia e infecção das vias aéreas superiores e consequentes quadros de febre, demonstrando que esses grupos podem estar relacionados, caso não tenham o devido acompanhamento.

A prevalência da classificação verde em relação à amarela e à laranja nas readmissões sugere que a utilização do pronto-socorro foi porta de entrada de condições que poderiam ser atendidas e acompanhadas por cuidados ambulatoriais e de atenção básica. Estudos sobre a classificação de risco Manchester em pronto-socorro pediátrico e geral mostram que a classificação amarela tem sido a mais frequente em lactentes, pré-escolares e escolares, nas admissões, oportunidade em que esses os agravos poderiam ter sido resolvidos, evitando readmissões (JUNIOR et al., 2012; AMTHAUER, 2015).

Embora se espere que os agravos sejam resolvidos na admissão índice, há a possibilidade de a criança não ter recebido a assistência necessária à sua condição. Isso remete à qualidade do cuidado prestado para a resolução da condição clínica, cujo plano de cuidados pode não estar voltado para prevenção e promoção da saúde, como orientações e encaminhamentos para posterior acompanhamento. Por outro lado, a criança pode ter recebido o cuidado efetivo, mas os seus responsáveis não cumpriram com o compromisso de acompanhamento ambulatorial ou não tiveram acesso efetivo à atenção básica (TURRINI; VALERA, 2008).

O enfermeiro é o profissional que está na linha de frente do acolhimento com 
classificação de risco não só para a gestão dos serviços de urgência e emergência, mas também por suas características generalistas, sendo capaz de assumir a responsabilidade pela avaliação inicial, obtendo a classificação de risco e encaminhando a criança para a área clínica adequada. Esse processo deve ser dinâmico e, além de identificar o risco, a vulnerabilidade e as prioridades clínicas, o profissional de enfermagem tem a responsabilidade de, desde o primeiro momento, orientar, priorizar e decidir os encaminhamentos necessários para a resolução da demanda apresentada. (ANDRADE et al., 2011; SOUZA et al., 2012a).

Contudo, a ausência de uma rotina estabelecida tem como consequência, a falta de uma orientação sistematizada, considerando que o enfermeiro é o profissional que permanece em contato com a criança e seu acompanhante durante todo o atendimento, tendo a oportunidade de expandir a implementação do cuidado de forma integral, buscando identificar e compreender os fatores relacionados ao agravo para que possa formular um plano de implementação de cuidados domiciliares exercidos pela família, se necessário, e orientando a importância do cuidados pós-alta hospitalar (SOUZA et al., 2012b).

A qualidade do cuidado assistencial prestado pela equipe de enfermagem às crianças hospitalizadas também influencia no processo saúde-doença, recuperação, alta e em possíveis readmissões. Um estudo sobre readmissões pediátricas realizado em 225 hospitais evidenciou que a relação entre a razão paciente/enfermeiro e as taxas de readmissão estavam diretamente relacionadas, pois foi observado que crianças assistidas por enfermeiros que cuidavam de um menor número de crianças eram menos susceptíveis a passarem por readmissão devido ao agravamento de suas condições, sejam crônicas ou agudas (TUBBS-COOLEY et al., 2013).

As frequentes readmissões com classificações de risco maiores, menores ou mantidas em relação ao primeiro atendimento podem estar associadas a cuidados ineficientes, sejam no pronto-socorro, no domicílio ou no acompanhamento na atenção básica. Um estudo realizado no HRC com o objetivo de caracterizar as ICSAP em todo o hospital, entre 2008 e 2012, identificou que essas internações em menores de quatro anos tinham como principais condições sensíveis as pneumonias bacterianas, as gastroenterites infecciosas e a asma, com aumento significativo, durante o período, nas doenças pulmonares e nos casos de asma. Esses achados sugerem que, principalmente nos casos das doenças respiratórias, o acompanhamento pela atenção primária tem sido ineficiente (SOUSA et al., 2016).

A predominância das classificações laranja e amarelo nas readmissões em doenças do sistema respiratório podem estar relacionadas às condições precárias de moradia que parte da população de Ceilândia possui. Cerca de 16,3\% dos moradores ainda usam fossa séptica ou rudimentares, $20 \%$ não possuem acesso à rede de água pluvial e 7,5\% ainda vivem com esgoto 
a céu aberto, sendo esses fatores que predispõem a riscos de infecções respiratórias, gastrointestinais e infecciosas (CODEPLAN, 2013; SOUSA et al., 2016).

Apesar de 91,1\% da população de Ceilândia declarar que utiliza os serviços da APS, os dados do presente estudo somados aos de Sousa et al. (2016) permitem cogitar que o atendimento e a resolutividade da APS podem não ser efetivos. Esse fato pode estar relacionado à falta de integração das equipes de saúde e, principalmente, da equipe de enfermagem, que possui papel de destaque na educação em saúde nos quesitos de prevenção de agravos e promoção da saúde, a fim de otimizar os determinantes sociais (CODEPLAN, 2013; SOUSA et al., 2016).

Para que as readmissões não planejadas por fatores evitáveis - como os relacionados à assistência otimizada à criança, o adequado planejamento de alta, e a provisão de recursos no domicílio para atender às referidas demandas - sejam prevenidas, é importante que o enfermeiro exerça o seu papel de gestor do cuidar. A enfermagem é um dos principais atores no processo de adaptação da criança e sua família, pois estimula e trabalha a potencialidade do autocuidado e das melhorias de seus comportamentos de saúde, incluindo as condições biopsicossociais e culturais que interferem no processo saúde-doença (BORGES; TURRINI, 2011).

Neste contexto, conhecer o perfil das readmissões não planejadas na pediatria pode trazer indicadores que permitem a equipe de enfermagem compreender o contexto em que as crianças e seus responsáveis estão inseridos. Identificar o perfil por meio do acolhimento, da escuta qualificada e percepção crítica, é possível conhecer as reais necessidades de cuidado e de aprendizagem das crianças, o que torna o planejamento do cuidado mais individualizado e efetivo. 


\section{RESULTADOS E DISCUSSÃO DOS DADOS QUALITATIVOS}

\subsection{PERCEPÇÃO DOS ENFERMEIROS E FAMILIARES NAALTA HOSPITALAR}

\subsubsection{Perfil sociodemográfico dos enfermeiros}

Foram entrevistados 5 enfermeiros do pronto-socorro da pediatria e 5 enfermeiros da unidade de internação pediátrica para cuidados intermediários, pois, frequentemente, as crianças admitidas na internação para observação no pronto-socorro são transferidas para a unidade de internação. Todos os participantes aceitaram participar da pesquisa.

Dos 5 enfermeiros do pronto-socorro que foram entrevistados, 4 são do sexo feminino e 1, do masculino. A idade média dos participantes foi de 40,8 anos. O tempo médio de formação deles foi de 14,4 anos e apenas um enfermeiro não possuía pós-graduação. Entretanto, nenhum desses profissionais era especializado na área de pediatria. O tempo médio de serviço na unidade em questão foi de 6,8 anos.

Por sua vez, os enfermeiros da unidade de internação possuíam, quanto ao gênero, a mesma distribuição daqueles do pronto-socorro: 4 mulheres e 1 homem. A idade média desses entrevistados foi de 45,6 anos, com tempo médio de formação de 11,6 anos. Todos possuíam pós-graduação e apenas 1 tinha especialização em pediatria e neonatologia. O tempo médio de serviço na unidade foi de 9,6 anos.

Na etapa da pré-análise, após a transcrição das entrevistas, foi elaborado um quadro com as respostas dos enfermeiros, de acordo com a temática das questões referentes às readmissões e orientações no momento da alta. Com a saturação das informações, iniciou-se a exploração do material, emergindo duas categorias quanto ao papel da equipe de enfermagem no momento da alta do paciente. A primeira categoria diz respeito aos procedimentos e rotinas da equipe de enfermagem no momento da alta; a segunda categoria explorou como são dadas as orientações de alta e por quais membros da equipe de saúde são realizadas.

\subsubsection{Percepção dos enfermeiros}

$\mathrm{Na}$ categoria sobre os procedimentos de enfermagem no momento da alta, foi possível apreender que a rotina de alta, para o enfermeiro do pronto-socorro, está relacionada, principalmente, a procedimentos técnicos de semiologia, como o cuidado com a retirada dos acessos venosos, bem como o uso correto das medicações a serem utilizadas em domicílio.

Durante os relatos, foi apreendida a sobrecarga da equipe por déficit de profissionais, influenciando na eficácia das orientações no momento da alta. 
É retirar o acesso venoso, se tiver; orientar a mãe que a criança está de alta; se tem algum exame, entregar os exames para mãe, são essas as rotinas de alta...a gente faz só na saída (orientações), orientando a mãe (Enfermeiro 1).

A criança recebe um relatório médico e o enfermeiro orienta em relação mais ao uso da medicação inalatória, que é o salbutamol, porque aqui tem um índice muito grande de doenças pulmonares como bronquiolite, asma...então é só essa a orientação. Só que, normalmente, a equipe é muito sobrecarregada, tem um déficit de pessoas, então não dá pra fazer essa orientação de forma eficaz, de modo que esses pacientes sempre voltam pra cá. Eles nunca recebem uma alta, aprendem e ficam sem vir, normalmente são sempre crianças que são readmitidas (Enfermeiro 2).

O perfil das crianças admitidas e readmitidas foi identificado pelos enfermeiros como o de pacientes crônicos, que sempre retornam, mas que, pela falta de uma rotina específica para orientação na hipótese de repetidas readmissões, por vezes, o responsável da criança recebe somente as orientações de rotina.

A realidade da readmissão aqui no PS (pronto-socorro) é de pacientes crônicos, as crianças que já são nossas, elas vão embora da internação e sempre voltam ou por crise convulsiva ou a mãe só confia aqui...Então, a orientação que a gente dá é orientação de rotina da casa. Como são mães que vão e voltam, elas já sabem...não se faz necessária toda a orientação novamente de rotina (Enfermeiro 4).

A gente não especifica a alta da criança para readmissão. Muito raramente a gente cumpre o procedimento de alta, porque a grande parte das crianças readmitidas são pacientes crônicos e sindrômicos, né. Então, o nosso pronto-socorro é a porta de entrada. Mas, geralmente, a gente utiliza o procedimento de transferência, porque ele dá entrada no pronto-socorro e é transferido para internação...mas assim, a gente não especifica o paciente vindo de alta do paciente readmitido, a gente não tem essa especificação... Os cuidados específicos com aquela criança. A gente orienta sim (Enfermeiro 5).

$\mathrm{Na}$ categoria que evidencia como as orientações são dadas, se são verbais ou escritas, e por quais profissionais elas são realizadas, observou-se que são os médicos e os residentes os responsáveis por dar as orientações de alta. As orientações são fornecidas apenas de forma oral e somente no momento da alta.

Destaca-se ainda que um dos fatores que influenciam os episódios de readmissões, diz respeito ao problema social enfrentado pelas famílias atendidas, sendo a unidade de prontosocorro pediátrica o único lugar que os responsáveis pelas crianças confiam para serem atendidos e terem seus problemas, por hora, resolvidos.

Geralmente, a gente faz as orientações...a médica já faz as orientações antes. A gente faz só na saída, orientando a mãe (Enfermeiro 1).

Orientações da alta? É a médica. Aqui é a médica ou os residentes, eles que fazem questão de dar (Enfermeiro 1).

Verbalmente. Não tem nenhum material escrito, assim, dessas orientações. Aí, normalmente, a gente fala com a mãe quando é para usar o espaçador, quando é para 
usar o salbutamol, a gente mostra, vê se ela consegue fazer, mas não tem nenhuma orientação escrita, que eu acho até que seria importante (Enfermeiro 2).

A criança recebe um relatório médico e o enfermeiro orienta em relação ao uso da medicação inalatória... (Enfermeiro 2).

Geralmente, na rotina, são os médicos. Durante a visita ele fala que vai dar alta e faz as orientações (Enfermeiro 3).

As orientações são verbais (Enfermeiro 3).

Somente verbal. A gente não tem nenhum folder, nenhuma cartilha. Somente verbal...Mas, a gente aqui tem um problema social muito grande. $\mathbf{O}$ problema de saúde pública que eu falo que é nosso é o problema social, mas o entendimento da mãe...como é uma coisa tão comum...a gente reconhece os pacientes que a gente readmite, né....a gente vê que alguns cuidados eles têm boa noção (Enfermeiro 5).

O cuidado individualizado e integral à criança e à sua família deve ser compreendido pela equipe de enfermagem como parte do processo de humanização. A assistência segura é uma das responsabilidades da equipe de saúde que vai além dos procedimentos técnicos, ou seja, consiste em apreender, compreender e intervir, no que for necessário, conforme a demanda apresentada. Tal atitude de empatia deve ter como objetivo a compreensão das experiências e dúvidas dos sujeitos para que o processo de adaptação, auxiliado também pela enfermagem, seja mais confortável (REIS et al., 2013).

Costa et al. (2011) afirmam que a equipe de enfermagem e, principalmente, o enfermeiro são os primeiros profissionais responsáveis pelo acolhimento e pela mediação e adaptação quanto à situação de doença e hospitalizações vivenciadas pela família e pela criança. Devido a isso, a equipe tem o papel de não padronizar e estereotipar genericamente o cuidado, sendo estimuladora de um ambiente de trocas e valorização dos conhecimentos para que a educação em saúde seja uma intervenção eficiente no cuidado individualizado.

A sobrecarga da enfermagem também é citada por Reis et al. (2013) e Montanholi. et al. (2011), além da escassez de apoio ao profissional e investimento na capacitação para o cuidado integral devido ao não planejamento de intervenções favoráveis à integralidade, resultando em assistência com foco apenas em procedimentos técnicos. A capacitação da equipe é entendida como fator fundamental para o estímulo de ações autônomas e resolutivas por parte do enfermeiro, como o planejamento das orientações quanto aos cuidados pós-alta e a importância do acompanhamento no caso de agravos crônicos.

A qualidade do cuidado exercido pela equipe de enfermagem às crianças admitidas e readmitidas interfere consideravelmente no processo saúde-doença, recuperação, alta e pós-alta. Sabe-se que a proporção de enfermeiros por pacientes influencia na eficiência da assistência, podendo resultar em maiores taxas de readmissão e agravamento das condições crônicas ou agudas (TUBBS-COOLEY et al., 2013). 
O processo de adaptação da criança e seus responsáveis é suscetível a estímulos que interferem nos comportamentos adaptativos relacionados à cronicidade da doença, à rotina da família e às suas condições para lidar com os fatores estressores de todo esse sistema. Nesse sentido, Compas et al. (2012) esclarecem que tanto a criança quanto os pais, quando são colocados diante do estresse presente no momento do diagnóstico, bem como do estresse crônico, ao longo do tratamento, necessitam do auxílio do enfermeiro para lidar com a falta de adaptação aos estímulos impostos pela rotina de tratamento e por características da própria doença.

Após o tratamento recebido durante a hospitalização, o momento da alta hospitalar simboliza para os pais um ciclo tão importante quanto foi o anterior, pois se refere à capacidade de cuidar e de alterar, quando necessário, as rotinas e o estilo de vida da família, sendo uma fase caracterizada por inseguranças e dúvidas. A partir de então, é fundamental que a enfermagem estimule os mecanismos de enfrentamento dessa família para desenvolver o novo papel, buscando evitar futuras complicações e readmissões da criança (RIBEIRO et al., 2012).

A teorista de enfermagem Callista Roy defende que a enfermagem tem como ofício a promoção da saúde por meio da capacitação da pessoa em se adaptar ao seu ambiente. Neste contexto, a educação em saúde é ferramenta essencial do enfermeiro para a promoção da saúde e prevenção de agravos no processo de adaptação ao cuidado à criança, por parte da família, desde o período de hospitalização, passando pela alta e até a pós-alta hospitalar (ROY; ANDREWS, 2001; RIBEIRO et al., 2012).

Além da equipe de enfermagem, a abordagem multidisciplinar - composta por vários profissionais de saúde como médicos, psicólogos, nutricionistas e assistentes sociais - também tem como responsabilidade as ações de educação em saúde. Ao receberem amparo pela equipe de saúde durante a preparo para alta da criança, os responsáveis passam a adquirir e sentir maior segurança e habilidade para proporcionar os cuidados necessários para o restabelecimento e manutenção da saúde. Entretanto, as orientações e cuidados devem ser integrados e discutidos entre a equipe de saúde responsável pela criança com a devida participação dos familiares para que os cuidados sejam adequados e individualizados, e não mecânicos e genéricos, o que pode gerar dúvidas (RIBEIRO et al., 2012).

Por vezes, a realização das orientações quanto aos cuidados é feita partindo do pressuposto que aquele que recebe a orientação está compreendendo a informação e que não irá esquecê-la. Todavia, a compreensão pode estar relacionada a fatores complexos como o grau de instrução, o padrão socioeconômico e até mesmo a rotina familiar, podendo influenciar na apoderação do que é ensinado (RIBEIRO et al., 2012). 
Diante disso, é relevante o investimento em tecnologias leves como a elaboração de orientações sistematizadas, claras e acessíveis através de folders e cartilhas com os principais cuidados e intervenções, de acordo com as queixas mais frequentes durante e após a alta hospitalar, com o objetivo de contribuir para minimizar as dúvidas referentes ao processo saúdedoença e servir de base para estimular a adesão ao tratamento proposto, evitando as readmissões (CRUZ; MONTOVANI, 2014).

No tratamento e interpretação dos resultados das entrevistas dos enfermeiros da unidade de internação, a primeira categoria mostrou que as principais rotinas, no momento da alta do paciente, estão diretamente relacionadas aos cuidados com as medicações a serem utilizadas em domicílio, de acordo com a prescrição médica.

Contudo, como na enfermaria de internação as crianças ficam um maior período de tempo hospitalizadas, existem orientações diferentes, como a importância do comparecimento na consulta de retorno e a realização de exames, caso sejam pedidos, além dos cuidados gerais em domicílio, de acordo com a patologia apresentada.

Porém, assim como no pronto-socorro, não existe uma rotina ou um cuidado direcionado às crianças readmitidas. Consequentemente, as orientações de alta ficam restritas a informações sobre a patologia tratada durante a internação de acordo com a prescrição médica.

\footnotetext{
Geralmente, quando o paciente recebe alta, a gente dá uma olhada nas receitas médicas que os médicos geralmente fornecem...solicita os medicamentos para a continuidade do tratamento em casa. Orienta os horários de administração, orienta as diluições, caso seja necessário; a gente orienta o retorno caso seja marcado; orienta curativo, caso seja necessário. Tem criança que sai com consulta pendente, às vezes a gente orienta os familiares que a gente vai entrar em contato para, posteriormente, eles retornarem à unidade para pegar os pedidos e os cuidados de uma forma geral, dependendo da patologia do paciente, né (Enfermeiro 1).

Bom, na verdade, aqui não existe uma rotina especifica para isso não. Quando a criança ela é internada ou readmitida, a gente recebe a criança, aí, colhe os dados, né, avalia, faz a avaliação física da criança, vê o que a criança ainda está tomando de medicação e basicamente é isso. Não tem uma rotina pré-estabelecida por conta da criança estar sendo readmitida (Enfermeiro 2).
}

A segunda categoria mostra que, diferente da rotina de alta do pronto-socorro, onde são principalmente os médicos que dão as orientações, os enfermeiros da enfermaria de internação são tão responsáveis quanto a equipe médica por orientar os familiares das crianças no momento da alta e adequar, quando necessário, a forma como as orientações são feitas, passando a ser escritas ao invés de serem somente orais.

Somos nós enfermeiros que passamos (as orientações). A partir da alta médica, a gente vê quais são essas informações que a gente vai tá passando (Enfermeiro 1). 
Não tem protocolo de orientação. Na verdade, a gente passa essa orientação verbal. Ela não é escrita. Tem alguns pacientes que acontece que ela seja escrita. A gente vê de alguns pacientes que a gente acha que é de difícil compreensão, que a gente acha que eles vão esquecer...tem algumas coisas que a gente até escreve. Mas não é uma constância (Enfermeiro 1).

Sempre é o enfermeiro quem dá as orientações (Enfermeiro 3).

Dependendo é verbal e às vezes é por escrito, porque depende da patologia. Por exemplo, da ortopedia já tem um procedimento diferente do que os pacientes da clínica médica da pediatria. Os da ortopedia, nós temos as orientações conforme as orientações do ortopedista para aquelas crianças, que são orientadas conforme a patologia dentro da ortopedia e neles dispensamos os antibióticos para a continuação do tratamento no ambiente domiciliar. Então, tem uma orientação diferenciada do paciente diabético que a gente realiza. Com o paciente diabético que a gente realiza toda uma orientação para que este paciente saiba proceder no ambiente domiciliar e isso causa essa particularidade de cada patologia (Enfermeiro 3).

A seguinte fala mostra que a equipe de enfermagem é um dos principais responsáveis por identificar, com assertividade, a demanda necessária para que a orientação seja segundo as reais necessidades da criança e da sua família.

\footnotetext{
No todo, acaba que é a equipe em geral que dá as orientações, mas, a maior parte das vezes acaba sendo nós, enfermeiros... Se, por exemplo, a criança antes, no processo pré-alta, dependendo do dispositivo hospitalar que a criança vá utilizar na sua residência, ela é ensinada a como lidar com esse dispositivo...se é uma sonda, seja ela de nutrição ou seja ela vesical (Enfermeiro 5).
}

A rotina das enfermarias que assistem pacientes com maiores períodos de internação facilita a integração entre a enfermagem, a criança e a família, otimizando a percepção multidimensional da experiência vivenciada, considerando que é um paciente que deve ser assistido de forma integral. Os enfermeiros do estudo de Lelis et al. (2011) entendem que o cuidado à criança em situação de desconforto demanda um cuidado mais aprofundado para que toda a sua integralidade seja compreendida e seja possível o planejamento de uma assistência otimizada, para o alcance da satisfação tanto da criança em sua totalidade, quanto de seus familiares, assistindo-os integralmente.

A falta de rotina para a alta das crianças readmitidas apreendida nas entrevistas demonstra que, mesmo com a implementação de tecnologias voltadas ao tratamento específico das patologias, a equipe de saúde ainda possui dificuldades em planejar e implementar intervenções que estimulem a continuidade da assistência após a alta hospitalar. A orientação feita apenas oralmente deixa a desejar caso surjam dúvidas e anseios quanto aos cuidados em domicílio e sobre o acompanhamento ambulatorial e na APS, interferindo de forma negativa na implementação da educação em saúde individualizada (NIETSCHE et al., 2012). 
A passagem da alta hospitalar deve ser considerada como uma intervenção de educação em saúde que exerce papel importante na integralidade e continuidade do cuidado. O trabalho em equipe e a aproximação entre os protagonistas do cuidado, profissionais e usuários, consolida a educação em saúde, uma vez que a construção dos saberes é valorizada, reduzindo o risco de regras autoritárias e dificultando a falta de adesão ao tratamento (BRASIL, 2007).

Frequentemente, os familiares passam por períodos de dúvidas quanto aos cuidados com a criança pois, como foi visto, parte considerável das crianças possui agravos crônicos que demandam cuidados complexos. Com isso, o planejamento e a implementação da alta pelos profissionais de saúde, baseado na rotina de cada família através da sua participação e concomitante educação em saúde, é essencial para a continuidade da assistência ambulatorial e em domicílio pelos pais, sendo determinante à qualidade do cuidado (NIETSCHE et al., 2012).

Para que os familiares, os responsáveis e as crianças sintam-se empoderados na participação da construção do plano de cuidados, é importante que a equipe de enfermagem continue sendo acolhedora e assertiva na identificação das demandas apresentadas. Por intermédio do acolhimento e do estreitamento dos laços entre a equipe e os usuários, há a possibilidade de implementação de um plano de cuidados efetivo e integrado com ações da APS e ambulatoriais (SOUZA, 2012a).

\subsubsection{Perfil sociodemográfico dos familiares entrevistados}

Todas as entrevistas foram feitas com responsáveis do sexo feminino, com idade média de 35 anos, sendo 92,3\% residentes de Ceilândia e 7,7\%, de Taguatinga. Em relação ao estado civil, $46,2 \%$ se declararam solteiras, $30,8 \%$ casadas, $15,3 \%$ afirmaram que têm um companheiro e $7,7 \%$ são divorciadas.

Quanto à escolaridade, 23\% referiram ter o ensino fundamental incompleto, 7,7\% tinham o ensino fundamental completo, 7,7\% têm ensino médio incompleto, 38,4\% relataram ter o ensino médio completo, $7,7 \%$ atingiram o ensino superior incompleto e $15,3 \%$ alcançaram o nível superior completo. Apenas 7,7\% trabalham fora de casa e 100\% das entrevistadas são as principais cuidadoras das crianças e acompanharam as admissões anteriores.

Dentre as faixas etárias das crianças readmitidas, predominaram os lactentes, com $53,8 \%$. E tanto os pré-escolares como os pré-púberes representaram 23,1\% do total, cada grupo. Quanto aos diagnósticos que levaram as crianças à readmissão, 53,8\% estavam relacionadas ao grupo respiratório (bronquiolite, pneumonia e IVAS); 15,4\%, ao grupo urinário (infecção do trato urinário), 15,4\% ao grupo cardiovascular (tetralogia de Fallot e derrame agudo do pericárdio) e 15,4\% ao grupo neurológico (epilepsia). 


\subsubsection{Percepção dos familiares}

Duas categorias emergiram após a leitura flutuante e exploração do material. A primeira diz respeito aos fatores que influenciavam na readmissão das crianças, segundo os familiares. A segunda categoria evidenciou o tipo e a forma de orientação da equipe de enfermagem que o familiar recebia no momento da alta, se era verbal ou escrita e também sobre quais cuidados necessários no caso de cada criança.

Em relação à primeira questão, a maior parte dos relatos mostrou que o principal fator influenciador para a readmissão era a própria patologia, por piora da condição aguda ou por quadro de condições crônicas. Geralmente, tais afecções estavam relacionadas a problemas respiratórios ou a condições neurológicas que levavam à broncoaspiração e, consequentemente, à pneumonia.

Ele estava com falta de ar e deu bronquiolite, aí deu falta de ar, aí ele voltou. Teve que ficar no oxigênio (Familiar 1).

É porque assim, ele tem problemas crônicos já, né. Então, assim, ele tem uma paralisia cerebral, o que acarretou vários quadros de pneumonia, bronquite e por isso a gente sempre, de vez em quando, está aqui (Familiar 2).

É... eu cheguei a vir 3 vezes com ela no pronto-socorro e, das 3 vezes, os 3 médicos que atenderam disseram que era só garganta inflamada, que era só para medicar com dipirona e se persistisse a febre, pra voltar. Na quarta vez que médica resolveu examinar, ela fez o raio $X$ e exame de urina e constatou que ela estava com pneumonia (Familiar 3).

É, na verdade, ele tá broncoaspirando, então o fator é isso. Ele precisa da cirurgia, mas com o tempo da demora ele só vai piorando e voltando (Familiar 7).

Porque o quadro dele não mudou em nada. Ele continua desde a primeira vez só piorando, né?! Ele teve só uma pausa, né, aí continuou piorando, aí eu trouxe ele de volta pra cá (Familiar 8).

Os principais fatores? É a pneumonia. O tempo aqui da nossa cidade muda assim muito rápido, uma mudança muito brusca para essas crianças assim acamadas, né? Aí, ele sempre tá dando pneumonia...pneumonia e infecção urinária. Sempre vem junto as duas (Familiar10).

Todas as participantes que disseram ter recebido orientações da equipe de enfermagem, relataram que as orientações eram sempre verbais. Contudo, assim como os enfermeiros do pronto-socorro, foi apreendido, pelas falas, que as orientações estavam frequentemente relacionadas às medicações que seriam administradas em domicílio e, apenas uma relatou orientações sobre os cuidados gerais com a criança em casa. 
Ah...eles me orientaram pra eu cuidar bem dela, mais cuidado...dar os remédios direito...assim (Familiar 12).

É sobre os cuidados em casa. Sempre ele ficar limpo, entendeu...sempre não ter sujeira...isso causa muita infecção, né e muito muito mais...só isso (Familiar 11).

Apesar de a maior parte das participantes referirem que receberam algum tipo de orientação da equipe de enfermagem, mesmo que frequentemente voltados somente à administração de medicamentos, algumas relataram não terem recebido qualquer tipo de orientação. Uma das responsáveis referiu que as orientações não são mais necessárias por já as ter recebido anteriormente.

Não, nenhuma. Assim, tudo que eu via o profissional fazendo, eu copiava...vou fazer também (Familiar 4).

Não, só mesmo ela falando que eu tinha que tomar cuidado com ela porque ela é cardiopata, assim...mas escrita não (Familiar 5).

Não, não orienta porque nas outras internações eles já me orientaram. Agora não precisa (Familiar 7).

Uma das preocupações em saúde pública é a falta de adesão das mães aos programas voltados à redução da mortalidade e morbidade perinatal e infantil, como o acompanhamento do pré-natal e puerpério, a importância da amamentação, a assistência ao crescimento e desenvolvimento infantil, a vacinação e outras medidas cujos resultados são comprovadamente eficazes no combate à morbimortalidade e às internações hospitalares (COSTA et al., 2011).

É conhecido que a escolaridade das mães pode ser um fator considerável para a compreensão adequada dos riscos de agravamentos das condições de saúde dos filhos e da necessidade de cuidados complexos na infância. A baixa escolaridade materna pode acarretar maiores riscos de contrair enfermidades e de hospitalizações, como foi identificado no estudo de Granzotto et al. (2014), em que a escolaridade materna ficou entre 5 a 8 anos, semelhante à do presente estudo.

Junto à baixa adesão aos programas de prevenção e promoção de saúde da criança e à baixa escolaridade materna, pesquisas têm demonstrado a importância dos fatores socioeconômicos na saúde infantil. Entre estes, a renda tem sido considerada como indicador da disponibilidade de recursos e conhecimentos em relação à saúde. Tais fatores são vistos nos resultados deste estudo como a baixa escolaridade materna e a possível baixa renda, já que parte considerável das mães se declarou solteira, donas de casa e principais cuidadoras de seus filhos (RIESE et al., 2014; PAIM et al., 2011). 
Uma pesquisa realizada em São Luiz (MA) apontou que, em um hospital de referência, a maior parte das crianças que foram internadas eram do sexo masculino $(56,67 \%)$, lactentes $(32,96 \%)$ e foram admitidas com problemas respiratórios como a pneumonia (RIBEIRO et al., 2012). Granzotto et al. (2014) também exploraram, em um hospital do Rio Grande do Sul, o perfil das crianças admitidas e os fatores relacionados, e descreveram que houve prevalência de lactentes com problemas respiratórios. Ambos coincidem com os achados do presente estudo, mostrando o perfil prevalente dos agravos que acometem as crianças.

As regiões Sul e Centro-Oeste do Brasil, nas estações do outono e do inverno, apresentam o clima frio, o que favorece admissões e readmissões por problemas respiratórios com a asma, a pneumonia, bronquiolite e as infecções das vias aéreas superiores, fator estressor à saúde das crianças, principalmente aquelas com problemas crônicos e neurológicos, que demandam um cuidado mais atencioso e planejado.

Sabe-se que os principais fatores de risco para as readmissões pediátricas estão associados à menor faixa etária, com a dos lactentes, à presença de problemas de saúde crônicos, ao baixo nível socioeconômico, à quantidade de admissões anteriores e ao acompanhamento ambulatorial e pela atenção primária ineficientes para o tratamento e ações de promoção da saúde e prevenção de possíveis complicações e agravos. Lasmar et al. (2006) afirmam que, após uma hospitalização, por causas respiratórias como a asma ou a pneumonia, o serviço de atenção básica tem como responsabilidade captar essa criança para esclarecimento diagnóstico e iniciar os cuidados de acompanhamento, pois crianças com várias readmissões possuem riscos mais prevalentes, como danos psicossociais.

A captação da atenção primária para o acompanhamento das crianças deve começar desde o nascimento, pois a estimulação de vínculos entre a equipe de saúde, a criança e a família responsável pelo cuidado influencia de maneira positiva para que essa prática vire rotina e sejam identificadas precocemente as queixas. Com a identificação prévia de possíveis complicações e agravos é possível intervir em nível primário, desafogando os prontos-socorros por condições sensíveis à atenção primária.

Para que exista a criação de vínculos e haja resolutividade das condições sensíveis à atenção primária e dos agravos atendidos no hospital, é necessário que a equipe de enfermagem identifique, através da sistematização da assistência de enfermagem, a complexidade do cuidado demandado pela criança e sua família e compreenda as resistências que surgirão juntamente às inseguranças. Desse modo, o enfermeiro tem o papel de auxiliar a fase de adaptação, propondo intervenções individualizadas com a participação ativa da família e 
acompanhando e avaliando os comportamentos adaptativos e os ineficazes (MARTINS et al., 2010).

A enfermagem, profissão responsável por promover e acompanhar o processo de alta e adaptação, deve prover orientações que vão além de cuidados pontuais como a forma de administração das medicações, pois o cuidado integral está relacionado ao equilíbrio do bemestar físico, psíquico e espiritual. Portanto, intervenções capazes de proporcionar a adaptação da criança e de seus responsáveis podem ter como objetivo a combinação de informes orais e escritos acessíveis como estratégia para a realização da continuidade dos cuidados em domicílio (GOZZO et al., 2012).

Contudo, para que o seguimento do plano de cuidados seja implementado fora do ambiente hospitalar de maneira segura e acessível - mesmo que os familiares já digam estar habituados à rotina de cuidados - é essencial que tenham acessibilidade às orientações sempre que quiserem, a fim de esclarecer a finalidade das orientações pautadas em como auxiliar pacientes e familiares sobre a recuperação; estimular o autocuidado; auxiliá-los a entender sua trajetória de adoecimento e sua adaptação, os tratamentos farmacológicos e não farmacológicos e estratégias de prevenção de agravos e promoção da saúde (GOZZO et al., 2012).

\section{INTEGRAÇÃO DOS ESTUDOS QUANTITATIVO E QUALITATIVO}

Observou-se que a população prevalente neste estudo foi a de lactentes do sexo masculino, residentes de Ceilândia, principal região de abrangência do HRC. Tanto nas admissões índices quanto nas readmissões, nos estudos quantitativo e qualitativo, o grupo respiratório foi o de maior prevalência, com ênfase em agravos como asma, bronquiolite, pneumonia e infecção das vias aéreas superiores.

As doenças do aparelho respiratório, frequentemente prevalentes em crianças menores de dois anos de idade e do sexo masculino devido à maior fragilidade imunológica, mostraram ser as principais causas de admissão e readmissões evitáveis. Esses agravos, classificados como CSAP, estão associados não só a condições biológicas, mas também a questões sociais como baixa escolaridade, baixa renda, condições inadequadas de moradia e resistência à adesão ao acompanhamento pela APS, por parte dos cuidadores, estando esses fatores presentes nos dados das entrevistas.

O mesmo perfil sociodemográfico e de morbidade foi identificado tanto nos dados quantitativos como nos qualitativos, o que permitiu a compreensão mais aprofundada das readmissões e seus fatores relacionados, uma vez que foi evidenciada a inexistência de rotina 
específica e preparo para a alta hospitalar das crianças acometidas pelos principais agravos encontrados, segundo a fala dos enfermeiros e das mães das crianças readmitidas entrevistadas.

Fatores como a possível falta de preparo para a alta hospitalar, ineficiência no acompanhamento pós-alta e a não implementação de um plano de cuidados individualizado apreendidos nas entrevistas podem estar relacionados à elevada taxa de readmissões encontrada.

Como consequência do panorama exposto tanto neste estudo quanto na literatura, podese afirmar que, frequentemente, os prontos-socorros têm sido porta de entrada de crianças readmitidas classificadas predominantemente na cor verde e que poderiam ter seus agravos acompanhados no nível de complexidade mais baixo, ou seja, na APS e em consultas ambulatoriais.

O acompanhamento das crianças e seus familiares pela APS poderia diminuir a taxa de readmissão, uma vez que os responsáveis por crianças readmitidas referiram que as complicações das patologias crônicas foram o principal fator influenciador para as readmissões. Apesar de também relatarem receber orientações da equipe de enfermagem, principalmente na administração de medicamentos domiciliares, as readmissões ainda ocorrem, corroborando com o relato dos enfermeiros e com o perfil de readmissão.

As orientações realizadas, tanto pela equipe de enfermagem quanto pela equipe de saúde, foram predominantemente verbais e direcionadas apenas às patologias e não aos cuidados gerais com a criança e à participação ativa dos responsáveis. Esse cenário implica em um preparo para a alta com orientações genéricas e mecânicas e em um cuidado não individualizado, o que pode gerar frequentes dúvidas, inseguranças e possíveis readmissões.

A qualidade das orientações para a alta hospitalar para a adaptação da criança e seus familiares deve estar centrada no esclarecimento da demanda apresentada, além de ações de promoção de saúde e não somente acerca da utilização dos medicamentos em domicílio e cuidados pontuais, como foi evidenciado nas entrevistas.

Mesmo que a enfermagem oriente quanto aos cuidados domiciliares pertinentes e incentive o acompanhamento pela atenção básica, por vezes, pode não haver compreensão do que foi orientado. Diante disso, durante toda a hospitalização, é importante que exista um preparo para a alta, pois há muito a ser esclarecido pelos enfermeiros e técnicos de enfermagem.

Portanto, a partir do perfil da demanda de atendimento, das readmissões e da visão tanto da equipe de enfermagem quanto dos familiares das crianças readmitidas, é possível rever o planejamento da assistência de maneira mais individualizada e objetiva. A elaboração de orientações sistematizadas de enfermagem para a alta hospitalar das crianças pode ser uma 
estratégia de prover, de forma clara e acessível, os principais cuidados e intervenções de acordo com as queixas mais frequentes durante e após a alta hospitalar.

A implementação de um plano de alta acessível ao cuidador na forma de um material educativo e do treinamento e aprendizagem durante a hospitalização pode contribuir na minimização das questões que podem surgir fora do hospital referentes ao processo saúdedoença e servir de base para estimular a adesão ao tratamento proposto, evitando as readmissões. 


\section{CONSIDERAÇÕES FINAIS}

As readmissões hospitalares pediátricas, de forma geral, podem ser consideradas um problema de saúde pública, uma vez que sugere a falta de efetividade e resolutividade da atenção básica no acompanhamento das condições sensíveis à atenção primária e na baixa qualidade assistencial hospitalar prestada às crianças e seus familiares por sobrecarga do sistema.

A implementação da sistematização da assistência de enfermagem na identificação e no aprofundamento das principais demandas apresentadas pode influenciar de maneira positiva o plano assistencial e as intervenções domiciliares, de forma que a família seja adaptada à complexidade dos cuidados necessários à criança.

Pode ser considerada como limitação deste estudo a fonte de dados secundários pelo sistema TrakCare, que - apesar de ser a fonte institucional para a coleta das variáveis estudadas - este possui algumas lacunas, há déficit de informações no sistema, o que pode subestimar os resultados.

Todavia, a realização deste estudo foi importante para a compreensão do fenômeno readmissão, assim como, descrever a realidade das readmissões pediátricas do HRC, a partir de um recorte nos meses de maior demanda. Os resultados deste estudo possibilitarão fazer a devolutiva para a equipe de saúde do HRC, visando refletir o cotidiano e implementação de rotinas que permita reduzir as taxas de readmissão por intermédio de uma rotina específica para alta das crianças, especialmente pela equipe de enfermagem.

A partir da presente pesquisa, é importante o aprofundamento do estudo em relação às orientações específicas da equipe de enfermagem, durante a hospitalização no preparo para a alta hospitalar. A confecção e implementação de um material educativo acessível às crianças e familiares sobre os cuidados gerais e de acompanhamento pode ser o foco de futuros estudos quanto à efetividade dessas intervenções. 


\section{REFERÊNCIAS}

ANDRADE, M.A.C.; ARTMANN, E.; TRINDADE, Z.A., et. al. Humanização da saúde em um serviço de emergência de um hospital público: comparação sobre representações sociais dos profissionais antes e após a capacitação. Ciênc. Saúde Coletiva, v. 16, supl. 1, p. 1115-1124, 2011.

ALFRADIQUE, M.E.; BONOLO, P.F; DOURADO.; I.; LIMA. et al. Lista brasileira de internações por condições sensíveis à atenção primária: uma nova ferramenta para medir o desempenho do serviço de saúde. Cad Saúde Pública, v. 25, p. 1337-1349, 2009.

ALMEIDA, L.W.; ROBAZZI, M.L.C.C.; SANTOS, R.M. et al. Planejamento para a alta hospitalar como estratégia de cuidado de enfermagem: revisão integrativa. Rev enferm UFPE on line, v. 7, n.(esp):7151-9, dez., 2013.

AMTHAUER, C. Características da utilização do sistema de triagem de Manchester em uma unidade de emergência pediátrica. Porto Alegre, 2015.

BARDIN, L. Análise de conteúdo. Lisboa: Edições 70, 1977.

BARROS, F.C.; MATIJASEVICH, A.; REQUEJO, J.H., et al. Recent Trends in Maternal, Newborn, and Child Health in Brazil: Progress Toward Millennium Development Goal 4 and 5. Am J Public Health, v 100, n. 10, p.1877-1899, 2010.

BERGET, L.; PATEL, S.J.; KIMATA, C., et al. Linking patient-centered medical home and asthma measures reduces hospital readmission rates. Pediatrics, v. 134, n.1, 249-256, 2014.

BERRY, J.G.; HALL, D.E.; KUO, D.Z. et al. Hospital utilization and characteristics of patients experiencing recurrent readmissions within children's hospitals. JAMA, v.305, n.7, p.682-690, 2011.

BERRY, J.G.; TOOMEY, S.L.; ZASLAVSKY, A.M. et al. Pediatric readmission prevalence and variability across hospitals. JAM,. v.309, n.4, p.372-380, 2013.

BORGES, F.K.; SOLIMAN, F.; PIRES, D.O., et al. Reinternação hospitalar precoce: avaliação de um indicador de qualidade assistencial. HCPA, v. 28, n.3, p.147-152, 2008.

BORGES, M.F.; TURRINI, R.N.T. Readmissão em serviço de emergência: perfil de morbidade dos pacientes. Rev Rene, v. 12, n.3, p.453-61, 2011.

BRASIL. Ministério da Saúde, Organização Pan-Americana da Saúde, Organização Mundial da Saúde. AIDPI Atenção integrada às doenças prevalentes na infância: curso de capacitação: introdução: módulo 1. 2. ed. Brasília, DF: Ministério da Saúde, 2003.

Ministério da Saúde. Secretaria Executiva. Núcleo Técnico da Política Nacional de Humanização. HumanizaSUS: Política Nacional de Humanização: a humanização como eixo norteador das práticas de atenção e gestão em todas as instâncias do SUS - Brasília: Ministério da Saúde, 2004.

Ministério da Saúde. Secretaria de Atenção à Saúde. Departamento de Atenção Básica

(Série C. Projetos, Programas e Relatórios). Saúde da família no Brasil: uma análise de indicadores selecionados: 1998-2004. Brasília, 2006. 
Ministério da Saúde. Portaria ${ }^{0} 221$, de 17 de abril de 2008. Publica a lista brasileira de internações por condições sensíveis à atenção primária. Diário Oficial da União, Brasília, p. 70, 18 abr. 2008.

. Ministério da Saúde. Secretaria de tenção Saúde. Política Nacional de Humanização da Saúde. Documento Base. Ed. Brasília: Ministério da Saúde, 2007.

Ministério da Saúde. Manual de vigilância do óbito infantil e fetal e do Comitê de

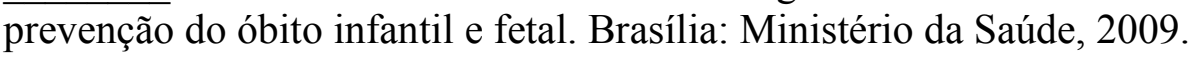

- Ministério da Saúde. Secretaria de Atenção à Saúde. Departamento de Ações Programáticas e Estratégicas. Manual AIDPI neonatal. Organização Pan-Americana de Saúde. 3a ed. Brasília (DF): Ministério da Saúde; 2012.

. Agência Nacional de Vigilância Sanitária. Assistência segura: uma reflexão teórica aplicada à prática. Brasília: Anvisa; 2013.

Objetivos de Desenvolvimento do Milênio: Relatório Nacional de Acompanhamento/Coordenação: Instituto de Pesquisa Econômica Aplicada e Secretaria de Planejamento e Investimentos Estratégicos; supervisão: Grupo Técnico para o acompanhamento dos ODM. - Brasília: Ipea: MP, SPI, 2014.

. Ministério da Saúde. Política Nacional de Atenção Integral à Saúde da Criança. Brasília: Ministério da Saúde, 2015.

CAMINAL, J.; STARFIEL, D. B.; SANCHEZ, E., et al. The role of primary care in preventing ambulatory care sensitive conditions. Eur J Public Health, v.14, n.3, p.246-251, 2004.

CAMPOS, A. Z.; THEME-FILHA, M.M. Internações por condições sensíveis à atenção primária em Campo Grande, Mato Grosso do Sul, Brasil, 2000 a 2009. Cad. Saúde Pública, v. 28, n.5, p. 845-855, 2012.

CASTRO, M.S.M.; CARVALHO, MS,; TRAVASSOS, C. Fatctors associated with readmission to a general hospital in Brazil. Cad Saúde Pública, v. 21, n.4, p.1186-1200, 2005.

CAVALCANTE, R.B.; RATES, H.F.; SILVA, L.T.C., et al. Acolhimento com classificação de risco: proposta de humanização nos serviços de urgência. R. Enferm. Cent. O. Min, v.2, n.3, p.428-437, 2012.

CODEPLAN. Pesquisa distrital por amostra de domicílios - PDAD 2013. Ceilândia: Governo do Distrito Federal, 2013.

COMPAS, B. E.; JASER, S. S.; DUNN, M. J. et al. Coping with chronic illness in childhood and adolescence. Annual Reviews Clinical Psychology, v. 27, n.8 p.455-480, 2012.

COSTA, E.L.; SENA, M.C.F.; DIAS, A. et al. Gravidez na adolescência determinante para prematuridade e baixo peso. Com Ciências Saúde, v.;22 Supl 1, p.183-188, 2011.

CRESWELL, J.W. Projeto de Pesquisa: métodos qualitativo, quantitativo e misto. Artemed, 2010. 
CRUZ, I.M.L.; MONTOVANI, M.F. orientação de enfermagem para a alta hospitalar do paciente neoplásico. Cogitare Enferm, v.19, n.4, p.687-93, 2014.

CURSINO, E.G.; FUJIMORI, E. Integralidade como uma dimensão das práticas de atenção à saúde da criança: uma revisão bibliográfica. Rev. Enferm, v. 20, (esp1), p.676-80, 2012.

DUARTE, J.G.; GOMES, S.C.; PINTO, M.T,. et al. Perfil dos pacientes internados em serviços de pediatria no município do Rio de Janeiro: mudamos? Physis Revista de Saúde Coletiva, v.22, n.1, p.199-214. 2012.

ELIAS, E.; MAGAJEWSKI, F. AAtenção Primária à Saúde no sul de Santa Catarina. Rev Bras Epidemiol, v.11, n.4, p.633-647, 2008.

FERRER, A.P.S. Estudo das causas de internação hospitalar das crianças de 0 a 9 anos de idade no município de São Paulo [dissertação]. São Paulo: USP, Departamento de pediatria; 2009.

FEUDTNER, C.; LEVIN, J.E.; SRIVASTAVA, R. et al. How well can hospital readmission be predicted in a cohort of hospitalized children? A retrospective, multicenter study. Pediatrics, v.123, n.1, p.286-293, 2009.

FOWLER, D.J.; SÁ, A.C. Humanização nos cuidados de paciente com doenças crônicodegenerativas. O Mundo da Saúde, v. 33, n. 2 p. 225-230, 2009.

GAY, J.C.; HAIN, P.D.; GRANTHAM, J.A., et al. Epidemiology of 15-Day readmissions to a children's hospital. Pediatrics, v.127, n.2, p.1505, 2011.

GEORGE, J.B.; BELCHER, J.R.; BENNETT, A.M. et al. Teorias de enfermagem: os fundamentos à prática profissional. $4^{\mathrm{a}}$ ed. Porto Alegre: Artmed; 2000.

GOZZO, T.O.; LOPES, R.R.; PRADO, M.A.S. et al. Informações para a elaboração de um manual educativo destinado às mulheres com câncer de mama. Esc. Anna Nery, v.12, n.2, p.306-311, 2012.

GRANZOTTO, J.A.; MOTA, D.M.; VECCHI, A.A. et al. Características sociodemográficas maternas e perfil das crianças internadas em um hospital do sul do brasil. Rev Enferm UFSM, v. 4, n.1, p. 97-104, 2014.

HOWRYLAK, J.A.; SPANIER, A.J.; HUANG, B., et al. Cotinine in children admitted for asthma and readmission. Pediatrics, v.133, n. 2, p.355-62, 2014.

JUNIOR, P.E.F.; PAULA, V.G.; SANTIAGO, L.C. et al. Implementação da classificação de risco em unidade de emergência de um hospital público do Rio de Janeiro - um relato de experiência. R. pesq.: cuid. fundam. Online, v.4, n.1, p.2723-2732, 2012.

JURGENS, V.; SPAEDER, M.C.; PAVULURI, P. et al. Hospital readmission in children with complex chronic conditions discharged from subacute care. Hosp Pediatr, v.4, n.3, p.153-158, 2014.

LASMAR, L.M.L.B.F.; CAMARGOS, P.A.M.; GOULART, E.M.A. et al. Fatores de risco para readmissão hospitalar de crianças e adolescentes asmáticos. J Bras Pneumol, v. 32, n.5, p.391399, 2006. 
LEITE, F.; FARIA, C. Readmissões não previstas após alta na unidade de internação de curta duração de um serviço de urgência pediátrica de Viseu, Portugal. Scientia Medica, v. 19, n. 4, p. 170-175, 2009.

LELIS, A.L.P.A.; FARIAS, L.M.; CIPRIANO, M.A.B., et al. Cuidado humanístico e percepções de enfermagem diante da dor do recém-nascido. Escola Anna Nery, v. 15, n. 4, p. 694-700, 2011.

MALTA, D.C.; SARDINHA, L.M.V.; MOURA, L., et al. Atualização da lista de causas de mortes evitáveis por intervenções do Sistema Único de Saúde do Brasil. Epidemiol. Serv. Saúde. v.19, n.2, p.173-176, 2010.

MARTINS, M.C.F.N.; BERSUSA, A.A.S.; SIQUEIRA, S.R. et al. Humanização e voluntariado: estudo qualitativo em hospitais públicos. Revista de Saúde Pública, v. 44, n. 5, p. 942-949, 2010 .

MAURER, P.P.; BALLMER, P.E. Hospital readmissions-are they predictable and avoidable? Swiss Med Wkly, v.134, n.41-42, p. 606-611. 2004.

MERHY, E.E. Saúde: a cartografia do trabalho vivo. 2a ed. São Paulo: Hucitec; 2005.

MONTANHOLI, L.L.; MERIGHI, M.A.B.; JESUS, M.C.P. et al. Atuação da enfermeira na unidade de terapia intensiva neonatal: entre o ideal, o real e o possível. Rev. Latino-Am. Enfermagem, v. 19, n. 2, 2011.

MOREIRA, M.L. Readmissões no sistema de serviços hospitalares no Brasil. [tese] São Paulo: Universidade de São Paulo. 2010.

NEDEL, F.B.; FACCHINI, L.A.; MARTÍN,-MATEO, M., et al. Programa saúde da família e condições sensíveis à atenção primária, Bagé (RS). Rev Saúde Pública, v.42, p.1041-1052, 2008.

NEDEL, F.B.; FACCHINI, L.A.; MARTÍN-MATEO, M. et al. Características da atenção básica associadas ao risco de internar por condições sensíveis à atenção primária: revisão sistemática da literatura. Epidemiol. Serv. Saude, v. 19, n.1, p.61-75, 2010.

NIETSCHE, E.A.; NORA, A.D.; LIMA, M.G.R. et al. Educação em saúde: planejamento e execução da alta em uma unidade de terapia intensiva neonatal. Esc Anna Nery, v.16, n.4, p.809-816, 2012.

OLIVEIRA, B.R.G.; VIEIRA, C.S.; COLETT, N. et al. Causas de hospitalização de crianças no SUS de zero a quatro anos no Brasil. Rev Bras Epidemiol, v.13, n.2, p.286-277, 2010.

OLIVEIRA, R.R.; COSTA, J.R.; MATHIAS, T.A.F. et al. Hospitalizações de menores de cinco anos por causas evitáveis. Rev. Latino-Am. Enfermagem, v.20, n.1, [08 telas], 2012.

PAIM, J.; TRAVASSOS, C.; ALMEIDA, C. et al. The Brazilian health system: history, advances, and challenges. The Lancet, v. 377, n.9779, p1778-1797, 2011.

PARANHOS, V.D.; PINAS J.C.; MELLO, D.F. et al. Atenção integrada às doenças prevalentes na infância e o enfoque nos cuidadores: revisão integrativa da literatura. Rev. Latino-Am. Enfermagem, v.10, n.1, [09 telas], 2011. 
PEIXOTO, B.V., PIAZZETTA, E., RISCHINI, F.A. et al. A difícil realidade do pronto atendimento infanto-juvenil mostrando a situação de saúde de uma cidade. Rev Paul Pediatr, v.31, n.2, p.231-236, 2013.

PROBIST, J.C.; LADITKA, J.N.; LADITKA, S.B. et al. Association between community health center and rural health clinic presence and county-level hospitalization rates for ambulatory care sensitive conditions: an analysis across eight US states. BMC Health Serv Res, v.9, n.134, 2009.

REIS, L.S. et al. Percepção da equipe de enfermagem sobre humanização em unidade de tratamento intensivo neonatal e pediátrica. Revista Gaúcha de Enfermagem, v. 34, n. 2, p. 118- 124, 2013.

RIBEIRO, T.S.F.; FONSECA, M.S.S.; SOUSA, N.V.S. et al. Prevalência de internações em crianças de 0-2 anos em um hospital de referência, São Luis - MA. Rev Ciênc Saúde, v.14, n.2, p.127-132, 2012.

RIESE, J.; MCCULLOH, R.J.; KOEHN, K.L. et al. Demographic factors associated with bronchiolitis readmission. Hosp Pediatr, v.4, n.3, p.147-152, 2014.

ROY, S.C.; ANDREWS, H.A. Teoria da enfermagem. O modelo de adaptação de Roy. Lisboa: Instituto Piaget; 2001.

SALAZAR, O.A.B. Rejeição dos pacientes no cuidado do enfermeiro. Invest Educ Enferm, Colombia, p. 343-352, 2011.

Secretaria do Estado de Saúde do Distrito Federal - SESDF. Brasília, 2014.

Secretaria do Estado de Saúde do Distrito Federal - SESDF. Brasília, 2016.

SELLI, L.; JUNGES, J.R.; VIAL, E.A. et al. O cuidado da ressignificação da vida diante da doença. O Mundo da Saúde, v. 32, n. 1, p. 85-90, 2008.

SILVA, F. S.; SANTOS, I. Expectativas de familiares de clientes em UTI sobre o atendimento em saúde: um estudo sociopoético. Esc Anna Nery, v. 14, n. 2, p. 230-235, 2010.

SIQUEIRA, M.B.C.; DIAS, M.A.B. A percepção materna sobre vivencia e aprendizado de um bebê prematuro. Epidemiologia, Serviços de Saúde, v. 27, n. 1, p. 27-36, 2011.

SHIROMA, L.M.B.; PIRES, D.E.P. Classificação de risco em emergência: um desafio para as/os enfermeiras/os. Enf. Foco, v.2, n.1, p.14-17, 2009.

SOUZA, P.M.B.B. Protocolo de orientações de enfermagem para o paciente com insuficiência cardíaca à alta hospitalar [dissertação]. Rio de Janeiro (RJ): Universidade Federal Fluminense; 2012a.

SOUZA, A.; FERNANDES, W.A.; PAVÃO, H.G. et al. Potenciais impactos da variabilidade climática sobre a morbidade respiratória em crianças, lactentes e adultos. J Bras Pneumol, v.38, n.6, p. 708-715, 2012 b. 
SOUSA, N.P.; REHEN, T.C.S.M.B.; SANTOS, W.S. et al. C.E. Internações sensíveis à atenção primária à saúde em hospital regional do Distrito Federal. Rev Bras Enferm, v.69, n.1, p.118$125,2016$.

TRENTINI, M.; PAIM, L.P.; VASQUEZ, M.L., et al. A responsabilidade social da enfermagem frente à política de humanização da saúde. Colombia Médica, v. 42, n. 2 p. 95-102, 2011.

TREMARIN, R.A.; GAWLETA, F.; ROCHA, D.L.B. et al. A teoria da adaptação sustentando o cuidado de enfermagem em hospital pediátrico: um estudo de caso. Cogitare Enferm, v. 14, n.3, p.569-574, 2009.

TUBBS-COOLEY, H.L.; CIMIOTTI, J.P.; SILBER, J.H. et al. An observational study of nurse staffing ratios and hospital readmission among children admitted for common conditions. BMJ Qual Saf, v.22, n.9, p. 735-742, 2013.

TUBINO, P.; ALVES, E. Anatomia funcional da criança. Bases morfológicas para a prática pediátrica, clínica e cirúrgica. Brasília: Editora UnB, 2007.

TURRINI, R.N.T.; VALERA, R.V. Fatores relacionados à readmissão de pacientes em serviço hospitalar de emergência. Ciencia y Enfermeria, v.14, n.2, 2008.

URRUTIA-PEREIRA, M.; ÁVILA, J.; SOLÉ, D. et al. Programa Infantil de Prevenção de Asma: um programa de atenção especializada a crianças com sibilância/asma. J Bras Pneumol, v. 42, n.1, p.42-47, 2016.

ZAMIR, D.; ZAMIR, M.; REITBLAT, T., et al. Readmissions to hospital within 30 days of discharge from the internal medicine wards in southern Israel. Eur J Intern Med, v.17, n.1, p.20-23, 2006. 


\title{
APÊNDICE A - Termo de consentimento livre e esclarecido utilizado com os
}

\section{responsáveis por crianças readmitidas}

\author{
Universidade de Brasília \\ Faculdade de Ciências da Saúde \\ Programa de Pós-graduação em Enfermagem \\ Termo de Consentimento Livre e Esclarecido - TCLE
}

Convidamos o(a) Senhor(a) a participar do projeto de pesquisa PERFIL DAS READMISSÕES EM UMA UNIDADE DE INTERNAÇÃO PEDIÁTRICA. O nosso objetivo é compreender o perfil das doenças das crianças de 0 a 5 anos de idade que são internadas e readmitidas na clínica pediátrica do Hospital Regional de Ceilândia (HRC).

$\mathrm{O}$ (a) senhor(a) receberá todos os esclarecimentos necessários antes e no decorrer da pesquisa e lhe asseguramos que seu nome não aparecerá, sendo mantido o mais rigoroso sigilo pela omissão total de quaisquer informações que permitam identificá-lo(a)

A sua participação se dará por meio de uma entrevista que terá duração de aproximadamente 20 minutos, realizada no Hospital Regional de Ceilândia na data combinada, sendo gravada e posteriormente transcrita. Além da entrevista, o prontuário da criança/menor pela qual o(a) senhor(a) é responsável será consultado.

Os riscos decorrentes de sua participação na pesquisa são relacionados à divulgação de informações obtidas, através das entrevistas realizadas e a um possível constrangimento durante a entrevista. Entretanto, serão explicadas para todos os participantes a finalidade e as etapas da pesquisa, bem como o comprometimento em relação à garantia da manutenção do sigilo ético e à confidencialidade dos dados, além da possibilidade de desistência de participação da pesquisa a qualquer momento, podendo recusar-se a responder (ou participar de qualquer procedimento) de modo a minimizar as possibilidades de riscos e de constrangimentos, sem nenhum prejuízo para o(a) senhor(a). Se você aceitar participar, estará contribuindo para a melhora da qualidade do plano de cuidados prestado às crianças e seus responsáveis. Sua participação é voluntária, isto é, não há pagamento por sua colaboração.

Todas as despesas que você tiver relacionadas diretamente ao projeto de pesquisa (passagem para o local da pesquisa, alimentação no local da pesquisa ou exames para realização da pesquisa) serão cobertas pelo pesquisador responsável. Caso haja algum dano direto ou indireto decorrente de sua participação na pesquisa, você poderá ser indenizado, obedecendo-se às disposições legais vigentes no Brasil.

Os resultados da pesquisa serão divulgados na Universidade de Brasília podendo ser publicados posteriormente. Os dados e materiais serão utilizados somente para esta pesquisa e ficarão sob a guarda do pesquisador por um período de cinco anos, após isso serão destruídos.

Se o(a) Senhor(a) tiver qualquer dúvida em relação à pesquisa, por favor telefone para: Raíza Rana de Souza Lima (iza.rslima@gmail.com), na Universidade de Brasília, no telefone (61) 8403-3815/ (61) 3107-1702, no horário de 10:00hs às12:00h e de 13:30hs às 17:30hs no telefone fixo.

Este projeto foi Aprovado pelo Comitê de Ética em Pesquisa da Faculdade de Ciências da Saúde (CEP/FS) da Universidade de Brasília. O CEP é composto por profissionais de diferentes áreas cuja função é defender os interesses dos participantes da pesquisa em sua integridade e dignidade e contribuir no desenvolvimento da pesquisa dentro de padrões éticos. As dúvidas com relação à assinatura do TCLE ou os direitos do participante da pesquisa podem ser obtidos através do telefone: (61) 3107-1947 ou do e-mail cepfs@unb.br ou cepfsunb@gmail.com, horário de atendimento de 10:00hs às 12:00hs e de 13:30hs às 17:30hs, de segunda a sextafeira.

Este documento foi elaborado em duas vias, uma ficará com o pesquisador responsável e a outra com o Senhor(a).

$\overline{\text { Nome / assinatura do participante }}$ de 


\title{
APÊNDICE B - Termo de consentimento livre e esclarecido utilizado com os enfermeiros
}

\author{
Universidade de Brasília \\ Faculdade de Ciências da Saúde \\ Programa de Pós-graduação em Enfermagem \\ Termo de Consentimento Livre e Esclarecido - TCLE
}

Convidamos o(a) Senhor(a) a participar do projeto de pesquisa PERFIL DAS READMISSÕES EM UMA UNIDADE DE INTERNAÇÃO PEDIÁTRICA. O nosso objetivo é compreender o perfil das doenças das crianças de 0 a 5 anos de idade que são internadas e readmitidas na clínica pediátrica do Hospital Regional de Ceilândia (HRC).

$\mathrm{O}$ (a) senhor(a) receberá todos os esclarecimentos necessários antes e no decorrer da pesquisa e lhe asseguramos que seu nome não aparecerá sendo mantido o mais rigoroso sigilo pela omissão total de quaisquer informações que permitam identificá-lo(a)

A sua participação se dará por meio de uma entrevista que terá duração de aproximadamente 20 minutos, realizada no Hospital Regional de Ceilândia na data combinada, sendo gravada e posteriormente transcrita.

Os riscos decorrentes de sua participação na pesquisa são relacionados à divulgação de informações obtidas, através das entrevistas realizadas e a um possível constrangimento durante a entrevista. Entretanto, serão explicadas para todos os participantes a finalidade e as etapas da pesquisa, bem como o comprometimento em relação à garantia da manutenção do sigilo ético e à confidencialidade dos dados, além da possibilidade de desistência de participação da pesquisa a qualquer momento, podendo recusar-se a responder (ou participar de qualquer procedimento) de modo a minimizar as possibilidades de riscos e de constrangimentos, sem nenhum prejuízo para o(a) senhor(a). Se você aceitar participar, estará contribuindo para a melhora da qualidade do plano de cuidados prestado às crianças e seus responsáveis. Sua participação é voluntária, isto é, não há pagamento por sua colaboração.

Todas as despesas que você tiver relacionadas diretamente ao projeto de pesquisa (passagem para o local da pesquisa, alimentação no local da pesquisa ou exames para realização da pesquisa) serão cobertas pelo pesquisador responsável. Caso haja algum dano direto ou indireto decorrente de sua participação na pesquisa, você poderá ser indenizado, obedecendo-se as disposições legais vigentes no Brasil.

Os resultados da pesquisa serão divulgados na Universidade de Brasília podendo ser publicados posteriormente. Os dados e materiais serão utilizados somente para esta pesquisa e ficarão sob a guarda do pesquisador por um período de cinco anos, após isso serão destruídos.

Se o(a) Senhor(a) tiver qualquer dúvida em relação à pesquisa, por favor telefone para: Raíza Rana de Souza Lima (iza.rslima@gmail.com), na Universidade de Brasília, no telefone (61) 8403-3815/ (61) 3107-1702, no horário de 10:00hs às12:00h e de 13:30hs às 17:30hs no telefone fixo.

Este projeto foi Aprovado pelo Comitê de Ética em Pesquisa da Faculdade de Ciências da Saúde (CEP/FS) da Universidade de Brasília. O CEP é composto por profissionais de diferentes áreas cuja função é defender os interesses dos participantes da pesquisa em sua integridade e dignidade e contribuir no desenvolvimento da pesquisa dentro de padrões éticos. As dúvidas com relação à assinatura do TCLE ou os direitos do participante da pesquisa podem ser obtidos através do telefone: (61) 3107-1947 ou do e-mail cepfs@unb.br ou cepfsunb@gmail.com, horário de atendimento de 10:00hs às 12:00hs e de 13:30hs às 17:30hs, de segunda a sextafeira.

Este documento foi elaborado em duas vias, uma ficará com o pesquisador responsável e a outra com o Senhor(a).

$\overline{\text { Nome / assinatura do participante }}$

Pesquisador Responsável

Nome e assinatura

Brasília, de de 
APÊNDICE C - Banco de dados para a coleta dos dados secundários

$\mathrm{N}^{\mathrm{o}}$ Prontuário:

Sexo:

Idade:

Etnia:

Procedência:

Data da admissão: Data da alta hospitalar:

Classificação de risco no momento da admissão:

Diagnóstico principal da admissão:

Data da readmissão: Data da alta da readmissão:

Diagnósticos da readmissão:

Classificação de risco no momento da readmissão: 


\title{
APÊNDICE D - Roteiro de entrevista com os enfermeiros
}

\author{
Universidade de Brasília - UnB \\ Faculdade de Ciências da Saúde - FS \\ Programa de Pós-Graduação em Enfermagem - PPGENF \\ Roteiro de Entrevista
}

Entrevista com enfermeiros da internação

1- Idade:

2- Sexo:

3- Tempo de formação:

4- Pós-Graduação: ( ) sim ( ) não

5- Há quanto tempo trabalha na pediatria do HRC?

6- Quais são os procedimentos da equipe de enfermagem da pediatria no momento da alta e nas readmissões? Verbal? Papel? Como é feita a orientação?

7- Quem dá as orientações? 


\title{
APÊNDICE E - Roteiro de entrevista utilizado com os responsáveis por crianças
} readmitidas

\author{
Universidade de Brasília - UnB \\ Faculdade de Ciências da Saúde - FS \\ Programa de Pós-Graduação em Enfermagem - PPGENF \\ Roteiro de Entrevista
}

- Dados da criança:

Nome (iniciais): SES:

Sexo:

Data de Nascimento:

Idade:

Motivo da Internação:

Número de Readmissões:

- Dados do Responsável

1. Idade do Responsável: anos

2. Sexo:

3. Responsável por qual criança/idade/:

4. Local de Residência:

5. Situação conjugal:

( ) Casado (a)

( ) Solteiro (a)

( ) Divorciado (a)

( ) Tem um companheiro (a)

( ) Separado (a)

( ) Viúvo (a)

6. Escolaridade:

( ) Sem estudos ( ) Ensino Fundamental Incompleto

( ) Ensino Fundamental Completo ( ) Ensino Médio Incompleto

( ) Ensino Médio Completo ( ) Ensino Superior Incompleto

( ) Ensino Superior Completo

7. Trabalha fora? ( ) Sim ( ) Não

8. O responsável é o principal cuidador ou quem passa maior tempo com a criança?

9- Na sua opinião, quais foram os principais fatores que influenciaram na readmissão da criança? 10 - Você acompanhou a(s) admissão(ões) anterior(es) da criança?

11- Você recebeu alguma orientação da equipe de enfermagem com relação aos cuidados com a situação da criança? Verbal ou escrita? 
ANEXO A - Parecer de Aprovação no Comitê de Ética em Pesquisa

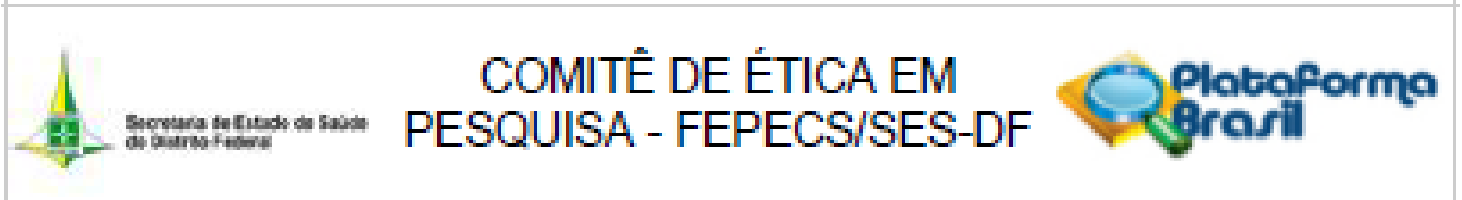

\section{PARECER CONSUBSTANCIADO DO CEP}

\section{Elaborado pela Institulç-äo Coparticipante}

\section{DADOS DO PROJETO DE PESQUISA}

Titulo da Pesquisa: Pernl das Readmissరీes em uma Unidade de Internaçăo Pedlatrica

Pesqulsador: Ralza Rana de Souza LIma

Area Tematica:

Versao: 1

CAAE: 44493415.0 .3001 .5553

Institulça Proponente: FUNDACAO UNIVERSIDADE DE BRASILIA

Patrocinador Princlpal: Financlamento Proprio

\section{DADOS DO PARECER}

Nümero do Parecer: 1.167.834

Data da Relatorla: 03/08/2015

Apresentaçà do Projeto:

Trata-se de um projeto de mestrado do Programa de Pos-graduacao em Enfermagem do Departamento de Enfermagem da Faculdade de Clenclas da Saude da Unlversidade de Brasilla.

O objetivo deste estudo consiste na caracterizacao do pernl de readmissoes das Internacoes na clinica pedlatrica do Hospltal Reglonal de Cellandla (HRC) em crlancas de ate 5 anos de Idade, atendldas de Janeiro de 2014 ate Dezembro do mesmo ano. Sera um estudo exploratorio, descritlvo, transversal de abordagem mlsta explanatorla sequenclal. Os dados quantitatlvos serao obtldos atraves da amostra de dados secundarios provenlentes dos registros de internacoes da unidade pedlatrica, enquanto os dados primarlos serao coletados por intermedlo de entrevistas reallzadas com responsavels por crlancas readmitidas e internadas na mesma unidade.

\section{Objetivo da Pesqulsa:}

"Objetivo Primario:

- objetivo do estudo consiste na caracterizacao do perill de readmissoes das Internacoes na cllnica pedlatrica do Hospltal Reglonal de Cellandla (HRC) em crlancas de ate 5 anos de Idade.

Objetivo Secundarlo:

- Identificar e quantificar o pernil de morbldade das crlancas de ate 5 anos readmitidas na pedlatrla do HRC de Janelro ate Dezembro de 2014;

- Tracar o pernil de classincacao de risco das criancas readmitidas;

Enderego: SMHN 2 Od SO1 BLOCO A - FEFECS

Balro: ASA NORTE

UF: DF MUniolplo: BRABILIA

Toletone: [51]3325-4955 Fax (33)33254955
CEP: $70.710-904$

E-malt: comtedectica secretartade anal.com 


\section{COMITÊ DE ÉTICA EM

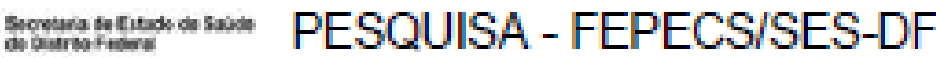

Contruaçbo do Rareser: 1.167 ast

- Identifcar os fatores de risco (causas) das readmissao;

- Relacionar o perfil de classíncacao de risco e a taxa de readmissoes;

- Caracterizar e entrevistar os responsavels pelas criancas readmitldas."

Avallaçå dos Rlacos $\theta$ Beneficlos:

Nas palavras da pesqulsadora responsavel:

"Rlscos:

Essa pesquisa tem como riscos a dlvulgacao de Informacoes obtldas atraves dos prontuarios e das entrevistas realizadas, alem de posslvels constrangimentos durante elas, entretanto, serao expllcadas para todos os particlpantes a finalidade e as etapas da pesqulsa, bem como o comprometimento quanto a manutencao do sigllo etico e confidenclalldade dos dados e a possibilidade de desistencla de participacao da pesquisa a qualquer momento, de modo a minimizar as posslbilidades de riscos e de constrangimentos. Beneficlos:

Atraves desta pesqulsa, tanto o servico de saude quanto os paclentes que 0 utllizam serao beneficlados pela otimizacao da assistencla as criancas e seus famlliares atendidos, proporcionando atendimento Indlviduallzado e baseado nas suas reals necessldades, alem da melhora nos processos de trabalho da equipe de saude por Intermedio do acolhimento e da gestao dos atendimentos."

\section{Comentarlos e Consideraçסes sobre a Pesqulsa:}

Apos anallse do projeto, concordamos e aprovamos.

Consideraçర̄es sobre os Termos de apresentaçăo obrigatorla:

Cumprido.

Apresentou:1. projeto em word; 2 . folha de rosto; 3 . termo de concordancla da UNB; 4. termos de anuencla da Institulçăo HRC; 5 . curriculo lattes dos pesquisadores; 6 . TCLE

Recomendaç๐es:

Conclusoes ou Pendenclas e Llsta de Inadequaçoes:

aprovado

Sltuaçå do Parecer:

Aprovado

Necessita Apreclaçąo da CONEP:

N5้อ

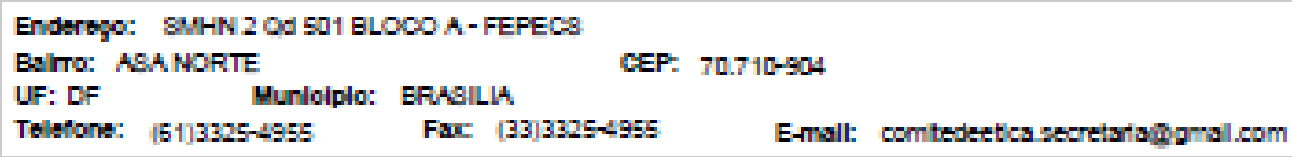




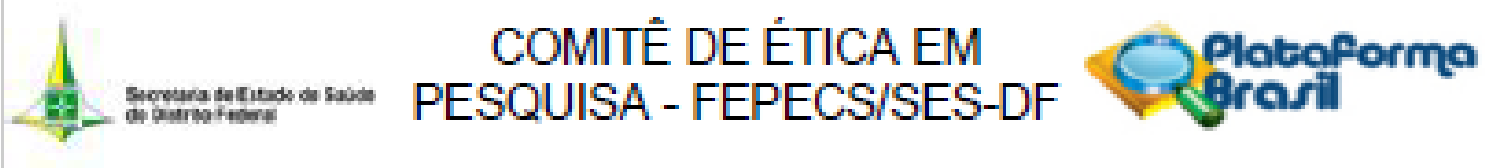

Conthuapso do Mareser: 1.167 ays

Consıderaçסes Finals a criterio do CEP:

BRASILIA, 03 de Agosto de 2015

$$
\begin{aligned}
& \text { Assinado por: } \\
& \text { Hello Bergo } \\
& \text { (Coordenador) }
\end{aligned}
$$

Enderego: SMHN 2 Od 501 BLOCO A - FEPECS 
ANEXO B - Comprovante de Submissão do Artigo

\section{REVISTA B A A N A D E \\ E N F E R M A G E M}

\begin{tabular}{|c|c|c|c|c|c|}
\hline \multirow[t]{2}{*}{ CAPA } & SOBRE & PÁG: & DO USUÁRIO & PESQUISA & ATUAL. \\
\hline & ANTE & ORES & SURMISSOES & ARTIGOS & \\
\hline
\end{tabular}

\section{\#17054 SINOPSE}

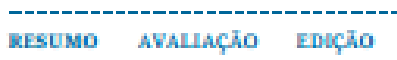

OFEN pOURNAL. SYSTEMS

Ajuda do sistema

USUÁRIO

Logado come:

paolacosta1

Meus peribdices

Perfil

Sair do sistema

\section{SUBMISSÃO}

\begin{tabular}{|c|c|}
\hline Autnres & $\begin{array}{l}\text { Paola Costa Carvalho, Raiza Rana de Souza Lima, Diana Lúcia Moura } \\
\text { Pinho }\end{array}$ \\
\hline Titulo & $\begin{array}{l}\text { READMASSĨO HOSPTIALAR PEDLITTRLCA: UMA REVISĨo } \\
\text { INTECRATIVA }\end{array}$ \\
\hline $\begin{array}{l}\text { Documento } \\
\text { ariginal }\end{array}$ & 17054-57150-2-SM_DOCX 2016.07-06 \\
\hline Docs. sup. & $\begin{array}{l}\text { 17054-57154-1- } \\
\text { SP.PDF 2016-07-06 } \\
\text { 170S4-57155-1- } \\
\text { SP.PDF 2016-07.06 } \\
\text { 170S4-57156-1- } \\
\text { SP.PDF 2016.07.06 }\end{array}$ \\
\hline Submetido por & Psola Costa Carvalho \\
\hline $\begin{array}{l}\text { Data de } \\
\text { submissalo }\end{array}$ & julho 6, $2016 \cdot 07: 39$ \\
\hline Seçäo & Artigos de Bevisato \\
\hline Editar & Glmara Rodrigues $\square$ \\
\hline
\end{tabular}

AUTOR

Subenksebes

Artivo (1)

Arquivo (D)

Nova submisstio

IDIOMA

Ponugula (Brasi) *

CONTEÚDO DA

REVISTA

Pesquisa

\begin{tabular}{|l|}
\hline \\
\hline Todoe \\
Pesquisar
\end{tabular}

Procurar

Poe Edicylo

Poe Autor

Poe titula

SITUAÇÃO

Situaçằ Em avaliaçằ

Dutras revistas

Categorias

Ûltima 2016-07-06

alteracto

TAMANHO DE FONTE

\section{METADADOS DA SUBMISSÃO}

EDITAR METADADOS

INFORMAÇOES

Para leirores

Para Autares

Para Bibliotecírins

\section{AUTORES}

Nome

Paola Costa Carvalho

Instituiçăo|Afiliaçầ Universidade de Brasilia

Pais Brasil

POLITICA DE

CONFLITO DE.

INTEBPSES

Besumb da 
Bingrafia

Contato principal para correspondéncia.

\begin{tabular}{|c|c|}
\hline Nome & Raiza Rana de Souza Lima \\
\hline Instituiçào/Rfiliaçầ & Universidade de Brasilia \\
\hline Pais & Brasil \\
\hline $\begin{array}{l}\text { POLITICA DE. } \\
\text { CONFLITO DE. } \\
\text { INTESPSSES }\end{array}$ & - \\
\hline $\begin{array}{l}\text { Besumb da } \\
\text { Bingrafia }\end{array}$ & $\begin{array}{l}\text { Enfermeira, Mestranda em Enfermagem pelo Programa de Pós. } \\
\text { gradusçato da Universidade de Brasilia/Faculdade de Ciencias da } \\
\text { Saúde. }\end{array}$ \\
\hline Nome & Diana Lúcia Moura Pinho 믈 \\
\hline Instituiçào/Rfiliaçầ & Universidade de Brasilia \\
\hline Pais & Brasil \\
\hline $\begin{array}{l}\text { POL.ITICA DE } \\
\text { CONFLITO DE. } \\
\text { DNTBESSES }\end{array}$ & - \\
\hline $\begin{array}{l}\text { Besumo da } \\
\text { Bingrafia }\end{array}$ & $\begin{array}{l}\text { Enfermeira, Doutara em Psicolngia pela Universidade de } \\
\text { Brasilia, Professora Adjunta da Universidade de Brasilia. }\end{array}$ \\
\hline \multicolumn{2}{|c|}{ TÍTULO E RESUMO } \\
\hline Titulo & 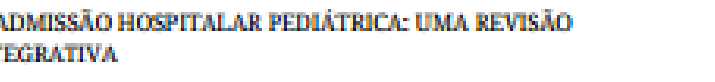 \\
\hline $\begin{array}{l}\text { Ob } \\
\text { no } \\
\text { Me } \\
\text { na } \\
\text { en } \\
\text { Re } \\
\text { Mr } \\
\text { par } \\
\text { cat } \\
\text { rel } \\
\text { alt } \\
\text { Ca } \\
\text { ind } \\
\text { en } \\
\text { da } \\
\text { a a } \\
\text { seg }\end{array}$ & 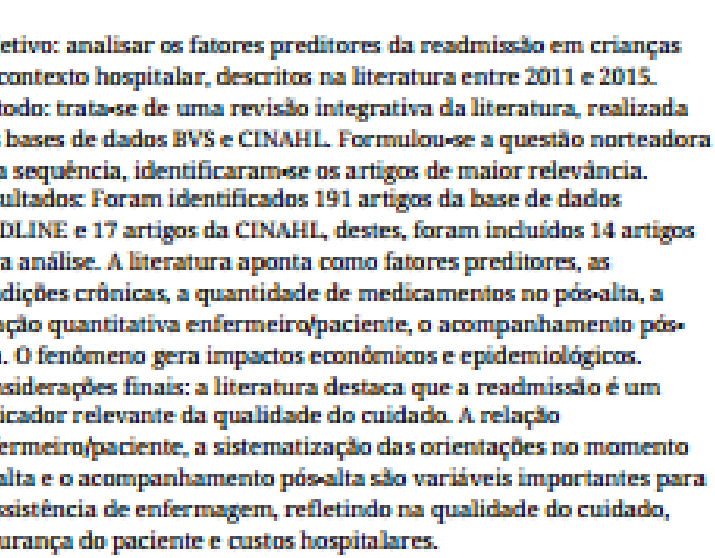 \\
\hline
\end{tabular}

INDEXAÇĀo

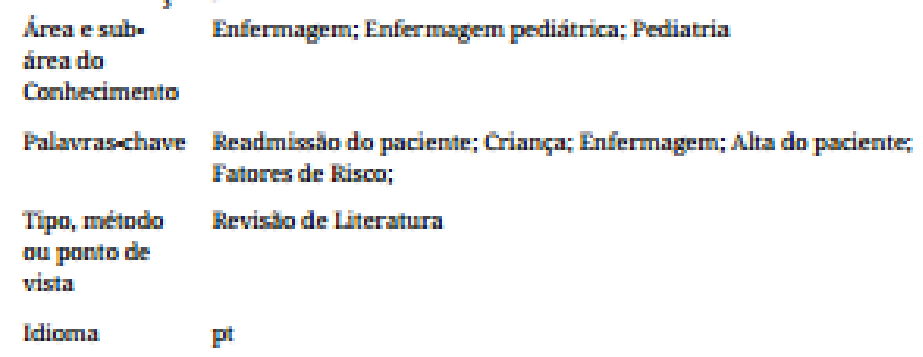

AGÊNCIAS DE FOMENTO

Agências Universidade de Brasilia

ISSN $2178-8650$ (eletrônico)

ISSN 0102.5430 (impresso) 
(c) (1) (3)

Otrabalho Bevista Baiana de Enfermagem possui a Licença Creative Commons. AtribuiçilonNaloComercial 4.0 Internacional.

A Revista Baiana de Enfermagemn é memhro da Associsçào Brasileira de Editores Cientificns.

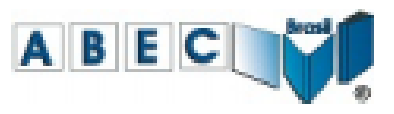

